\title{
DINÂMICA DO NITROGÊNIO NA CULTURA DE CANA-DE-AÇÚCAR EM DIFERENTES SISTEMAS DE MANEJO DE RESÍDUOS DA COLHEITA
}

\author{
MARÍA del VALLE BASANTA
}

Tese apresentada à Escola Superior de Agricultura "Luiz de Queiroz", Universidade de São Paulo, para obtenção do título de Doutor em Agronomia, Área de Concentração: Fitotecnia.

P I R A C I C A B A

Estado de São Paulo - Brasil

Abril - 2004 


\title{
DINÂMICA DO NITROGÊNIO NA CULTURA DE CANA-DE-AÇÚCAR EM DIFERENTES SISTEMAS DE MANEJO DE RESÍDUOS DA COLHEITA
}

\author{
MARÍA del VALLE BASANTA \\ Engenheira Agrônoma
}

Orientador: Prof. Dr. DURVAL DOURADO NETO

\begin{abstract}
Tese apresentada à Escola Superior de Agricultura "Luiz de Queiroz", Universidade de São Paulo, para obtenção do título de Doutor em Agronomia, Área de Concentração: Fitotecnia.
\end{abstract}

P I R A C I C A B A

Estado de São Paulo - Brasil

Abril - 2004 
Dados Internacionais de Catalogação na Publicação (CIP)
DIVISÃO DE BIBLIOTECA E DOCUMENTAÇÃO - ESALQ/USP

Basanta, Maria del Valle

Dinâmica do nitrogênio na cultura de cana-de-açúcar em diferentes sistemas de manejo de resíduos da colheita / Maria del Valle Basanta. - - Piracicaba, 2004.

$82 p$.

Tese (doutorado) - Escola Superior de Agricultura Luiz de Queiroz, 2004.

Bibliografia.

1. Cana-de-açúcar 2. Colheita 4. Matéria orgânica do solo 5. Modelos

matemáticos 6. Nitrogênio 7. Relação solo-planta 8. Resíduos agrícolas (Manejo) I.

Título

CDD 633.61 
Aos meus pais:

Enrique Daniel Basanta (in memorian), e Inés Dolores Castro;

\section{Ofereço}

Ao meu esposo:

Jorge Omar Gieco.

Por nosso amor e amizade;

Dedico 


\section{AGRADECIMENTOS}

A Deus, por conceder-me perseverança e força nos momentos difíceis para concretizar este trabalho.

À Universidade de São Paulo, em especial ao Programa de Pós-graduação em Fitotecnia da Escola Superior de Agricultura "Luiz de Queiroz" - (ESALQ), pela oportunidade de realizar este curso, e ao Centro de Energia Nuclear na Agricultura, pelo auxílio nas análises laboratoriais de nitrogênio e carbono.

À Fundação de Amparo a Pesquisa do Estado de São Paulo - FAPESP, pela concessão da bolsa de estudo e o auxílio financeiro à pesquisa.

À Agencia Internacional de Energia Atômica, Organização das Nações Unidas, pelo fornecimento do fertilizante marcado com ${ }^{15} \mathrm{~N}$.

Ao Prof. Dr. Durval Dourado Neto, pela orientação, amizade, e ensinamentos durante toda minha etapa de formação de Pós-Graduação na ESALQ.

Ao Prof. Dr. Klaus Reichardt, pela orientação e ensinamentos durante minha permanência no Laboratório de Física de Solos do CENA - USP.

Ao Prof. Dr. Paulo César Ocheuze Trivelin, pelos ensinamentos, sugestões e colaboração ao desenvolvimento deste trabalho.

Ao Prof. Dr. Osny Oliveira Santos Bacchi, por ter me aberto as portas do Laboratório de Física de Solos do CENA - USP e pela sua colaboração.

Ao Prof. Dr. Chris Van Kessel, pela orientação (programa Sandwich no período de janeiro de 2001 a junho de2001) durante o trabalho no Agroecosistems Laboratory Department of Agronomy and Range Science, University of California, Davis, CA, Estados Unidos da América. 
Ao meu esposo, Jorge, pela permanente companhia, compreensão e estímulo para a realização deste trabalho.

Aos meus pais, ao meu sogro e minha sogra, por terem sempre acreditado no nosso projeto de estudar no Brasil.

Aos colegas e amigos Ramiro López Ovejero, Axel García y García e Norma Virginia Migone Segovia, pela amizade e companheirismo.

Aos colegas e amigos, Graciela Cordone e Fernando Martínez, por estarem sempre presentes em todos os momentos.

Aos colegas do Laboratório de Física de Solos do CENA-USP, Luis Carlos Timm, Vladia Correchel, Luiz Fernando Pires, Fábio Cássaro, Tânia Tominaga e Júlio César de Oliveira, pela ajuda durante a fase experimental deste trabalho e pelos bons momentos compartilhados.

À Sandra Nicolete, do Laboratório de Biogeoquímica Ambiental do CENA-USP, por ter realizado o fracionamento do solo e as determinações de carbono, agradeço a valiosíssima colaboração.

À equipe técnica do Laboratório de Isótopos Estáveis do CENA-USP, em especial a Raquel, Hugo, Miguel e Pingin, pelo apoio e colaboração na realização das análises de nitrogênio.

À equipe técnica do laboratório de Física de Solos do CENA - USP (Ademir e Dudu), pela amizade e colaboração.

Aos funcionários do Departamento de Produção Vegetal da ESALQ - USP pelo apoio no trabalho de campo.

$\mathrm{E}$ a todos que, mesmo não citados nominalmente, contribuíram indiretamente para a realização deste trabalho. 


\section{SUMÁRIO}

Página

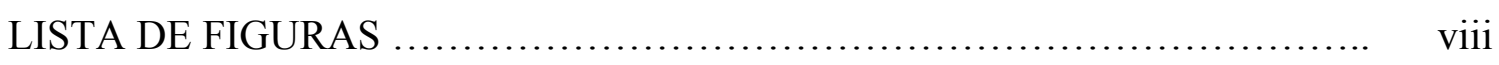

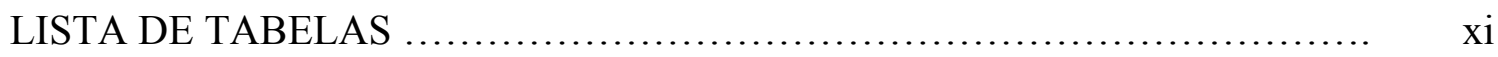

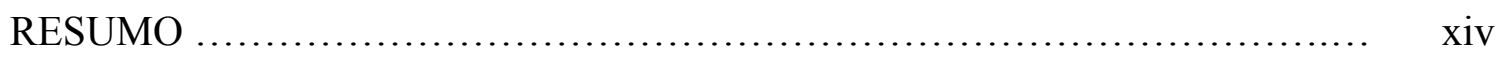

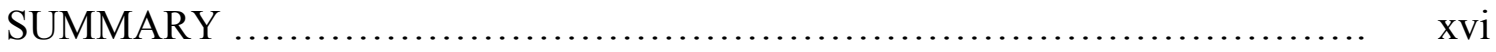

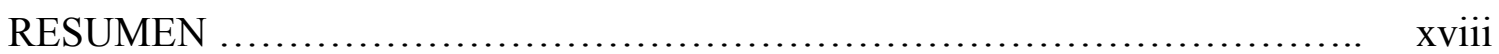

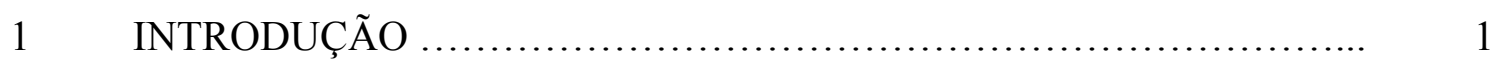

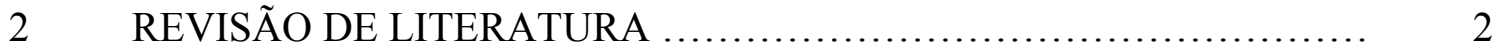

2.1 Panorama da produção de cana-de-açúcar no Brasil e no Estado de São Paulo ....................................................... 2

2.2 Colheita de cana-de-açúcar sem prévia queima da palhada..................... 3

2.3 Efeito da colheita sem prévia queima na produtividade de cana-de-açúcar 4

2.4 Os resíduos culturais como fonte de nitrogênio ........................ 5

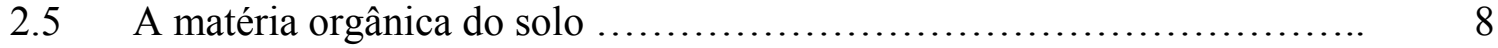

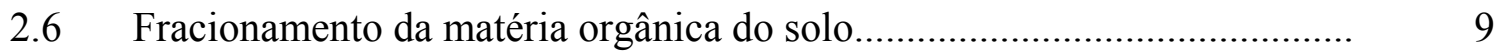

2.7 Mudanças nos níveis de matéria orgânica e na sua distribuição nas frações do solo induzidas pelo manejo dos resíduos culturais.............................. 12

2.8 O isótopo ${ }^{15} \mathrm{~N}$ e sua utilização em estudos da dinâmica de nitrogênio em sistemas agrícolas........................................................................... 13

3 MATERIAL E MÉTODOS.............................................................. 16

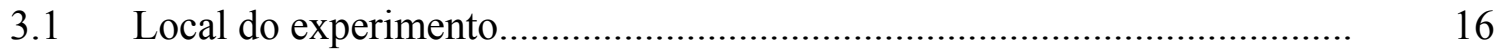

3.2 A cultura, os tratamentos e o delineamento experimental.......................... 16 
3.3 Resíduos culturais marcados com ${ }^{15} \mathrm{~N}$ usados nas parcelas do tratamento $\mathrm{T} 2$

3.4 Amostragem da planta e do solo........................................................... 18

3.5 Fracionamento granulométrico do solo.................................................... 19

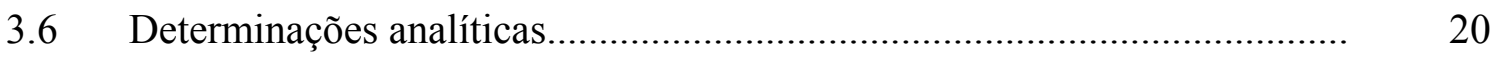

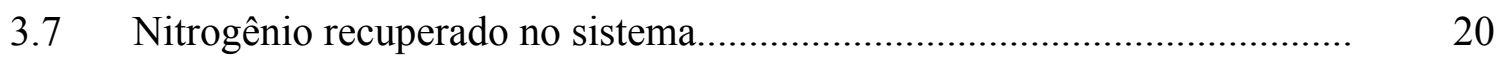

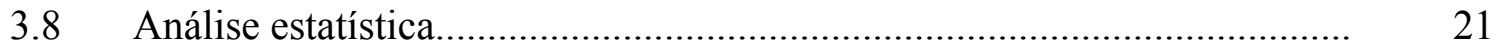

3.9 Modelo descritivo da dinâmica do nitrogênio adicionado ao sistema soloplanta via fertilizante ........................................................................... 22

$4 \quad$ RESULTADOS E DISCUSSÃO........................................................ 28

4.1 Produtividade de colmos e quantidade de nitrogênio contido na parte aérea das plantas.......................................................................... 28

4.2 Recuperação do nitrogênio derivado do fertilizante no sistema solo-planta 31

4.3 Os resíduos da cana como fonte de nitrogênio......................................... 36

4.3.1 Quantidade de resíduos produzidos pela cultura de cana-de-açúcar........... 36

4.3.2 Recuperação no sistema solo-planta do nitrogênio contido nos resíduos da cultura..

4.4 Distribuição do carbono e do nitrogênio nas frações granulométricas e no

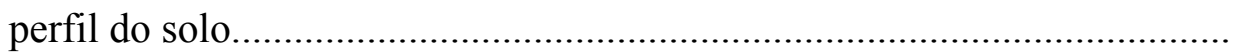

4.5 Distribuição do nitrogênio derivado do fertilizante nas frações granulométricas e no perfil do solo.

4.6 Distribuição do nitrogênio derivado dos resíduos da cultura nas frações granulométricas e no perfil do solo.

4.7 Modelo descritivo da dinâmica do nitrogênio adicionado ao sistema soloplanta via fertilizante......................................................................... 54

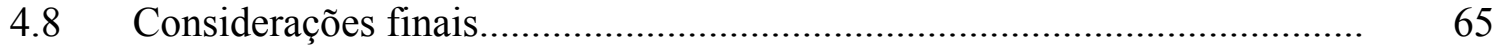

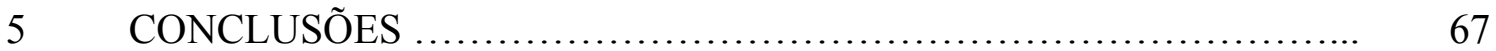

REFERÊNCIAS BIBLIOGRÁFICAS .................................... 69

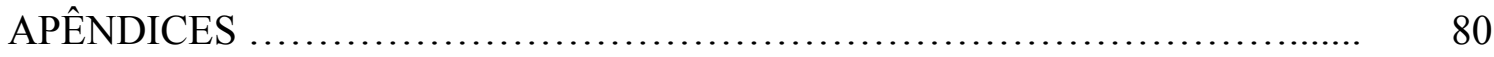




\section{LISTA DE FIGURAS}

Página

1 Modelo proposto referente à dinâmica de nitrogênio adicionado via fertilizante no sistema solo-planta $(\mathrm{k}=3)$............................................ 24

2 Modelo proposto referente à dinâmica no compartimento planta $(\mathrm{k}=2)$ do nitrogênio adicionado via fertilizante ...................................................... 24

3 Recuperação do nitrogênio derivado do fertilizante (NFRec, \%) na parte aérea da cultura (Planta), no solo até a profundidade de $50 \mathrm{~cm}$ (Solo 0-50 cm) e no sistema solo-planta $(\mathrm{P}+\mathrm{S})$ sob os sistemas de manejo dos resíduos da cultura de cana-de-açúcar: (a) sem queima (SQ) e (b) com queima (CQ), nos cinco ciclos analisados

4 Parcelas do tratamento sem queima dos resíduos (SQ) logo após a colheita da cana-planta.

5 Parcelas do tratamento com queima dos resíduos (CQ) logo após a colheita da cana-planta.

6 Redistribuição porcentual do nitrogênio derivado dos resíduos (NddR) nas profundidades de solo nos quatro anos analisados (1999-2002)............

7 Distribuição do nitrogênio derivado do fertilizante (NddF) nas frações do solo e nas camadas de solo durante os cinco ciclos analisados (19982002)

8 Distribuição do nitrogênio derivado dos resíduos (NddR) nas frações do solo e nas camadas de solo durante os quatro ciclos analisados (19992002) 
9 Quantidade relativa de nitrogênio do fertilizante recuperado no sistema solo-planta $\left(\mathrm{N}_{3, \mathrm{j}}\right)$ nos sistemas de manejo dos resíduos da cultura de canade-açúcar (a) sem queima (SQ) e (b) com queima (CQ), desde o plantio da cana-planta em $1997(j=0)$ até a colheita da quarta cana-soca em 2002 $(j=5)$. Valores observados ( $\mathbf{\square})$; valores estimados $(-)$

10 Quantidade relativa de nitrogênio do fertilizante recuperado na planta $\left(\mathrm{N}_{2, \mathrm{j}}\right)$ nos sistemas de manejo dos resíduos da cultura de cana-de-açúcar (a) sem queima (SQ) e (b) com queima (CQ), desde o plantio da canaplanta em $1997(\mathrm{j}=0)$ até a colheita da quarta cana-soca em $2002(\mathrm{j}=5)$. Valores observados ( $\square)$; valores estimados (-)

11 Quantidade relativa de nitrogênio do fertilizante recuperado no solo $\left(\mathrm{N}_{1, \mathrm{j}}\right)$ nos sistemas de manejo dos resíduos da cultura de cana-de-açúcar (a) sem queima (SQ) e (b) com queima (CQ), desde o plantio da cana-planta em $1997(j=0)$ até a colheita da quarta cana-soca em $2002(j=5)$. Valores observados ( $\square)$; valores estimados (-)

12 Quantidade relativa de perdas de nitrogênio do fertilizante no sistema solo-planta $\left(\mathrm{Nl}_{3, \mathrm{j}}\right)$ utilizando manejo dos resíduos da cultura de cana-deaçúcar (a) sem queima (SQ) e (b) com queima (CQ), desde o plantio de cana-planta em $1997(j=0)$ até a colheita da terceira cana-soca em 2002 $(j=5)$. Valores observados $(\mathbf{\square})$; valores estimados $(-)$

13 Análise de comparação entre os resultados experimentais (valores observados) e dos modelos propostos (valores estimados) de nitrogênio derivado do fertilizante no compartimento planta $(\mathrm{k}=2)$ e no sistema soloplanta $(\mathrm{k}=3)$ utilizando manejo do resíduo da cultura de cana-de-açúcar sem queima (SQ) e com queima (CQ) 
14 Balanço de nitrogênio derivado do fertilizante no sistema solo-planta, especificando os compartimentos solo $\left(\mathrm{N}_{1, \mathrm{j}}\right)$ e planta $\left(\mathrm{N}_{2, \mathrm{j}}\right)$ e as perdas $\left(\mathrm{Nl}_{3, \mathrm{j}}\right)$, utilizando manejo do resíduo da cultura de cana-de-açúcar sem queima (SQ) nos anos 0 (plantio em 1997), 1 (colheita de cana-planta em 1998), 2 (colheita da primeira cana-soca em 1999), 3 (colheita da segunda cana-soca em 2000), 4 (colheita da terceira cana-soca em 2001) e 5 (colheita da quarta cana-soca em 2002): (A) valores definidos com base nos resultados experimentais, e (B) valores definidos com base nas estimativas do modelo

15 Balanço de nitrogênio derivado do fertilizante no sistema solo-planta, especificando os compartimentos solo $\left(\mathrm{N}_{1, \mathrm{j}}\right)$ e planta $\left(\mathrm{N}_{2, \mathrm{j}}\right)$ e as perdas $\left(\mathrm{Nl}_{3, \mathrm{j}}\right)$, utilizando manejo do resíduo da cultura de cana-de-açúcar com queima (CQ) nos anos 0 (plantio em 1997), 1 (colheita de cana-planta em 1998), 2 (colheita da primeira cana-soca em 1999), 3 (colheita da segunda cana-soca em 2000), 4 (colheita da terceira cana-soca em 2001) e 5 (colheita da quarta cana-soca em 2002): (A) valores definidos com base nos resultados experimentais, e (B) valores definidos com base nas estimativas do modelo

16 Balanço de nitrogênio derivado do fertilizante no sistema solo-planta, especificando os compartimentos solo $\left(\mathrm{N}_{1, \mathrm{j}}\right)$ e planta $\left(\mathrm{N}_{2, \mathrm{j}}\right)$ e as perdas $\left(\mathrm{Nl}_{3, \mathrm{j}}\right)$, utilizando manejo do resíduo da cultura de cana-de-açúcar sem queima (SQ) e com queima (CQ). Previsão para os anos 6 (colheita da quinta cana-soca em 2003), 7 (colheita da sexta cana-soca em 2004), e 8 (colheita da sétima cana-soca em 2005): (B) valores definidos com base nas estimativas do modelo 


\section{LISTA DE TABELAS}

Página

1 Hipóteses do modelo proposto referentes à dinâmica de nitrogênio

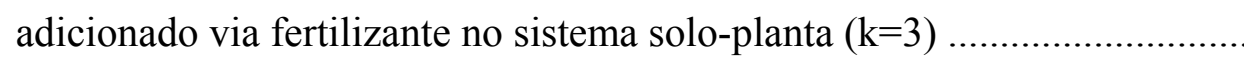

2 Hipóteses do modelo proposto referentes à dinâmica no compartimento planta $(\mathrm{k}=2)$ do nitrogênio adicionado via fertilizante

3 Conjunto de equações referentes à dinâmica do nitrogênio aplicado via fertilizante no sistema solo-planta $(\mathrm{k}=3)$, especificando os compartimentos solo $(\mathrm{k}=1)$ e planta $(\mathrm{k}=2)$, e as perdas de $\mathrm{N}$ no sistema (procedimentos I e II)

4 Produtividade de colmos, nitrogênio total $(\mathrm{Nt})$, nitrogênio derivado do fertilizante (QNddF) e nitrogênio não marcado (Nnm) nos diferentes compartimentos da planta. (1998-2001)

5 Quantidade de nitrogênio derivado do fertilizante (QNddF, kg.ha ${ }^{-1}$ ) e porcentagem de nitrogênio do fertilizante recuperado (NFRec, \%) no sistema solo-planta nos dois sistemas de manejo dos resíduos da cultura (1998-2002)

6 Nitrogênio derivado dos resíduos (NddR) nos distintos compartimentos do sistema solo-planta

7 Distribuição porcentual das frações granulométricas do solo, conteúdo de carbono e conteúdo de nitrogênio nas frações de solo nas profundidades 0-15; 15-30 e 30-50 cm e nos tratamentos sem queima (SQ) e com queima (CQ) dos resíduos da colheita da cana-de-açúcar. Ano 1998 ......... 
8 Distribuição porcentual das frações granulométricas do solo, conteúdo de carbono e conteúdo de nitrogênio nas frações de solo nas profundidades 0-15; 15-30 e 30-50 cm e nos tratamentos sem queima (SQ) e com queima (CQ) dos resíduos da colheita da cana-de-açúcar. Ano 1999

9 Distribuição porcentual das frações granulométricas do solo, conteúdo de carbono e conteúdo de nitrogênio nas frações de solo nas profundidades $0-15 ; 15-30$ e $30-50 \mathrm{~cm}$ e nos tratamentos sem queima (SQ) e com queima (CQ) dos resíduos da colheita da cana-de-açúcar. Ano 2000 .

10 Distribuição porcentual das frações granulométricas do solo, conteúdo de carbono e conteúdo de nitrogênio nas frações de solo nas profundidades 0-15; 15-30 e 30-50 cm e nos tratamentos sem queima (SQ) e com queima (CQ) dos resíduos da colheita da cana-de-açúcar. Ano 2001

11 Distribuição porcentual das frações granulométricas do solo, conteúdo de carbono e conteúdo de nitrogênio nas frações de solo nas profundidades 0-15; 15-30 e 30-50 cm e nos tratamentos sem queima (SQ) e com queima (CQ) dos resíduos da colheita da cana-de-açúcar. Ano 2002 .........

12 Distribuição nas frações de solo do $\mathrm{N}$ derivado do fertilizante (NddF) nas profundidades $0-15 ; 15-30$ e $30-50 \mathrm{~cm}$ e nos tratamentos sem queima (SQ) e com queima (CQ) dos resíduos da colheita da cana-de-açúcar. Período 1998-2002

13 Distribuição nas frações de solo do $\mathrm{N}$ derivado dos resíduos (NddR) nas profundidades $0-15 ; 15-30$ e $30-50 \mathrm{~cm}$ e nos tratamentos sem queima (SQ) e com queima (CQ) dos resíduos da colheita da cana-de-açúcar. Período 1999-2002

14 Parâmetros do modelo referentes à porcentagem do nitrogênio derivado do fertilizante recuperado no sistema solo-planta $(\mathrm{k}=3)$ nos tratamentos SQ (sem queima) e CQ (com queima)

15 Parâmetros do modelo referentes à porcentagem do nitrogênio derivado do fertilizante recuperado no compartimento planta $(\mathrm{k}=2)$ nos tratamentos SQ (sem queima) e CQ (com queima) 
16 Temperatura (T), precipitação (P) e radiação solar global (Rs) correspondente ao período de 1997 a 1999 .............................................. 81

17 Temperatura (T), precipitação (P) e radiação solar global (Rs) correspondente ao período de 2000 a 2002 .............................................. 82 


\title{
DINÂMICA DO NITROGÊNIO NA CULTURA DE CANA-DE-AÇÚCAR EM DIFERENTES SISTEMAS DE MANEJO DE RESÍDUOS DA COLHEITA
}

\author{
Autora: MARÍA del VALLE BASANTA \\ Orientador: Prof. Dr. DURVAL DOURADO NETO
}

\section{RESUMO}

Com o objetivo de avaliar, durante cinco anos, o efeito de dois sistemas de manejo dos resíduos culturais, colheita tradicional com queima prévia (CQ) e colheita sem queima (SQ), sobre a produtividade da cana-de-açúcar e a dinâmica do nitrogênio no sistema solo-planta em função do nitrogênio introduzido através do fertilizante e dos resíduos culturais, foi instalado um experimento com adubação no plantio com $63 \mathrm{~kg} \cdot \mathrm{ha}^{-1}$ de N com os seguintes tratamentos: (T1) ${ }^{15} \mathrm{~N}-\mathrm{SA}$ (sulfato de amônio) e colheita SQ, recebendo na primeira colheita o total dos resíduos não marcados produzidos no $\mathrm{T} 2$; (T2) SA e colheita SQ, recebendo na primeira colheita o total dos resíduos marcados produzidos no T1; e (T3) ${ }^{15} \mathrm{~N}-\mathrm{SA}$ e colheita CQ. Anualmente, na época da colheita, a planta foi dividida em colmos, ponteiros e palhada; o solo $(<2000 \mu \mathrm{m})$ foi amostrado nas camadas de $0-15,15-30$ e $30-50 \mathrm{~cm}$, e foram determinadas as frações granulométricas

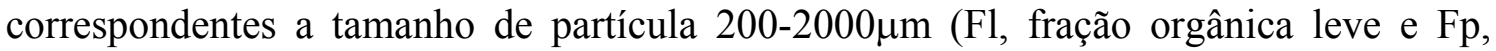
fração mineral pesada), 53-200 $\mu \mathrm{m}$ (Fom, fração organo-mineral) e $<53 \mu \mathrm{m}$ (Fsa, fração

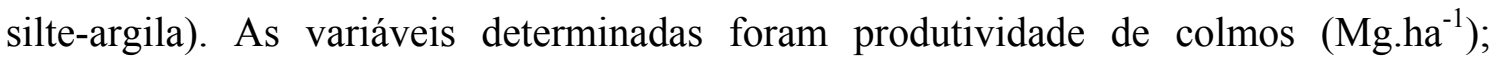
nitrogênio total $\left(\mathrm{Nt}, \mathrm{kg} \cdot \mathrm{ha}^{-1}\right)$, nitrogênio derivado do fertilizante (QNddF, $\mathrm{kg} \mathrm{ha}^{-1}$ ) e nitrogênio derivado dos resíduos (QNddR, $\mathrm{kg} \cdot \mathrm{ha}^{-1}$ ) em solo e planta; e carbono total no solo $\left(\mathrm{C}, \mathrm{Mg} \cdot \mathrm{ha}^{-1}\right)$. Em todos os anos, observou-se maior produtividade $(\mathrm{p}<0,05)$ e maior 
absorção de nitrogênio $(\mathrm{p}<0,05)$ no tratamento CQ em relação ao SQ. Considerando a quantidade de resíduos que permaneceu no sistema e seu conteúdo de $\mathrm{Nt}$, o potencial estimado de reciclagem de $\mathrm{N}$ no sistema SQ foi de $65 \%$ do $\mathrm{Nt}$ contido na parte aérea da cultura. O potencial de perda de Nt foi estimado em $85 \%$ do nitrogênio da parte aérea no sistema CQ. Na colheita da cana-planta, a recuperação do QNddF no sistema solo-planta foi de $46,9 \mathrm{~kg} \cdot \mathrm{ha}^{-1}$, sendo que $63,0 \%$ foi medido na parte aérea. Nos anos seguintes, observou-se uma diminuição exponencial do NddF recuperado na parte aérea da planta. No sistema SQ, o NddF recuperado no sistema solo-planta no segundo ano foi significativamente superior $(\mathrm{p}<0,05)$ que no sistema CQ. Aproximadamente $95 \%$ do NddR ficou imobilizado no solo, permanecendo no sistema no final da colheita da quarta cana-soca. Os conteúdos de carbono e nitrogênio nas frações do solo apresentaram valores crescentes na seguinte ordem: Fsa $>$ Fom $>$ Fl. A Fsa continha mais de $70 \%$ do $\mathrm{C}$ e do Nt do solo. O sistema de manejo dos resíduos não influenciou o conteúdo de carbono do solo, nem sua distribuição nas frações granulométricas. Na avaliação da colheita da última cana-soca (2002), o sistema SQ apresentou valores de Nt superiores $(\mathrm{p}<0,05 \%)$ em Fl e Fom na camada $0-15 \mathrm{~cm}$, e em Fom na camada $30-50 \mathrm{~cm}$. Os conteúdos de NddF e NddR nas frações do solo aumentaram na ordem Fsa $>$ Fom $>$ Fl. No sistema SQ, na colheita da primeira cana-soca em 1999, a ordem no conteúdo de NddF foi Fl>Fom $>$ Fsa. No mesmo ano, a ordem no conteúdo de NddR foi $\mathrm{Fl}>\mathrm{Fsa}>\mathrm{Fom}$. O enriquecimento em ${ }^{15} \mathrm{~N}$ dos resíduos gerados durante o ciclo da cana-planta explica os maiores conteúdos de ${ }^{15} \mathrm{~N}$ em $\mathrm{Fl}$. 


\title{
NITROGEN DYNAMICS IN A SUGARCANE CROP UNDER DIFFERENT TRASH MANAGMENT SYSTEMS
}

\author{
Author: MARÍA del VALLE BASANTA \\ Adviser: Prof. Dr. DURVAL DOURADO NETO
}

\section{SUMMARY}

To evaluate during five years the effects of two trash management systems in a sugarcane crop, the traditional harvest system with trash burning before harvest (CQ) and an alternative system without trash burning (SQ), on stalk yield and nitrogen nutrition of the crop, and on the distribution in the soil-plant system of the nitrogen introduced by fertilizer and trash, an experiment was carried out in Piracicaba, SP, Brazil, with the following treatments fertilized at planting with $63 \mathrm{~kg} \cdot \mathrm{ha}^{-1}$ of $\mathrm{N}$ : (T1) ${ }^{15} \mathrm{~N}$ labeled ammonium sulfate (AS), harvested with SQ system, and after the first harvest received all the unlabeled trash from T2; (T2) unlabeled AS, harvested with the SQ system, and after the first harvest received all the ${ }^{15} \mathrm{~N}$-labeled trash from $\mathrm{T} 1$; and (T3) ${ }^{15} \mathrm{~N}-\mathrm{AS}$, and harvested with the CQ system. Annually, at harvest, plants were divided in stalks, tips and residues; and the soil $(<2000 \mu \mathrm{m})$ was sampled in the 0-15, 15-30 and 30$50 \mathrm{~cm}$ layers, and physically fractionated in particle sizes of 200-2000 $\mu \mathrm{m}$ (Fl, light organic fraction, and Fp, heavy mineral fraction), 53-200 $\mu \mathrm{m}$ (Fom, organomineral fraction) and $<53 \mu \mathrm{m}$ (Fsa, silt-clay fraction). The evaluated variables were: stalk yield $\left(\mathrm{Mg}_{\mathrm{ha}}{ }^{-1}\right)$; total nitrogen $\left(\mathrm{Nt}, \mathrm{kg} \cdot \mathrm{ha}^{-1}\right)$, nitrogen derived from fertilizer $\left(\mathrm{NddF}, \mathrm{kg} . \mathrm{ha}^{-1}\right)$, and nitrogen derived from residues (NddR, kg.ha $\left.{ }^{-1}\right)$ in soil and plant; and total carbon in soil $\left(\mathrm{C}, \mathrm{Mg} \mathrm{ha}^{-1}\right)$. During all years, stalk yield and uptake nitrogen were higher $(\mathrm{p}<0.05)$ in the CQ than in the SQ system. Considering the quantity of residues that remained in 
the system and their Nt content, the estimated potential of $\mathrm{N}$ recycling for the system SQ was $65 \%$ of the $\mathrm{Nt}$ contained in the aboveground parts of the crop. For the CQ harvest system, the potential loss of $\mathrm{N}$ was estimated as $85 \%$ of $\mathrm{N}$ in the aboveground parts of the crop. In the cane-plant harvest, the recovery of NddF in the soil-plant system was of $46,9 \mathrm{~kg} \cdot \mathrm{ha}^{-1}$ (63,0\% were found in the aboveground part of the crop). In the following years, an exponential decrease of NddF recovered in the aboveground part of the plant was observed. In the SQ harvest system, the NddF recovered in the soil-plant system in the second year (first ratoon cane) was significantly higher $(\mathrm{p}<0.05)$ than in the CQ system. Approximately, $95 \%$ of NddR were immobilized in the soil, remaining in the system at the end of the crop of the fourth ratoon cane, four years after that it have been added. The contents of total carbon and nitrogen in the soil fractions presented growing values in the following order: Fsa $>$ Fom $>$ Fl. The fraction Fsa contained more than $70 \%$ of the total $\mathrm{C}$ and total $\mathrm{N}$ of the soil. The harvest system did not influence the soil carbon content neither his distribution in the fractions. At the fourth ratoon cane (2002), the SQ system presented values of $\mathrm{Nt}$ higher $(\mathrm{p}<0.05 \%)$ in $\mathrm{Fl}$ and Fom in the $0-15 \mathrm{~cm}$ layer, and in Fom in the $30-50 \mathrm{~cm}$ layer. The ${ }^{15} \mathrm{~N}$-residues from the first crop cycle explain the higher content of ${ }^{15} \mathrm{~N}$ in Fl. 


\title{
DINÁMICA DEL NITRÓGENO EN CAÑA DE AZÚCAR BAJO DIFERENTES SISTEMAS DE MANEJO DE LOS RASTROJOS
}

\author{
Autora: MARÍA del VALLE BASANTA \\ Consejero: Prof. Dr. DURVAL DOURADO NETO
}

\section{RESUMEN}

Con el objetivo de evaluar, durante cinco años, el efecto de dos sistemas de manejo de los rastrojos de caña de azúcar, cosecha tradicional con quema previa (CQ) y cosecha de caña verde (SQ), sobre el rendimiento de tallos y la dinámica de nitrógeno en el sistema suelo-planta, en función del nitrógeno introducido a través del fertilizante y de los residuos de cosecha, fue instalado un experimento fertilizado con $63 \mathrm{~kg} . \mathrm{ha}^{-1}$ de $\mathrm{N}$ en el momento de plantación, con los siguientes tratamientos: (T1) ${ }^{15} \mathrm{~N}-\mathrm{SA}$ (sulfato de amonio) y cosecha SQ, recibiendo en la primera cosecha todo el rastrojo no marcado producido en T2; (T2) SA y cosecha SQ, recibiendo en la primera cosecha todo el rastrojo marcado con ${ }^{15} \mathrm{~N}$ producido en $\mathrm{T} 1$; (T3) ${ }^{15} \mathrm{~N}-\mathrm{SA}$ y cosecha $\mathrm{CQ}$. En cada muestreo (a la cosecha), la planta fue separada en tallos, puntas y rastrojo. El suelo $(<2000 \mu \mathrm{m})$ fue muestreado en las camadas de $0-15,15-30$ y $30-50 \mathrm{~cm}$, y fue realizado el fraccionamiento físico determinándose las fracciones de 200-2000 $\mu \mathrm{m}$ (F1, fracción orgánica liviana y Fp, fracción mineral pesada), 53-200 $\mu \mathrm{m}$ (Fom, fracción organo mineral) y $<53 \mu \mathrm{m}$ (Fsa, fracción limo-arcilla). Las variables determinadas fueron

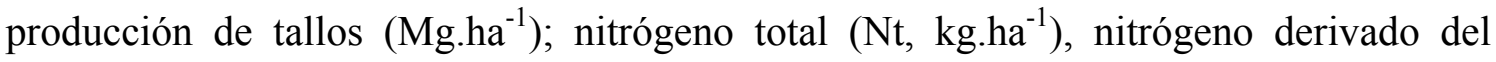
fertilizante (QNddF, kg.ha $\left.{ }^{-1}\right)$ y nitrógeno derivado del rastrojo (QNddR, kg.ha ${ }^{-1}$ ) en

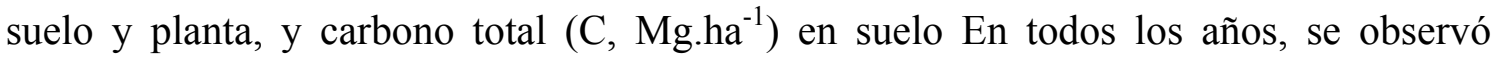
mayor producción $(p<0,05)$ y mayor absorción de nitrógeno $(p<0,05)$ en el tratamiento 
$\mathrm{CQ}$ con relación a SQ. Considerando la cantidad de rastrojo que permaneció en el sistema y su contenido de $\mathrm{Nt}$, el potencial estimado de reciclaje de $\mathrm{N}$ en el sistema SQ fue de $65 \%$ del $\mathrm{Nt}$ contenido en la parte aérea del cultivo. El potencial de pérdida de $\mathrm{N}$ en CQ fue estimado de $85 \%$ del nitrógeno de la parte aérea. En la cosecha de la caña planta, la recuperación de QNddF en el sistema suelo-planta fue de $46,9 \mathrm{~kg} \cdot \mathrm{ha}^{-1}$, siendo que $63,0 \%$ fue medido en la parte aérea. En los años siguientes, se observó una disminución exponencial del NddF recuperado en la parte aérea de la planta. En el segundo año, el NddF recuperado en el sistema solo-planta en SQ fue significativamente superior $(p<0,05)$ que en CQ. Aproximadamente $95 \%$ del NddR quedó inmovilizado en el suelo, permaneciendo en el sistema a la cosecha de la cuarta caña soca. Los contenidos de carbono y nitrógeno total en las fracciones de suelo presentaron valores crecientes en el siguiente orden: Fsa $>$ Fom $>$ Fl. La Fsa contenía más del 70\% del C y del $\mathrm{Nt}$ del suelo. El sistema de manejo de rastrojos no influyó en el contenido de carbono del suelo ni en su distribución en las fracciones granulométricas. En la evaluación de la cosecha de la última caña soca (2002), el sistema SQ presentó valores de Nt superiores $(\mathrm{p}<0,05 \%$ ) en Fl y Fom en la camada $0-15 \mathrm{~cm}$, y en Fom en la camada $30-50 \mathrm{~cm}$. Los contenidos de NddF y NddR en las fracciones del suelo aumentaron en el orden Fsa $>$ Fom $>$ Fl. En el sistema SQ, en la cosecha de la primera caña soca, el orden en el contenido de NddF fue Fl $>$ Fom $>$ Fsa. En ese mismo año, el orden en el contenido de NddR fue $\mathrm{Fl}>\mathrm{Fsa}>\mathrm{Fom}$. El enriquecimiento en ${ }^{15} \mathrm{~N}$ de los rastrojos generados durante el ciclo de caña planta explica los mayores contenidos de ${ }^{15} \mathrm{~N}$ en Fl. 


\section{INTRODUÇÃO}

O Brasil é atualmente o maior produtor mundial de cana-de-açúcar, com uma área cultivada de cerca de cinco milhões de hectares. A colheita de cana-de-açúcar foi tradicionalmente realizada após a despalha a fogo para facilitar o corte manual. Essa prática de manejo está sendo substituída pelo sistema de colheita de cana crua, sem prévia queima da palhada, no qual a palhada da cana permanece sobre a superfície do

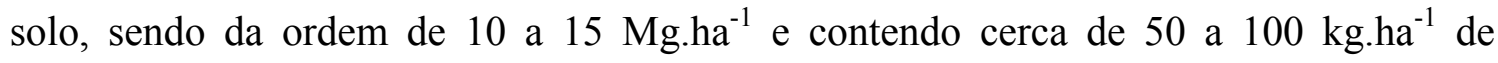
nitrogênio e de 3 a 6 Mg.ha ${ }^{-1}$ de carbono.

$\mathrm{Na}$ colheita de cana-de-açúcar com despalha a fogo, quantidades importantes de $\mathrm{N}$ e C são perdidas para a atmosfera na forma de óxidos. A colheita de cana crua permite que os nutrientes contidos na palhada permaneçam no campo e sejam reciclados no sistema. Assim, a maior parte do carbono e do nitrogênio contidos nos resíduos passa a formar parte da matéria orgânica do solo. Com o tempo, um equilíbrio pode ser alcançado quando a taxa de incorporação do nitrogênio (ou carbono) dos resíduos na matéria orgânica do solo for similar à taxa de mineralização do nitrogênio (ou carbono) orgânico, mantendo estável o conteúdo de nitrogênio (ou carbono) no sistema. Assim, para manter estáveis os níveis de nitrogênio no sistema, a adubação nitrogenada seria necessária para restituir o nitrogênio exportado nos colmos mais o que sai do sistema através dos diferentes processos de perda.

O objetivo deste trabalho foi (i) estudar o destino do nitrogênio introduzido no sistema solo-planta usando fertilizante e resíduos culturais marcados $\operatorname{com}{ }^{15} \mathrm{~N}$; (ii) estudar a distribuição do carbono e do nitrogênio nas frações granulométricas do solo, bem como sua evolução no tempo sob os diferentes manejos dos resíduos; e (iii) propor um modelo matemático simples que caracterize a dinâmica temporal da distribuição do nitrogênio introduzido no sistema solo-planta via fertilizante. 


\section{REVISÃO DE LITERATURA}

\subsection{Panorama da produção de cana-de-açúcar no Brasil e no Estado de São Paulo}

O Brasil é o maior produtor mundial de cana-de-açúcar e um dos principais exportadores, junto com a Austrália, Cuba e Tailândia (FNP CONSULTORIA \& AGRO-INFORMATIVO, 2003).

O cultivo da cana-de-açúcar se estabeleceu sobre os mais diferentes tipos de solos no território nacional, desde solos de textura arenosa a muito argilosos, assim como em solos com altos teores de matéria orgânica. A cultura é bem tolerante à acidez e à alcalinidade, desenvolvendo-se em solo com $\mathrm{pH}$ desde 4,0 até 8,3 . Devido à grande importância que assumiu para a economia nacional através da produção de álcool etílico (PROÁLCOOL), a cultura de cana-de-açúcar expandiu-se por todos os estados brasileiros, principalmente em São Paulo, Pernambuco e Alagoas (Ministério da Ciência e Tecnologia, 2004).

Dentre as regiões produtoras de cana no Brasil, a região sudeste é a de maior área plantada e de maior produção, sendo que no ano 2002 a área colhida foi de 3.146.340 ha (62\% da área colhida no Brasil - 5.095.753 ha) e a produção foi de 241.134 .000 t (66\% das 363.721.000 t produzidas em todo o país). Na região sudeste, destaca-se o estado de São Paulo, onde a cultura de cana-de-açúcar representa uma das principais atividades agropecuárias e a agroindústria sucro-alcooleira tem um relevante papel sócioeconômico. No ano 2002 a área plantada com cana no Estado foi de 2.660 .950 ha (83\% da área plantada na região sudeste) e a produção foi de 212.707 .000 t (87\% da produção total) (FNP CONSULTORIA \& AGRO-INFORMATIVO, 2003).

Para a safra 2003/04, estima-se uma expansão da área plantada no país de 4\% sobre a safra 2002/03. O crescimento é conseqüência da boa rentabilidade do setor nos 
últimos anos, o que estimulou a expansão dos canaviais das usinas existentes e a implantação de novas unidades nos estados de Minas Gerais e São Paulo (FNP CONSULTORIA \& AGRO-INFORMATIVO, 2003).

\subsection{Colheita de cana-de-açúcar sem prévia queima da palhada}

A colheita tradicional da cana inclui a retirada de palhada com fogo para facilitar as operações de corte e carregamento durante a colheita manual. Esse manejo, incluindo a queima, apresenta vantagens operativas e econômicas, porém, do ponto de vista técnico, apresenta a limitação de eliminar um grande volume de material orgânico que poderia ser deixado na superfície do solo, contribuindo para manter os teores de matéria orgânica (Delgado, 1985).

Nos últimos anos, observa-se na área plantada com cana no Brasil, a crescente adoção da colheita sem queima prévia (colheita de cana verde), na qual os restos vegetais são deixados na superfície do solo, como folhas inteiras, caso seja realizada manualmente; ou trituradas, se a colheita for mecânica (Oliveira et al., 1999a; Trivelin et al., 1997).

Segundo o Intergovernmental Panel on Climate Change - IPCC (1995) os resíduos da cana-de-açúcar representam $11 \%$ da produção mundial de resíduos agrícolas, cuja queima produz substancial liberação de $\mathrm{CO}_{2}$, que não é considerada como uma emissão líquida, pois através da fotossíntese, a biomassa queimada é reposta no ciclo seguinte da cultura. Porém, durante o processo de combustão, outros gases, além do $\mathrm{CO}_{2}$, são produzidos. As taxas de emissão desses gases dependem do tipo de biomassa e das condições da queima. Os gases $\mathrm{N}_{2} \mathrm{O}$ e $\mathrm{NO}_{\mathrm{x}}$ são gerados na fase de combustão com chama; e os gases $\mathrm{CO}$ e $\mathrm{CH}_{4}$ são formados sob condições de queima com predomínio de fumaça.

Além da redução das emissões dos gases de efeito estufa, outros benefícios da colheita sem queima são: a conservação da água do solo (Abramo Filho et al., 1993; Ball-Coelho et al., 1993; Tominaga et al., 2002), a diminuição da temperatura do solo (Abramo Filho et al., 1993; Dourado Neto et al., 1999; Oliveira et al., 2000; Timm, 2002), a redução da erosão (Albrecht, 1992), a reposição de nutrientes ao solo 
(principalmente nitrogênio e enxofre) (Furlani Neto et al., 1997), o aumento ou conservação dos níveis de matéria orgânica no solo (Vallis et al., 1996; Graham et al., 2002), e a melhoria na estrutura do solo (Blair, 2000).

Furlani Neto et al. (1997) quantificaram a energia contida na palhada remanescente de colheita mecânica. A queima do canavial promoveu uma perda energética importante nos resíduos de pós-colheita, da ordem de 50\% quando comparados ao resíduo da cana crua. A massa de matéria seca dos restos vegetais

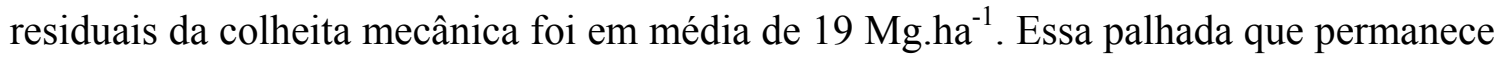
sobre a superfície do solo proporciona um retorno de nutrientes ao solo, principalmente de $\mathrm{N}$ e $\mathrm{S}$, e contribui ao incremento da matéria orgânica, resultando em inúmeras vantagens em relação à conservação do solo.

Ojima et al. (1994) estudaram os efeitos de queimadas em pradarias, e observaram que as mesmas alteram significativamente os processos de ciclagem de nutrientes. Em curto prazo, a queimada na pradaria melhora a atividade microbiana, aumenta a produção das partes aérea e subterrânea da planta e a eficiência no uso do N. Entretanto, repetidas queimadas anuais resultam em maiores entradas de resíduos de planta de menor qualidade, reduzindo significativamente o $\mathrm{N}$ orgânico do solo, a biomassa microbiana e a disponibilidade de $\mathrm{N}$, e aumentando a relação $\mathrm{C} / \mathrm{N}$ na matéria orgânica do solo.

\subsection{Efeito da colheita sem prévia queima na produtividade de cana-de-açúcar}

Existe controvérsia na literatura sobre o efeito dos resíduos deixados sobre a superfície do solo na produtividade de cana-de-açúcar.

Ball-Coelho et al. (1993) no Brasil, Wood (1986) na Austrália e McIntyre et al. (1996) nas Ilhas Maurício, observaram aumento na produtividade de colmos quando os resíduos culturais foram deixados sobre o solo. No caso do estudo de Ball-Coelho et al. (1993), essa maior produtividade foi atribuída à maior retenção de água no solo e ao reduzido crescimento das plantas daninhas promovidos pelos resíduos deixados na superfície do solo. 
Wood (1991) também observou que, em solos bem drenados, os resíduos da cana-de-açúcar deixados como cobertura promoveram acréscimo nos rendimentos de cana de até $10 \mathrm{Mg} \cdot \mathrm{ha}^{-1}$.ano ${ }^{-1}$, quando comparado à prática de despalha a fogo.

Todavia, Veiga et al. (1962) observaram redução na produtividade da cana quando os resíduos não foram queimados, possivelmente como conseqüência da imobilização de $\mathrm{N}$ ou pela inibição do perfilhamento promovida pela palhada sobre a superfície.

Carvalho et al. (1996) e Lovett \& Hurney (1992) observaram que a palhada de cana produzia inibição na rebrota da soqueira de cana, o que foi considerado um efeito auto-alelopático.

Existem na literatura pesquisas a respeito de queimadas realizadas em outras culturas, principalmente em cereais. Biederbeck et al. (1980) constataram que a queima de resíduos de trigo por mais de 20 anos consecutivos não afetou negativamente a produtividade da cultura, sendo que nos primeiros anos a produtividade foi superior no sistema de manejo com queima. Os autores atribuem esse fato aos efeitos benéficos imediatos da queima tais como a rápida liberação de $\mathrm{N}$ e $\mathrm{P}$ disponíveis. Entretanto, os efeitos negativos da queima, tais como redução da condutividade de água do solo, maior compactação, maior susceptibilidade à erosão, menor disponibilidade de N, menor atividade microbiana, redução dos níveis de matéria orgânica, são lentamente cumulativos.

Sem dúvida, todos ou muitos dos fatores acima mencionados atuam simultaneamente na lavoura influenciando as condições de crescimento e de desenvolvimento das plantas, determinando a produtividade final. A predominância dos efeitos de alguns deles determinará o tipo de influência (positiva ou negativa) sobre a produtividade da cultura.

\subsection{Os resíduos culturais como fonte de nitrogênio}

Os materiais orgânicos de origem vegetal se caracterizam pela sua natureza variada e complexa. Os tecidos vegetais são constituídos por lignina, celulose, hemicelulose, amido, substâncias pécticas, açúcares, proteínas e aminoácidos; além de 
outros constituintes como ceras, graxas, ácidos orgânicos, pigmentos e taninos (Siqueira \& Franco, 1988).

A presença e a proporção de determinados compostos determinam a resistência à degradação do material vegetal. Os compostos hidrossolúveis (açúcares, amido e proteínas) são decompostos rapidamente, seguidos pelos compostos resistentes à decomposição (hemicelulose e celulose), enquanto que a lignina, as gorduras e as ceras são consideradas recalcitrantes e, portanto, de decomposição muito lenta (Brady, 1989; Vanlauwe et al., 1994).

A disponibilidade na rizosfera do nitrogênio das proteínas, aminoácidos, ácidos nucléicos e nucleotídeos constituintes dos resíduos vegetais dependem do balanço entre a quantidade de nitrogênio mineralizada e imobilizada durante o processo de decomposição. A dinâmica dos nutrientes, entre eles o nitrogênio, introduzidos através dos resíduos vegetais no sistema solo-planta, é determinada pela composição específica da comunidade de microorganismos quimio-organotróficos (Seneviratne, 2000), e da mesofauna do solo (Tian et al., 1992). A atividade biológica, por sua vez, é influenciada por vários fatores do ambiente edáfico tais como temperatura, umidade, $\mathrm{pH}$, pressão parcial de oxigênio, disponibilidade de nutrientes, textura, estrutura e mineralogia (Evans, 1973; Vigil \& Kissel, 1991) e pela quantidade e qualidade dos resíduos (Larson et al., 1972; Rasmussen et al., 1980; Campbell \& Zentner, 1993).

Os principais fatores que determinam a qualidade dos resíduos, ou seja, sua velocidade potencial de degradação e conseqüentemente de liberação de nutrientes, são a relação C/N e os teores de nitrogênio, lignina e polifenóis (Vigil \& Kissel, 1991; Seneviratne, 2000).

Alexander (1977) achou que a relação $\mathrm{C} / \mathrm{N}$ crítica é de 20 a 30, ocorrendo imobilização líquida abaixo e mineralização líquida por acima desses valores. Vigil \& Kissel (1991) estimaram em 40 a relação C/N crítica, o que corresponde a uma concentração de $\mathrm{N}$ de cerca de 10 g. $\mathrm{kg}^{-1}$, assumindo uma concentração de $\mathrm{C}$ de 400 g. $\mathrm{kg}^{-1}$. Outros trabalhos mais recentes relatam relação C/N crítica de 25 (Myers, 1994) e de 27 (Seneviratne, 2000) concordando com Alexander (1977). 
Harmsen \& Van Schreven (1955) determinaram que ocorre mineralização líquida em materiais com concentração de $\mathrm{N}$ maior que 15 a $20 \mathrm{~g} \mathrm{~kg}^{-1}$ e relação $\mathrm{C} / \mathrm{N}$ menor que 20 a 25.

Em um trabalho que analisa em conjunto onze experimentos em uma variada gama de ambientes tropicais com diferentes tipos de resíduos e de solos, Seneviratne (2000) conclui que, em materiais com concentração de N limitada, a liberação do nitrogênio dos resíduos é determinada pela concentração de $\mathrm{N}$ (concentração crítica: 2\%) e pela relação polifenol/N (relação crítica: 1). O autor destaca também que o nível de lignina e a relação lignina/ $\mathrm{N}$ não foram boas variáveis preditivas da liberação de $\mathrm{N}$, e que a relação $\mathrm{C} / \mathrm{N}$ foi a variável que melhor determinou a liberação de $\mathrm{N}$ em uma ampla faixa de concentração de $\mathrm{N}$ nos resíduos.

Vigil \& Kissel (1991), analisando oito experimentos concluíram que as variáveis que melhor explicam a mineralização do $\mathrm{N}$ dos resíduos foram a relação $\mathrm{C} / \mathrm{N}$ e a concentração de $\mathrm{N}$, e que nos estudos que incluíram a lignina como segunda variável independente (após a relação $\mathrm{C} / \mathrm{N}$ ou a concentração de $\mathrm{N}$ ) melhorou a regressão que descreve a liberação do N.

É interessante salientar que inúmeros estudos têm demonstrado que os diferentes resíduos das espécies normalmente utilizadas na agricultura apresentam uma concentração de C de aproximadamente 400 g. $\mathrm{kg}^{-1}$ (Alexander, 1977; Vigil \& Kissel, 1991); portanto, a relação $\mathrm{C} / \mathrm{N}$ expressa o mesmo que a concentração de $\mathrm{N}$ (Vigil \& Kissel, 1991). Ou seja, em termos de qualidade do resíduo, a concentração de nitrogênio é a principal variável que governa a dinâmica da mineralização do nitrogênio.

Os resíduos de espécies não leguminosas, como a cana-de-açúcar, apresentam baixa concentração de N. A palhada da cana possui, em média, 390 a 450 g. $\mathrm{kg}^{-1}$ de C e 4,6 a 6,5 g. $\mathrm{kg}^{-1}$ de N (Trivelin, 1995) devendo apresentar, portanto, baixa mineralização líquida no início do processo de decomposição. Durante a decomposição, a degradação dos carboidratos solúveis (sacarose e amido) reduz a relação $\mathrm{C} / \mathrm{N}$, pois durante o metabolismo microbiano parte do carbono é perdida como $\mathrm{CO}_{2}$ (Alexander, 1977).

$\mathrm{Ng}$ Kee Kwong et al. (1987) verificaram que, após um período de 18 meses de decomposição, o nitrogênio derivado da palhada da cana representou menos que $15 \%$ do 
nitrogênio recuperado pelas plantas de cana, o que corrobora que a contribuição do nitrogênio dos resíduos de cana para a nutrição nitrogenada da cultura é pouco significativa. Os autores salientam que o valor agronômico dos resíduos da cana reside na sua capacidade de incrementar os níveis de matéria orgânica do solo no longo prazo.

Oliveira et al. (1999a) verificaram que, após um ano de permanência da palhada da cana no campo, houve uma redução de massa de aproximadamente $20 \%$, originária principalmente do conteúdo celular e da hemicelulose, sendo esse último o único carboidrato estrutural que apresentou decomposição. A liberação do $\mathrm{N}$ no mesmo período foi somente de $18 \%$.

Faroni et al. (2003), em um período de 12 meses, relataram que a quantidade de palhada que permaneceu em relação à inicial foi de aproximadamente $45 \%$, valor bem inferior ao relatado por Oliveira et al. (1999a). Os autores atribuem essa diferença à composição da palhada, já que no caso com menor decomposição, os resíduos da cana tinham maior proporção de colmos, portanto apresentavam maior relação $\mathrm{C} / \mathrm{N}$. Esse fato salienta a importância da adequada caracterização do resíduo vegetal que está sendo estudado para uma criteriosa discussão dos resultados obtidos.

\subsection{A matéria orgânica do solo}

A matéria orgânica do solo (MOS) é um fator determinante da fertilidade e produtividade agrícola. O clima, o tipo, o uso e o manejo do solo influenciam os fatores físicos, químicos e biológicos que controlam a dinâmica da MOS. Esse conjunto de fatores regula a quantidade e a qualidade das entradas de MOS, e também a composição e atividade da comunidade de microorganismos quimio-organotróficos, bem como as taxas de perda da MOS através dos processos de mineralização, lixiviação e erosão (Feller \& Beare, 1997).

A MOS é um conjunto de resíduos de plantas, animais e microorganismos em todos os estados de decomposição formada por substâncias orgânicas muito heterogêneas intimamente associadas aos componentes inorgânicos do solo (Christensen, 1992). 
Durante os processos de decomposição do material orgânico pelos microorganismos do solo são formados subprodutos (moléculas menores). Simultaneamente ocorre a estabilização desses subprodutos levando à formação de MOS recalcitrante, a qual é resistente à transformação química por centenas a milhares de anos (Hsieh, 1992).

É necessário conhecer a natureza e dinâmica da MOS para poder prever o comportamento dos fertilizantes e dos resíduos vegetais adicionados ao solo (Christensen, 1992).

\subsection{Fracionamento da matéria orgânica do solo}

O fracionamento químico da MOS, que tem sido feito por décadas, consiste na extração ou hidrólise da MOS com ácidos ou bases. Porém, do ponto de vista funcional, esse tipo de fracionamento tem pouco significado já que caracteriza quimicamente a MOS, mas não oferece informação nenhuma sobre sua dinâmica e sua função no solo (Jenkinson, 1971; Martel \& Paul, 1974).

Nas últimas três décadas, foram desenvolvidos muitos estudos objetivando a caracterização da MOS sob condições agrícolas, envolvendo técnicas de fracionamento físico (Feller, 1979; Tiessen \& Stewart, 1983; Feller, 1993; Feller \& Beare, 1997).

É reconhecida a relação entre dinâmica de MOS com a textura e a estrutura do solo (Feller \& Beare, 1997, Christensen, 1992). As associações da MOS com os constituintes minerais do solo, principalmente com as argilas, têm um papel muito importante na mineralização e armazenagem da MOS (Greenland, 1965a,b).

O fracionamento físico considera o papel dos minerais do solo na estabilização e dinâmica da MOS. Os métodos de fracionamento físico são considerados menos destrutivos e os resultados obtidos com eles estão mais relacionados com a estrutura e função da MOS in situ (Christensen, 1992).

O fracionamento físico da MOS se fundamenta no papel dos minerais do solo na estabilização e transformação (turnover) da mesma (Christensen, 1992). Existem dois grupos principais de metodologias para o fracionamento físico da MOS: (i) 
fracionamento densimétrico e (ii) fracionamento granulométrico (por tamanho de partículas) (particle size fractionation - PSF).

O fracionamento densimétrico é utilizado para separar a MOS não fortemente associada às partículas minerais. Geralmente, essas frações são separadas introduzindo o solo em líquidos orgânicos densos ou soluções salinas com densidades entre 1,6 e 2,2 g. $\mathrm{cm}^{-3}$. Assim, a MOS pode ser dividida em duas frações que diferem em estrutura e funcionamento: (i) fração leve (MOS livre ou não complexada) constituída por restos vegetais e animais em decomposição, mais ainda reconhecíveis, com relação $\mathrm{C} / \mathrm{N}$ relativamente alta, alta taxa de transformação e densidade específica consideravelmente menor que os minerais do solo; e (ii) fração pesada (MOS que forma complexos com os minerais do solo) formada também por produtos de decomposição, só que mais processados (húmus verdadeiro), com relação $\mathrm{C} / \mathrm{N}$ mais estreita, lenta taxa de transformação e densidade específica maior devido a sua associação com os minerais do solo (Monnier et al., 1962; Christensen, 1992).

O fracionamento por tamanho de partícula (PSF) se fundamenta no conceito de que as frações da MOS associadas com partículas de solo de diferentes tamanhos (e, portanto, de diferente composição mineralógica) diferem em estrutura e função, e em conseqüência, cumprem diferentes papéis na taxa de transformação da MOS (Christensen, 1992).

O objetivo do PSF é conseguir a máxima dispersão do solo, separando as frações areia, silte e argila, com a mínima alteração da MOS associada.

A dispersão pode ser realizada aplicando ao solo, em água, vibrações ultrasônicas com determinado nível de energia e período de tempo. Não é recomendável aplicar o tratamento na amostra completa do solo, já que a intensidade do ultrasom necessária para dispersar completamente o solo pode causar a liberação da MO microbiana, a qual pode ser redistribuída entre as frações obtidas (Christensen, 1992).

Outro problema que pode ocorrer é a ruptura dos restos vegetais do solo (fração superior a $50 \mu \mathrm{m}$ ) e sua transferência da fração grosseira para as frações menores de tamanho menor a $50 \mu \mathrm{m}$ (argila e silte) (Balesdent et al., 1991). 
Devido às dificuldades acima mencionadas, o uso de ultrasom não é recomendado para amostras de solo não fracionado $(0-2 \mathrm{~mm})$, sendo mais apropriado para ser aplicado à suspensão em água da fração 0-50 $\mu \mathrm{m}$. Assim, para dispersar a fração $>50 \mu \mathrm{m}$ pode ser utilizado o agitamento em água com bolas de vidro, ou dispersantes químicos como o hexametafosfato de sódio (HMF) ou resina sódica (Na-R) (Feller \& Beare, 1997).

Depois da dispersão, é realizado o fracionamento físico por peneiramento e sedimentação. Os limites de tamanho de partícula geralmente adotados são os estabelecidos pelo USDA ou pela ISSS (International Soil Science Society): (i) argila, com diâmetro de partícula $<2 \mu \mathrm{m}$; (ii) silte de 2 a $20 \mu \mathrm{m}$ (ISSS) ou de 2 a $50 \mu \mathrm{m}$ (USDA); e (iii) areia de 20 a $2000 \mu \mathrm{m}$ (ISSS) ou de 50 a 2000 (USDA) (Christensen, 1992).

O uso de diferentes limites no tamanho de partícula dificulta a comparação dos resultados, principalmente quando são comparados dados das frações argila e silte. Alguns trabalhos fazem referência à fração silte-argila em geral, desconsiderando que a fração silte em alguns estudos pode incluir partículas que em outros são isoladas como sendo parte da fração areia (Christensen, 1992).

Segundo Feller (1993), para solos tropicais, é possível distinguir três tipos de MOS pelo fracionamento em água por tamanho de partícula: (i) fração leve $(>20 \mu \mathrm{m})$ com predominância de resíduos vegetais em diferentes estágios de decomposição, com $\mathrm{C} / \mathrm{N}$ variando entre 12 e 33; (ii) fração organo-silte (2 a $20 \mu \mathrm{m})$, formada por fragmentos de fungos e restos vegetais muito humificados associados com microagregados organominerais que não foram destruídos durante o fracionamento, com $\mathrm{C} / \mathrm{N}$ variando entre 10 e 21; (iii) fração organo-argila $(<2 \mu \mathrm{m})$, constituída por matéria orgânica amorfa atuando como agente cimentante da matriz de argila. Também podem encontrar restos de bactérias ou metabólitos. A relação C/N geralmente varia entre 7 e 12 . 


\subsection{Mudanças nos níveis de matéria orgânica e na sua distribuição nas frações do solo induzidas pelo manejo dos resíduos culturais}

Os resíduos vegetais que permanecem na superfície do solo após a colheita das culturas são uma fonte importante de carbono, nitrogênio e outros elementos, que bem manejada, contribui na manutenção dos níveis de matéria orgânica do solo e na ciclagem dos nutrientes (Furlani Neto et al., 1997).

Deve-se levar em consideração que o manejo dos resíduos afeta diferencialmente as frações do carbono do solo, o que nem sempre se reflete em mudanças no conteúdo de carbono total. Em um experimento de cana-de-açúcar de longa duração, Graham et al. (2002) observaram que após 59 anos de utilização de manejos contrastantes (colheita com queima e colheita sem queima), a matéria orgânica total aumentou significativamente nos primeiros $10 \mathrm{~cm}$ do solo na colheita sem queima. Nas camadas de 10-20 e 20-30 cm foram detectadas diferenças no carbono lábil, no carbono e nitrogênio da biomassa microbiana e do $\mathrm{C}$ e $\mathrm{N}$ prontamente mineralizável, sendo todos esses fatores favorecidos pela retenção dos resíduos no sistema.

Blair et al. (1998), em experimentos de longo prazo com cana-de-açúcar na Austrália e em Pernambuco (Brasil), relataram que, na Austrália, após de 8 anos da implantação da cultura, os solos cultivados apresentaram níveis menores de carbono orgânico total $\left(\mathrm{C}_{\mathrm{t}}\right)$ e de carbono lábil $\left(\mathrm{C}_{1}\right)$ que os solos com pastagem ou floresta usados como referência. $\mathrm{O}$ manejo dos resíduos influenciou também nos níveis de $\mathrm{C}_{\mathrm{t}}$ e $\mathrm{C}_{\mathrm{l}}$, sendo esses inferiores nos tratamentos com queima em comparação à colheita sem queima. No caso estudado no Brasil, o manejo dos resíduos não influenciou os níveis de $\mathrm{C}_{\mathrm{t}}$; porém, no tratamento sem queima, o nível de $\mathrm{C}_{1}$ lábil foi superior.

Christensen (1987) estudou a evolução da matéria orgânica nas distintas frações granulométricas em solos de textura arenosa correspondente a um experimento de 18 anos com incorporação e com queima de resíduos de aveia. A maior parte do $\mathrm{C}$ e do $\mathrm{N}$ foi achada na fração argila (inferior a $2 \mu \mathrm{m}$ ), e a menor na fração areia. A incorporação dos resíduos aumentou levemente o conteúdo de $\mathrm{C}$ e $\mathrm{N}$ na maioria das frações e teve pouca influência na distribuição relativa de $\mathrm{C}$ e $\mathrm{N}$ entre as frações. A degradação da MOS decresceu na seguinte ordem: areia $>$ argila $>$ silte. Portanto, a MOS associada ao 
silte parece ser mais resistente ao ataque microbiano que a associada à argila. A fração areia apresentou menor estabilidade, sendo principalmente matéria orgânica constituída por resíduos vegetais grosseiros não associada às partículas minerais.

Chan et al. (2002) relataram que após 19 anos de manejo contínuo com queima dos resíduos em uma rotação trigo-lupino, a queima reduziu diferencialmente o carbono das frações do solo nos primeiros $20 \mathrm{~cm}$, sendo o carbono orgânico associado às partículas mais finas $(<53 \mu \mathrm{m})$ o mais afetado. A redução dessa fração do carbono orgânico se refletiu em uma significativa perda da estabilidade de agregados menores que $50 \mu \mathrm{m}$. O mecanismo pelo qual ocorre tal perda não está claro, mas parece estar relacionado à redução de certa classe de produtos da decomposição microbiana causada pela queima. Isso poderia ocorrer diretamente como conseqüência da queima ou indiretamente por mudanças na composição da população microbiana causadas pela queima. Outros autores (Rasmussen et al., 1980; Biederbeck et al., 1980; Boerner 1982; Collins et al., 1992) também têm constatado redução da biomassa microbiana e da atividade microbiana como conseqüência de sucessivas queimadas.

No sistema de colheita sem queima, o carbono derivado dos resíduos se incorpora à biomassa microbiana ou à matéria orgânica do solo contribuindo para um efetivo incremento de carbono no solo, enquanto que o carbono que permanece no sistema após a queima pode estar constituído por uma alta proporção de carbono na forma de compostos aromáticos ("black carbon" ou "charcoal") muito resistente à degradação biológica (Skjemstadt et al., 1999; Czimczik et al., 2003).

\subsection{O isótopo ${ }^{15} \mathrm{~N}$ e sua utilização em estudos da dinâmica de nitrogênio em sistemas agrícolas}

Os isótopos de um elemento possuem um mesmo número de prótons e, portanto, têm o mesmo número atômico, mas diferem na sua massa, a qual está definida pelo número de nêutrons no núcleo. No caso do nitrogênio, existem seis isótopos. Os isótopos ${ }^{12} \mathrm{~N},{ }^{13} \mathrm{~N},{ }^{16} \mathrm{~N}$ e ${ }^{17} \mathrm{~N}$ são artificiais, radioativos e de meia vida muito curta, enquanto que ${ }^{14} \mathrm{~N}$ e ${ }^{15} \mathrm{~N}$ ocorrem na natureza, são estáveis e de meia vida infinita (IAEA, 1983). 
Os isótopos estáveis ${ }^{14} \mathrm{~N}$ e ${ }^{15} \mathrm{~N}$ ocorrem na natureza numa taxa praticamente constante: o ${ }^{15} \mathrm{~N}$ tem uma abundância média na atmosfera de 3,66 mg.g $\mathrm{g}^{-1}$ de $\mathrm{N}(0,366 \%)$ e o ${ }^{14} \mathrm{~N}$ de $996,34 \mathrm{mg} \cdot \mathrm{g}^{-1}$ de $\mathrm{N}(99,634 \%)$, sendo a relação entre os dois isótopos de $272,0 \pm 0,3: 1$ (IAEA, 1983).

A abundância dos isótopos de um elemento se pode quantificar no espectrômetro de massa. $\mathrm{Na}$ determinação por espectrometria de massa da concentração isotópica de ${ }^{15} \mathrm{~N}$ (átomos \%) ou das variações da razão $\left({ }^{15} \mathrm{~N} /{ }^{14} \mathrm{~N}\right)$ de qualquer material, o nitrogênio contido nas amostras deve ser transformado em gás $\mathrm{N}_{2}$. Os métodos mais usados para a conversão de diferentes formas de $\mathrm{N}$ em $\mathrm{N}_{2}$ são o método de Dumas e o método de Rittemberg (Trivelin et al., 1973). Seguidamente, no espectrômetro de massa, as moléculas de $\mathrm{N}_{2}$ são ionizadas e os íons formados são separados pela sua razão carga/massa $(\mathrm{m} / \mathrm{z})$, num campo magnético sob vácuo. Posteriormente, no sistema de detecção do aparelho os íons formados são coletados permitindo a quantificação da abundância relativa através da corrente formada nos coletores. Assim, os íons de massa $28\left({ }^{14} \mathrm{~N}^{14} \mathrm{~N}\right)^{+}, 29\left({ }^{14} \mathrm{~N}^{15} \mathrm{~N}\right)^{+}$e $30\left({ }^{15} \mathrm{~N}^{15} \mathrm{~N}\right)^{+}$são quantificados para calcular a concentração do ${ }^{15} \mathrm{~N}$ no material estudado (Barrie \& Prosser, 1996).

Hart \& Myrold (1996) fizeram a seguinte classificação das técnicas que utilizam o ${ }^{15} \mathrm{~N}$ em estudos dos processos de transformação do $\mathrm{N}$ no solo: (i) técnica do traçador ${ }^{15} \mathrm{~N}$, quando um substrato ou fonte é marcado com ${ }^{15} \mathrm{~N}$, e o movimento do isótopo no sistema é monitorado no tempo; (ii) técnica da diluição do isótopo ${ }^{15} \mathrm{~N}$, quando um “pool" de $\mathrm{N}$ do solo é marcado com ${ }^{15} \mathrm{~N}$ e é monitorada a taxa na qual seu conteúdo muda pelo influxo de ${ }^{14} \mathrm{~N}$; (iii) técnica da abundância natural de ${ }^{15} \mathrm{~N}$, quando pequenas diferenças no enriquecimento de ${ }^{15} \mathrm{~N}$, como resultado da discriminação biológica durante longo período, são usadas para avaliar as relações substrato-produto em longo prazo; e (iv) técnica da distribuição dos isótopos de N, a qual é uma nova variante da técnica de traçador para nitrogênio, e aplica-se exclusivamente para a reação de desnitrificação quando o $\mathrm{N}$ do ${ }^{15} \mathrm{NO}_{3}{ }^{-}$dá origem a $\mathrm{N}_{2} \mathrm{O}$ e $\mathrm{N}_{2}$.

A técnica do traçador isotópico se fundamente no princípio da diluição isotópica, pelo qual o ${ }^{15} \mathrm{~N}$ do composto enriquecido introduzido no sistema é homogeneamente distribuído dentro do $\mathrm{N}$ do sistema. Portanto, o enriquecimento isotópico, em qualquer 
tempo, de um produto uniformemente misturado com o traçador é inversamente proporcional à concentração do traçador no substrato adicionado (IAEA, 1976).

O princípio da diluição isotópica é baseado nas seguintes premissas: (i) elementos complexos (com pelo menos dois isótopos) em estado natural apresentam uma composição isotópica constante; (ii) os sistemas biológicos não podem distinguir entre um isótopo e outro; e (iii) a identidade química dos isótopos é mantida nos sistemas bioquímicos (Hauck \& Bremner, 1976).

$\mathrm{O}$ uso do ${ }^{15} \mathrm{~N}$ como traçador consiste na alteração da proporção isotópica natural, aumentando (ou diminuindo) o teor de ${ }^{15} \mathrm{~N}$ na molécula ou composto do qual se quer monitorar seu destino no sistema. Os isótopos ${ }^{14} \mathrm{~N}$ e ${ }^{15} \mathrm{~N}$, por serem estáveis, podem ser utilizados em experimentos de longa duração, sendo amplamente usados para o estudo dos processos envolvidos no ciclo do nitrogênio e no movimento de compostos nitrogenados nos sistemas agrícolas (Axmann \& Zapata, 1990). 


\section{MATERIAL E MÉTODOS}

\subsection{Local do experimento}

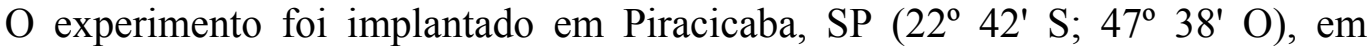
outubro de 1997, num solo classificado como NITOSSOLO VERMELHO EUTROFÉRRICO (Embrapa, 1999) de textura argilosa com 29\% de areia, 16\% de silte e $55 \%$ de argila, $\mathrm{pH}$, e $25 \mathrm{~kg} \cdot \mathrm{m}^{-3}$ de matéria orgânica.

O clima é Cwa, tropical, mesotérmico com inverno seco. O valor médio de temperatura é de $21,2^{\circ} \mathrm{C}$, sendo a temperatura média do mês mais frio inferior a $18^{\circ} \mathrm{C}$ e a do mês mais quente superior a $22^{\circ} \mathrm{C}$. A precipitação pluvial média anual é $1253 \mathrm{~mm}$. Os dados de temperatura, precipitação e radiação global dos períodos 1997-1999 e 20002002 se encontram nos APÊNDICES 1 e 2 (Tabelas 16 e 17).

\subsection{A cultura, os tratamentos e o delineamento experimental}

A variedade de cana-de-açúcar SP 80-3280 foi plantada numa área de $2100 \mathrm{~m}^{2}$ (15 linhas de $100 \mathrm{~m}$ de comprimento, com espaçamento de 1,4 m). A área experimental efetiva engloba as três linhas centrais, nas quais foram estabelecidos três tratamentos, separados entre si por bordaduras de $4 \mathrm{~m}$. Cada tratamento teve 4 repetições, cada uma de 3 linhas de cana de $4 \mathrm{~m}$ de comprimento $\left(16,8 \mathrm{~m}^{2}\right)$. Na implantação da cultura foi aplicado sulfato de amônio na linha de plantio numa seção de $0,5 \mathrm{~m}(0,25 \mathrm{~m}$ a cada lado da linha), cobrindo, portanto, $0,36(0,5 / 1,4)$ para favorecer uma maior absorção do nitrogênio pela cultura.

Os tratamentos foram: T1: adubação no plantio com $63 \mathrm{~kg} \cdot \mathrm{ha}^{-1}$ de $\mathrm{N}$ na forma de sulfato de amônio com $11,7 \%$ de ${ }^{15} \mathrm{~N}$ em excesso, e colheita de cana sem queima (SQ); T2: adubação no plantio com $63 \mathrm{~kg} \cdot \mathrm{ha}^{-1}$ de $\mathrm{N}$ na forma de sulfato de amônio comercial (não marcado) e colheita de cana sem queima (SQ); T3: adubação no plantio com 63 
kg.ha ${ }^{-1}$ de $\mathrm{N}$ na forma de sulfato de amônio com $11,7 \%$ de ${ }^{15} \mathrm{~N}$ em excesso, e colheita de cana com despalha a fogo (CQ).

Logo após a colheita da cana-planta (primeira colheita), T1 recebeu a palhada não marcada proveniente de T2, e T2 a palhada marcada com ${ }^{15} \mathrm{~N}$ proveniente de $\mathrm{T} 1$. O intercâmbio da palhada permitiu o seguimento do fertilizante marcado nos compartimentos solo e resíduos separadamente. Assim, o tratamento T2, além de ser complementar ao T1 para o estudo do nitrogênio derivado do fertilizante (NddF), permite estudar a redistribuição no sistema do nitrogênio derivado dos resíduos (NddR). Conseqüentemente, na análise dos resultados referentes à variável $\mathrm{NddF}$, o tratamento $\mathrm{SQ}$ corresponde à soma de $\mathrm{T} 1$ e $\mathrm{T} 2(\mathrm{SQ}=\mathrm{T} 1+\mathrm{T} 2)$, enquanto que o tratamento com queima (CQ), refere-se a T3 $(\mathrm{CQ}=\mathrm{T} 3)$.

Por outro lado, a variável NddR foi determinada nas parcelas correspondentes a T2, estudando-se seu comportamento ao longo de quatro ciclos, desde a colheita de 1999 até a colheita de 2002; já que no primeiro ano da cultura (1998), o tratamento referente ao seguimento do NddR ainda não tinha sido implementado. Para as demais variáveis, considerou-se $\mathrm{SQ}=\mathrm{T} 1$ e $\mathrm{CQ}=\mathrm{T} 3$.

A partir da segunda colheita, foram realizadas nas canas-soca adubações de cobertura com $80 \mathrm{~kg} \cdot \mathrm{ha}^{-1}$ de N em todos os tratamentos. A adubação fosfatada e outras práticas de manejo adotadas durante o desenvolvimento da cultura foram as mesmas para todos os tratamentos.

\subsection{Resíduos culturais marcados com ${ }^{15} \mathrm{~N}$ usados nas parcelas do tratamento $\mathrm{T} 2$}

Logo após a colheita da cana-planta em outubro de 1998, nas parcelas do tratamento T2 foram adicionados $7.533 \mathrm{~kg} \mathrm{ha}^{-1}$ de matéria seca (MS) de ponteiros e $11.000 \mathrm{~kg} \cdot \mathrm{ha}^{-1}$ de matéria seca de palhada (total de $18.533 \mathrm{~kg} \cdot \mathrm{ha}^{-1}$ de MS de resíduos adicionada) provenientes de T1, com $127 \mathrm{~kg} \cdot \mathrm{ha}^{-1}$ de $\mathrm{N}$ e $1,78 \%$ de átomos de ${ }^{15} \mathrm{~N}$ em excesso. Em cada repetição (parcela) do tratamento T2, foi adicionada a palhada da correspondente repetição (o mesmo número) de T1. Isso foi feito porque na análise do nitrogênio derivado do fertilizante, no tratamento sem queima, foi necessário considerar a somatória do conteúdo de ${ }^{15} \mathrm{~N}$ nos dois tratamentos. Portanto, a análise do tratamento 
T2 permitiu avaliar a dinâmica no sistema solo-planta do nitrogênio contido na palhada como sendo NddR (com base no $1,78 \%$ de átomos de ${ }^{15} \mathrm{~N}$ em excesso dos resíduos) e também o NddF (com base ao $11,7 \%$ de ${ }^{15} \mathrm{~N}$ em excesso do sulfato de amônio).

\subsection{Amostragem da planta e do solo}

Anualmente, no mês de outubro, foi realizada a colheita manual sendo coletados os colmos dos 2 m lineares centrais de cada uma das 3 linhas de cada parcela e pesados no campo para obtenção da produtividade $\left(\mathrm{Mg}_{\mathrm{h}} \mathrm{ha}^{-1}\right)$. Posteriormente, de cada amostra foram extraídas sub-amostras que, depois de acondicionadas, foram secas em estufa a $65^{\circ} \mathrm{C}$ até peso constante para o cálculo da massa de matéria seca ( $\mathrm{MS}, \mathrm{kg} \mathrm{ha}^{-1}$ ) dos colmos e, posteriormente moídas em moinho tipo Willey para a determinação de nitrogênio.

A amostragem dos resíduos culturais foi realizada no primeiro ano (colheita de cana-planta em 1998) coletando o material vegetal (ponteiros e palhada) achado sobre a superfície do solo em toda a parcela $\left(16,8 \mathrm{~m}^{2}\right)$. Os ponteiros e a palhada foram separados e pesados para determinação da massa úmida. De cada amostra foi separada uma subamostra que foi seca em estufa a $65^{\circ} \mathrm{C}$ até peso constante para a determinação da massa de matéria seca (MS, kg.ha ${ }^{-1}$ ) dos ponteiros e da palhada. Posteriormente, as subamostras foram moídas em moinho tipo Willey e usadas na análise de nitrogênio total $(\% \mathrm{Nt})$ e da abundância de ${ }^{15} \mathrm{~N}$ (átomos \%).

Nos anos seguintes, quatro ciclos de cana-soca, a massa de resíduos vegetais produzidos anualmente foi estimada com base na produtividade de colmos (medida a cada ano) e na relação colmo/resíduos $(\mathrm{Co} / \mathrm{R}=1,6)$, determinada na amostragem do primeiro ano. Em cada parcela foram amostrados os ponteiros e as folhas +3 de três plantas para a determinação da porcentagem de nitrogênio total $(\% \mathrm{Nt})$ e da abundância de ${ }^{15} \mathrm{~N}$ (átomos \%), assumindo que a porcentagem de $\mathrm{N}$ da folha +3 representa a média da porcentagem de $\mathrm{N}$ de toda as folhas da planta (palhada) (Carnaúba, 1989).

A amostragem do solo foi realizada anualmente logo após a colheita da cana, nas camadas de $0-15 ; 15-30$ e $30-50 \mathrm{~cm}$. Em cada parcela, para cada camada, foram extraídas 3 sub-amostras ( 3 pontos de amostragem por parcela), as quais logo foram 
misturadas resultando em uma amostra composta por parcela. As amostras foram secas ao ar e peneiradas (peneiras der $2 \mathrm{~mm}$ ) obtendo-se a TFSA (terra fina seca ao ar). Nessas amostras foram feitas as determinações de nitrogênio total $(\% \mathrm{Nt})$, da abundância de ${ }^{15} \mathrm{~N}$ (átomos \%) e de carbono orgânico.

No início do experimento, foi determinada a massa específica para cada camada do solo pelo método do anel volumétrico ( 5 determinações por parcela) resultando em valores médios de $1,351,51$ e 1,45 $\mathrm{Mg}^{-3} \mathrm{~m}^{-3}$ para as camadas de 0-15, 15-30 e 30-50 cm, respectivamente. Os valores de massa específica foram usados no cálculo dos conteúdos de $\mathrm{N}$ e de $\mathrm{C}$ do solo.

\subsection{Fracionamento granulométrico do solo}

Uma alíquota de cada amostra de TFSA foi fracionada fisicamente em diferentes frações granulométricas segundo a metodologia proposta por Feller $(1979,1994)$ e Cerri et al. (1990) para solos tropicais.

Em um frasco de $1000 \mathrm{~mL}$, foram colocados 40 gramas de TFSA e $200 \mathrm{~mL}$ de água deionizada com três esferas de vidro e agitou-se manualmente por 10 a 15 segundos. As amostras permaneceram na geladeira por 16 horas a baixa temperatura no intuito de produzir um efeito de contração dos agregados que facilita a ruptura dos mesmos na posterior agitação.

Posteriormente, procedeu-se ao agitamento por duas horas em um agitador rotativo a $50 \mathrm{rpm}$. É importante manter a baixa rotação para romper os agregados sem alterar o diâmetro das partículas ou fragmentar parte da fração da MOS superior a 200 $\mu \mathrm{m}$.

Para separar a fração 200-2000 $\mu \mathrm{m}$, o solo em suspensão foi passado através de peneira de $200 \mu \mathrm{m}$ sobre um Becker de $600 \mathrm{~mL}$. Foi realizada a lavagem da peneira com água deionizada para recuperar as partículas de menos de $200 \mu \mathrm{m}$, as quais foram adicionadas à fração que tinha passado pela peneira de $200 \mu \mathrm{m}$. A peneira com a fração 200-2000 $\mu \mathrm{m}$ foi submersa em água para separar os fragmentos orgânicos (Fl), que por serem mais leves ficam flutuando, das partículas de areia (Fp). 
A suspensão do solo com as frações menores que 200 recebeu energia ultrasônica (240 Watts) durante 10 minutos. Após a sonificação observou-se ao microscópio o grau de dispersão da amostra. Por último, o solo em suspensão foi passado pela peneira de $53 \mu \mathrm{m}$, obtendo-se a fração 53-200 $\mu \mathrm{m}$ (Fom) e a fração $<53 \mu \mathrm{m}$ (Fsa).

Assim, ficaram determinadas as seguintes frações: (i) Fl, fração leve, flutuando

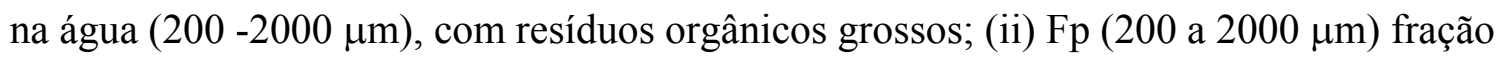
mineral pesada, com tamanho de partícula correspondente à areia; (iii) Fom (53 a 200 $\mu \mathrm{m})$, fração organo-mineral com resíduos vegetais em diferentes estádios de decomposição; e (iv) Fsa (inferior a $53 \mu \mathrm{m}$ ), fração organo-mineral com resíduos orgânicos humificados associados a partículas do tamanho do silte e da argila.

Cada fração granulométrica foi pesada para o cálculo da sua contribuição relativa à massa total da amostra. Posteriormente, foram determinadas as percentagens de $\mathrm{C}, \mathrm{N}$ e

${ }^{15} \mathrm{~N}$ em cada uma delas.

\subsection{Determinações analíticas}

Nas amostras das distintas partes da planta (colmo, ponteiro e palhada) e do solo (TFSA e frações granulométricas), realizaram-se as determinações do teor de nitrogênio $(\% \mathrm{~N})$ e da abundância de ${ }^{15} \mathrm{~N}\left(\%\right.$ de átomos de $\left.{ }^{15} \mathrm{~N}\right)$ através da análise isotópica do $\mathrm{N}$ no espectrômetro de massa (ANCA-SL, Europe Scientific, Crewe, UK) de acordo com Rittemberg (Bremner, 1965; Hauck, 1982), no laboratório de Isótopos Estáveis do CENA-USP.

Em cada amostra de solo, uma sub-amostra finamente moída $(<0,5 \mathrm{~mm})$ foi usada para a determinação do teor de carbono total por combustão a seco (Allison, 1965) no auto-analisador LECO CR 2000, no Laboratório de Biogeoquímica Ambiental do CENA-USP.

\subsection{Nitrogênio recuperado no sistema}

A porcentagem de nitrogênio derivado do fertilizante (NddF, \%), a quantidade de nitrogênio derivado do fertilizante (QNddF, $\mathrm{kg}_{\mathrm{h}} \mathrm{ha}^{-1} \mathrm{de} \mathrm{N}$ ) e a porcentagem do nitrogênio 
do fertilizante recuperado (NFRec, \%) em cada compartimento do sistema solo-planta foram calculados segundo IAEA (1983).

NddF e QNddF são assim calculadas:

$$
\begin{gathered}
N d d F_{K}=\frac{\left(\% \text { atom. }{ }^{15} N \text { exc. Comp. } \cdot_{k}\right)}{\left(\% \text { atom. }{ }^{15} N \text { exc. Fert. }\right)} \times 100 \\
\text { QNddF } F_{k}=\left(\frac{N d d F_{k}}{100}\right) \times Q T N_{k}
\end{gathered}
$$

em que QNddF (kg.ha ${ }^{-1}$ ) é o produto entre NddF e a quantidade total de nitrogênio $\left(\right.$ QTN, kg.ha ${ }^{-1}$ ) no compartimento k; QTN para cada parte da planta é o produto entre a massa de matéria seca (MMS, kg.ha ${ }^{-1}$ ) e a porcentagem de nitrogênio total (Nt, \%), e para o solo, o produto entre a massa seca do solo (MSS, kg.ha ${ }^{-1}$ ) e Nt do compartimento considerado (i e. camada), sendo a massa do solo o produto entre a massa específica do solo $\left(\rho_{\mathrm{s}}\right)$ e o volume total do solo $\left(\mathrm{V}_{\mathrm{s}}\right)$, ou seja, $\mathrm{QTN}=\rho_{\mathrm{s}} \cdot \mathrm{V}_{\mathrm{s}} \cdot \mathrm{Nt}$.

Finalmente, NFRec num compartimento (ou no sistema) é a relação entre QNddF e o nitrogênio total fornecido pelo fertilizante (TNF, $\mathrm{kg}_{\text {.ha }}{ }^{-1}$ ), ou seja, a eficiência de uso do fertilizante, podendo assim ser calculada:

$$
N F \operatorname{Re} c=\frac{Q N d d F}{T N F} \times 100
$$

O mesmo procedimento foi usado para calcular a porcentagem do nitrogênio derivado dos resíduos da cultura $(\mathrm{NddR}, \%)$, a quantidade do nitrogênio derivado dos resíduos (QNddR, kg.ha ${ }^{-1}$ ), e recuperação num determinado compartimento ou no sistema do nitrogênio dos resíduos (NRRec, \%).

\subsection{Análise estatística}

As variáveis analisadas foram: (i) produtividade de colmos ( $\left.\mathrm{Mg}^{-h a^{-1}}\right)$, (ii) nitrogênio total $\left(\mathrm{Nt}, \mathrm{kg} \cdot \mathrm{ha}^{-1}\right)$, (iii) nitrogênio derivado do fertilizante (NddF, $\left.\mathrm{kg} \cdot \mathrm{ha}^{-1}\right)$, (iv) nitrogênio derivado dos resíduos $\left(\mathrm{NddR},\left(\mathrm{kg} \mathrm{ha}{ }^{-1}\right)\right.$ e (v) carbono total no solo (C, Mg.ha- $\left.{ }^{-1}\right)$.

Para facilitar o manejo do fogo no campo, as quatro parcelas das repetições de cada tratamento ficaram contíguas. Devido a essa restrição na aleatoriedade, os 
resultados foram analisados comparando os dois grupos de dados (CQ vs. SQ) pelo Teste $t$ ao nível de significância de $5 \%$.

$\mathrm{Na}$ análise das variáveis ao longo do tempo, utilizou-se o Teste $t$ para comparar os resultados entre anos dentro de cada tratamento. Para as variáveis em que foram detectadas diferenças significativas na comparação entre anos, foi realizada a análise de regressão.

\subsection{Modelo descritivo da dinâmica do nitrogênio adicionado ao sistema solo- planta via fertilizante}

Foi desenvolvido um modelo descritivo simples da dinâmica do nitrogênio no sistema solo-planta, considerando no compartimento planta apenas a parte aérea da cultura.

Com base na quantidade de nitrogênio adicionada, o nitrogênio recuperado no sistema é expresso em valores relativos segundo as equações (4) e (5.1).

$$
N_{k, j}=\frac{A N E_{k, j}}{A N E F} \cdot \frac{Q N_{k, j}}{Q N A F} \cdot 100
$$

em que $\mathrm{N}_{\mathrm{k}, \mathrm{j}}$ se refere à quantidade relativa de nitrogênio (\%), a base de massa, retida no solo (compartimento 1: $k=1$ ) ou nitrogênio recuperado pela planta (compartimento 2: $k=2)$, no final do ano $j(j=1,2,3, \ldots, n)$, após uma única adição de $\mathrm{N}$ via fertilizante; $\mathrm{ANE}_{\mathrm{k}, \mathrm{j}}$ à porcentagem $(\%)$ de átomos de ${ }^{15} \mathrm{~N}$ em excesso no compartimento $k(k=1$ ou $k=2$ ), no final do ano $j$; ANEF à porcentagem (\%) de átomos de ${ }^{15} \mathrm{~N}$ em excesso no fertilizante; $\mathrm{QN}_{\mathrm{k}, \mathrm{j}}$ à quantidade $\left(\mathrm{kg} \cdot \mathrm{ha}^{-1}\right)$ de nitrogênio no compartimento $k(k=1$ ou $k=2)$, no final do ano $j$; QNAF à quantidade $\left(\mathrm{kg} \cdot \mathrm{ha}^{-1}\right)$ de nitrogênio adicionado via fertilizante; $k$ aos compartimentos solo $(k=1)$, planta $(k=2)$, ou solo e planta $(k=3)$.

$$
N_{3, j}=N_{1, j}+N_{2, j}
$$

em que $\mathrm{N}_{3, \mathrm{j}}$ se refere à quantidade relativa de nitrogênio (\%) recuperado no sistema soloplanta $(k=3)$ no ano $j$. 
As perdas relativas de nitrogênio $\left(\mathrm{Nl}_{3, \mathrm{j}}, \%\right)$ no sistema solo-planta $(k=3)$, no ano $j$, podem ser calculadas pela diferença com a quantidade relativa de nitrogênio recuperado, de acordo com a equação (6.1).

$$
N_{3, j}=100-N_{3, j}
$$

$\mathrm{Na}$ Tabela 1, são descritas as hipóteses referentes ao modelo descritivo da recuperação do nitrogênio adicionado no sistema solo-planta; e na Tabela 2 são descritas as hipóteses referentes ao compartimento planta.

A equação (7) foi desenvolvida para representar a variação temporal da recuperação relativa do nitrogênio aplicado no sistema solo-planta ( $k=3)$ (Figura 1):

$$
N_{k, j}=A_{k}+\frac{100-A_{k}}{1+B_{k} \cdot j^{C_{k}}}
$$

em que $\mathrm{N}_{\mathrm{k}, \mathrm{j}}$ se refere à quantidade relativa de $\mathrm{N}$ do fertilizante no sistema solo-planta $\left(\mathrm{N}_{3, j}, \%\right) ; \mathrm{A}_{\mathrm{k}}, \mathrm{B}_{\mathrm{k}}$ e $\mathrm{C}_{\mathrm{k}}$ aos parâmetros da curva para o compartimento $k=3$ (sistema soloplanta).

Para a variação temporal da recuperação relativa do nitrogênio aplicado no compartimento planta (parte aérea), foram propostas duas equações: a equação 8 que representa a absorção de nitrogênio do fertilizante entre o instante inicial, ou seja, o momento de aplicação do fertilizante $(j=0)$ e o final do primeiro ano $(j=1)$, e a equação 9 que simula a absorção do nitrogênio do fertilizante aplicado no tempo $j=0$, a partir do início do segundo ano da cultura $(j \geq 1)$, ou seja, a utilização pela planta do nitrogênio do fertilizante residual (Figura 2).

$$
\begin{gathered}
\left.N_{k, j}=A_{k} \cdot j \quad \text { se } 0 \leq \mathrm{j}<1\right) \\
\hat{N_{k, j}}=\frac{A_{k}}{1+B_{k} \cdot(j-1)^{C_{k}}}(\text { se } j \geq 1)
\end{gathered}
$$

em que $\mathrm{N}_{\mathrm{k}, \mathrm{j}}$ refere-se à quantidade relativa de $\mathrm{N}$ do fertilizante no compartimento planta $\left(\mathrm{N}_{2, j}, \%\right)$ e $A_{k}, B_{k}$ e $C_{k}$ aos parâmetros da curva para o compartimento planta $(k=2)$. 


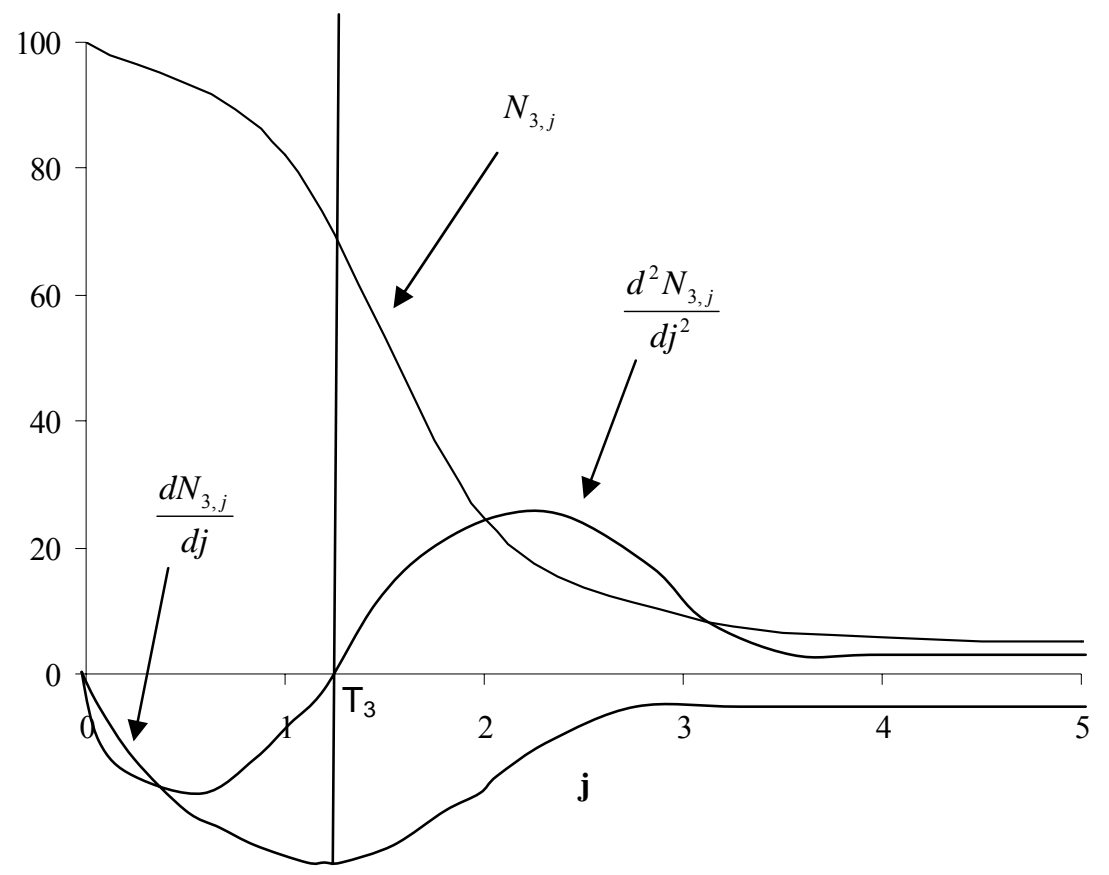

Figura 1 - Modelo proposto referente à dinâmica de nitrogênio adicionado via fertilizante no sistema solo-planta $(\mathrm{k}=3)$

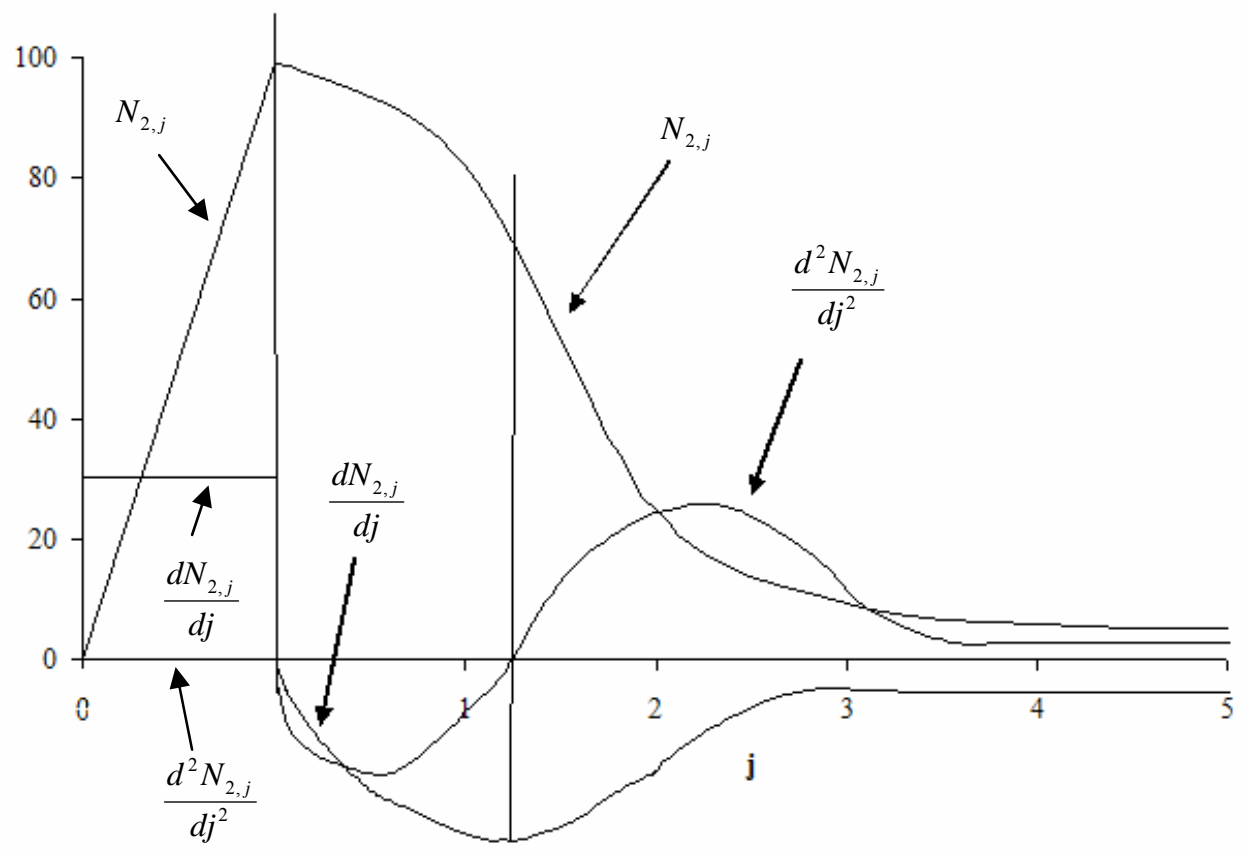

Figura 2 - Modelo proposto referente à dinâmica no compartimento planta $(k=2)$ do nitrogênio adicionado via fertilizante 
Tabela 1. Hipóteses do modelo proposto referentes à dinâmica de nitrogênio adicionado via fertilizante no sistema solo-planta $(\mathrm{k}=3)$

\begin{tabular}{|c|c|c|c|}
\hline Caso & Restrição & Conseqüência & Comentário \\
\hline 1 & $\mathrm{j}=0$ & $N_{3,0}=100$ & $\begin{array}{l}\text { Sem perdas do } \mathrm{N} \text { adicionado no } \\
\text { instante inicial. }\end{array}$ \\
\hline 2 & $\mathrm{j} \rightarrow \infty$ & $N_{3, \infty}=A_{3}$ & $\begin{array}{l}\text { Quantidade relativa residual do } \mathrm{N} \\
\text { adicionado no tempo infinito. }\end{array}$ \\
\hline 3 & $\mathrm{j}=\mathrm{T}_{3}$ & $\frac{d^{2} N_{3, T_{3}}}{d j^{2}}=0$ & $\begin{array}{l}\text { Máxima taxa de perda do } \mathrm{N} \\
\text { adicionado no instante } \mathrm{T}_{3} \text {. }\end{array}$ \\
\hline 4 & $0<\mathrm{j}<\mathrm{T}_{3}$ & $\frac{d^{2} N_{3, j}}{d j^{2}}<0$ & $\begin{array}{l}\text { Taxa da taxa de perda negativa do } \\
\mathrm{N} \text { adicionado. }\end{array}$ \\
\hline 5 & $\mathrm{j}>\mathrm{T}_{3}$ & $\frac{d^{2} N_{3, j}}{d j^{2}}>0$ & $\begin{array}{l}\text { Taxa da taxa de perda positiva do } \\
\mathrm{N} \text { adicionado. }\end{array}$ \\
\hline 6 & $\mathrm{j}=0$ & $\frac{d N_{3,0}}{d j}=0$ & $\begin{array}{l}\text { Taxa de perda nula do } \mathrm{N} \\
\text { adicionado no instante inicial. }\end{array}$ \\
\hline 7 & $\mathrm{j} \rightarrow \infty$ & $\frac{d N_{3, \infty}}{d j}=0$ & $\begin{array}{l}\text { Taxa de perda nula do } \mathrm{N} \\
\text { adicionado no tempo infinito. }\end{array}$ \\
\hline 8 & $\mathrm{j}>0$ & $\frac{d N_{3, j}}{d j}<0$ & $\begin{array}{l}\text { A função é estritamente } \\
\text { decrescente, onde a taxa de perda } \\
\text { do } \mathrm{N} \text { adicionado é sempre negativa } \\
\text { (exceto no instante inicial e no } \\
\text { infinito). }\end{array}$ \\
\hline
\end{tabular}

$j$ : tempo. $\mathrm{T}_{3}$ : instante de máxima taxa de perda de N. $\mathrm{N}_{3, \mathrm{j}}$ : quantidade relativa de nitrogênio recuperado no compartimento $k=3$ (sistema solo-planta) no ano $j$. 
Tabela 2. Hipóteses do modelo proposto referentes à dinâmica no compartimento planta $(\mathrm{k}=2)$ do nitrogênio adicionado via fertilizante

\begin{tabular}{|c|c|c|c|}
\hline Caso & Restrição & Conseqüência & Comentário \\
\hline 1 & $j=0$ & $N_{2,0}=0$ & $\begin{array}{l}\text { Quantidade relativa na planta do } \mathrm{N} \\
\text { adicionado no instante inicial é } \\
\text { nula. }\end{array}$ \\
\hline 2 & $\mathrm{j}=1$ & $N_{2,1}=A_{2}$ & $\begin{array}{l}\text { Quantidade relativa na planta do } \mathrm{N} \\
\text { adicionado mensurada na primeira } \\
\text { colheita. }\end{array}$ \\
\hline 3 & $\mathrm{j} \rightarrow \infty$ & $N_{2, \infty}=0$ & $\begin{array}{l}\text { Quantidade relativa na planta do } \mathrm{N} \\
\text { adicionado no tempo infinito é } \\
\text { igual a } 0 .\end{array}$ \\
\hline 4 & $\mathrm{j}=\mathrm{T}_{2}$ & $\frac{d^{2} N_{2, T_{2}}}{d j^{2}}=0$ & $\begin{array}{l}\text { Máxima taxa de perda do } \mathrm{N} \\
\text { adicionado na planta no instante } \\
\mathrm{T}_{2} \text {. }\end{array}$ \\
\hline 5 & $1<\mathrm{j}<\mathrm{T}_{2}$ & $\frac{d^{2} N_{2, j}}{d j^{2}}<0$ & $\begin{array}{l}\text { Taxa da taxa de perda negativa do } \\
\mathrm{N} \text { adicionado. }\end{array}$ \\
\hline 6 & $\mathrm{j}>\mathrm{T}_{2}$ & $\frac{d^{2} N_{2, j}}{d j^{2}}>0$ & $\begin{array}{l}\text { Taxa da taxa de perda positiva do } \\
\mathrm{N} \text { adicionado. }\end{array}$ \\
\hline 7 & $\mathrm{j}=1$ & $\frac{d N_{2,1}}{d j}=0$ & $\begin{array}{l}\text { Taxa de perda nula do } \mathrm{N} \\
\text { adicionado em } j=1 \text {. }\end{array}$ \\
\hline 8 & $\mathrm{j} \rightarrow \infty$ & $\frac{d N_{2, \infty}}{d j}=0$ & $\begin{array}{l}\text { Taxa de perda nula do } \mathrm{N} \\
\text { adicionado no tempo infinito. }\end{array}$ \\
\hline 9 & $\mathrm{j}>1$ & $\frac{d N_{2, j}}{d j}<0$ & $\begin{array}{l}\text { A função é estritamente } \\
\text { decrescente, onde a taxa do N } \\
\text { adicionado de perda é sempre } \\
\text { negativa (exceto no instante } j=1 \text { e } \\
\text { no infinito). }\end{array}$ \\
\hline
\end{tabular}

$j$ : tempo. $\mathrm{T}_{2}$ : instante de máxima taxa de perda de $\mathrm{N} . \mathrm{N}_{2, \mathrm{j}}$ : quantidade relativa de nitrogênio do fertilizante recuperado no compartimento $k=2$ (planta) no ano $j$. 
As equações referentes à recuperação do nitrogênio derivado do fertilizante no sistema solo-planta estão explicitadas nos seguintes procedimentos de cálculo: (I) valores determinados com base nas mensurações, e (II) valores determinados com base no modelo proposto (Tabela 3).

Tabela 3. Conjunto de equações referentes à dinâmica do nitrogênio aplicado via fertilizante no sistema solo-planta $(\mathrm{k}=3)$, especificando os compartimentos solo $(\mathrm{k}=1)$ e planta $(\mathrm{k}=2)$, e as perdas de $\mathrm{N}$ no sistema (procedimentos I e II)

\begin{tabular}{|c|c|c|c|}
\hline \multicolumn{2}{|r|}{ Procedimento I } & \multicolumn{2}{|r|}{ Procedimento II } \\
\hline Passo & Equação & Passo & Equação \\
\hline 1 & $\mathrm{~N}_{1, \mathrm{j}}=\frac{\mathrm{ANE}_{1, \mathrm{j}}}{\mathrm{ANEF}} \cdot \frac{\mathrm{QN}_{1, \mathrm{j}}}{\mathrm{QNAF}} \cdot 100$ (4) & 1 & $\hat{N}_{3, j}=A_{3}+\frac{100-A_{3}}{1+B_{3} \cdot j^{C_{3}}}$ \\
\hline 2 & $\mathrm{~N}_{2, \mathrm{j}}=\frac{\mathrm{ANE}_{2, \mathrm{j}}}{\mathrm{ANEF}} \cdot \frac{\mathrm{QN}_{2, \mathrm{j}}}{\mathrm{QNAF}} \cdot 100$ & 2 & $\hat{N}_{2, j}=A_{2} \cdot j(0 \leq \mathrm{j}<1)(8)$ \\
\hline & & & $\hat{N}_{2, j}=\frac{A_{2}}{1+B_{2} \cdot(j-1)^{C_{2}}}(\mathrm{j} \geq 1)(9)$ \\
\hline 3 & $N_{3, j}=N_{1, j}+N_{2, j}$ & 3 & $\hat{N}_{1, j}=\hat{N}_{3, j}-\hat{N}_{2, j}(5.2)$ \\
\hline 4 & $N l_{3, j}=100-N_{3, j}$ & 4 & $\hat{N l}_{3, j}=100-\hat{N}_{3, j}(6.2)$ \\
\hline
\end{tabular}

$k$ : compartimento. $j$ : ano. $\mathrm{N}_{\mathrm{k}, \mathrm{i}}$ : quantidade relativa de $\mathrm{N}$ do fertilizante recuperado no compartimento $k$, no ano $j$. $\mathrm{ANE}_{\mathrm{k}, j}: \%$ átomos de ${ }^{15} \mathrm{~N}$ em excesso no compartimento $k$ no final do ano $j$. ANEF: $\%$ de átomos de ${ }^{15} \mathrm{~N}$ em excesso no fertilizante. $\mathrm{QN}_{\mathrm{k}, \mathrm{j}}$ : quantidade de $\mathrm{N}$ do fertilizante no compartimento $k$ no final do ano j. QNAF: quantidade de nitrogênio adicionado via fertilizante. $A_{k}, B_{k}$ e $C_{k}$ : parâmetros da curva para o compartimento $k . \mathrm{Nl}_{3, j}$ : perdas relativas de nitrogênio do sistema solo-planta $(k=3)$ no ano $j$.

Nas equações 7 e 9 , os parâmetros $A_{k}, B_{k}$, e $C_{k}$ integram os efeitos de todos os atributos do ambiente que podem influenciar na dinâmica do N, tais como precipitações, temperatura do solo e umidade do solo, por exemplo. Esses parâmetros refletem também os efeitos das práticas de manejo da cultura, principalmente a dose e forma de aplicação do fertilizante e a adição dos resíduos de colheita, cuja quantidade e qualidade influenciam na dinâmica do nitrogênio adicionado. Portanto, ambas equações não poderiam ser diretamente extrapoladas a diferentes ambientes, mas são válidas para propósitos descritivos. 


\section{RESULTADOS E DISCUSSÃO}

\subsection{Produtividade de colmos e quantidade de nitrogênio contido na parte aérea das plantas}

Nos dois sistemas de manejo estudados observou-se redução da produtividade e da absorção de nitrogênio com o número de cortes, fato normalmente observado na cultura de cana-de-açúcar (Courtaillac et al., 1998; Vitti, 2003).

Nos três anos (1999-2001) em que foi avaliada a produtividade de colmos $\left(\mathrm{Mg} \mathrm{ha}^{-1}\right)$, nos dois sistemas de manejo dos resíduos, no tratamento CQ a produtividade sempre foi superior à verificada no tratamento SQ. Essa diferença correspondeu a 13, 18 e $22 \%$ nas colheitas 1999, 2000 e 2001, respectivamente (Tabela 4) e foi significativa $(\mathrm{p}>0,05)$ em todos os anos. Esses resultados concordam com os achados por Campos (2003) em Brasil, mas contrastam com os observados por Wood (1986) na Austrália, McIntyre et al. (1996) nas Ilhas Maurício e Urquiaga et al. (1991) no Brasil, que encontraram aumento no rendimento da cana quando os resíduos culturais foram deixados sobre o solo. Wood (1991) observou que, em solos bem drenados, os resíduos da cana-de-açúcar deixados como cobertura promoveram acréscimo nos rendimentos de cana de até $10 \mathrm{Mg} \cdot \mathrm{ha}^{-1}$.ano ${ }^{-1}$, quando comparado à prática de despalha a fogo.

Vários são os possíveis efeitos da palhada deixada como cobertura sobre a nova brotação da cana. Abramo Filho et al. (1993) em um experimento de cana colhida mecanicamente $\left(3^{\circ}\right.$ corte), sem prévia queima dos resíduos, observaram menor temperatura do solo em comparação com o solo desnudo, maior umidade do solo, retardamento da brotação, controle de várias plantas daninhas, possível aumento de pragas, e maior teor de matéria orgânica do solo. 
Um fator muito importante que contribui à redução da produtividade no sistema SQ é a imobilização do nitrogênio pela biomassa microbiana. A palhada da cana-deaçúcar, com elevada relação $\mathrm{C} / \mathrm{N}$, é uma fonte de energia (carbono) que estimula o crescimento da biomassa microbiana, a qual passa a demandar mais nitrogênio competindo com a cultura pelo nutriente.

Na Tabela 4, observa-se que nos três ciclos de cana-soca (1999 a 2001) em que foram comparados os sistemas SQ e CQ, a cultura teve sempre maior produtividade e absorveu mais nitrogênio no tratamento CQ. A dose de nitrogênio aplicada nas soqueiras foi de $80 \mathrm{~kg} \cdot \mathrm{ha}^{-1}$, que é a recomendação existente baseada no manejo tradicional com despalha a fogo. Diante disso, faz-se necessário pesquisar qual seria a dose adequada de nitrogênio para a cana-soca sob o manejo sem queima dos resíduos.

Assim, no sistema sem queima, nos primeiros anos e até a estabilização do mesmo (em que a mineralização do $\mathrm{N}$ no sistema possa suprir a demanda da biomassa microbiana e da cultura), deveria se incrementar a dose de fertilizante nitrogenado para compensar a falta de nitrogênio disponível no solo para a cultura devida à adição dos resíduos.

Analisando a quantidade de nitrogênio total contida nos ponteiros e na palhada (média das colheitas de 1999 a 2001), o potencial de reciclagem de nitrogênio no sistema do tratamento SQ foi $83,3 \mathrm{~kg} \cdot \mathrm{ha}^{-1} \cdot$ ano $^{-1}$ significando que em média $65 \%$ do total do nitrogênio contido na parte aérea da cana retornou ao sistema através dos resíduos culturais (Tabela 4). No caso do tratamento CQ, considerando que com a queima dos resíduos se perde para a atmosfera todo o do nitrogênio contido na palhada e a metade do contido nos ponteiros, foram perdidos em média $74,2 \mathrm{~kg} \cdot \mathrm{ha}^{-1} \cdot \mathrm{ano}^{-1}$, ou seja, aproximadamente $85 \%$ do nitrogênio da parte aérea. Essa quantidade de nitrogênio perdido pelo efeito da queima correspondeu a $75 \%$ do nitrogênio total contido nos resíduos (Tabela 4). Essa estimativa de perda do $\mathrm{N}$ contido nos resíduos, causada pela queima dos mesmos, é um pouco superior aos valores de perdas de $50 \%$ a $70 \%$ em pastagem e trigo reportados por Biederbeck et al. (1980), e de 64\% achados em cana-deaçúcar por Ball-Coelho et al. (1993). 
Tabela 4. Produtividade de colmos, nitrogênio total $(\mathrm{Nt})$, nitrogênio derivado do fertilizante (QNddF) e nitrogênio não marcado (Nnm) nos diferentes compartimentos da planta (1998-2001)

\begin{tabular}{|c|c|c|c|c|c|c|c|}
\hline \multirow{2}{*}{ Variável } & \multirow{2}{*}{$\begin{array}{c}1998 \\
\text { Cana-planta }\end{array}$} & \multicolumn{2}{|c|}{1999 (Colheita, $1^{\circ}$ soca $)$} & \multicolumn{2}{|c|}{2000 (Colheita, $2^{\circ}$ soca $)$} & \multicolumn{2}{|c|}{2001 (Colheita, $3^{\circ}$ soca) } \\
\hline & & SQ & $\mathrm{CQ}$ & SQ & $\mathrm{CQ}$ & SQ & $\mathrm{CQ}$ \\
\hline $\begin{array}{r}\text { Produtividade } \\
\qquad\left(\mathrm{Mg} \mathrm{ha}^{-1}\right),\end{array}$ & $112,0( \pm 9,5)^{1}$ & $120,0 \mathrm{~b}( \pm 10,5)$ & $138,0 \mathrm{a}( \pm 3,5)$ & $98,0 \mathrm{~b}( \pm 10,1)$ & 119,0 a $( \pm 9,7)$ & $86,0 \mathrm{~b}( \pm 16,8)$ & $110,0 \mathrm{a}( \pm 11,0)$ \\
\hline \multicolumn{8}{|l|}{$\mathrm{Nt}\left(\mathrm{kg} \cdot \mathrm{ha}^{-1}\right)$} \\
\hline Colmos $^{2}$ & $137,1( \pm 14,3)$ & $88,2 \mathrm{~b}( \pm 8,2)$ & $127,5 \mathrm{a}( \pm 14,3)$ & $30,4 \mathrm{~b}( \pm 8,6)$ & 47,0 a $( \pm 5,4)$ & $29,6 \mathrm{~b}( \pm 4,7)$ & 38,5 a $( \pm 4,1)$ \\
\hline Ponteiros ${ }^{3}$ & $77,1( \pm 2,1)$ & $48,3 \mathrm{a}( \pm 3,6)$ & $50,0 \mathrm{a}( \pm 5,0)$ & 50,9 a $( \pm 12,8)$ & $60,5 \mathrm{a}( \pm 3,3)$ & $28,5 \mathrm{~b}( \pm 3,3)$ & 37,5 a $( \pm 3,0)$ \\
\hline Palhada ${ }^{4}$ & $50,1( \pm 2,7)$ & 53,5 a $( \pm 9,0)$ & 59,0 a $( \pm 3,6)$ & $35,3 \mathrm{~b}( \pm 3,8)$ & $47,5 \mathrm{a}( \pm 5,0)$ & $33,5 \mathrm{~b}( \pm 6,4)$ & $42,1 \mathrm{a}( \pm 2,7)$ \\
\hline Total & $264,3( \pm 12,4)$ & $190,0 \mathrm{~b}( \pm 20,4)$ & $236,5 \mathrm{a}( \pm 18,9)$ & $116,6 \mathrm{~b}( \pm 22,1)$ & $155,0 \mathrm{a}( \pm 10,9)$ & $91,6 \mathrm{~b}( \pm 13,2)$ & $118,1 \mathrm{a}( \pm 9,3)$ \\
\hline \multicolumn{8}{|c|}{ QNddF (kg.ha $\left.{ }^{-1}\right)$} \\
\hline Colmos & $22,3( \pm 5,0)$ & 3,1 a $( \pm 0,3)$ & $3,2 \mathrm{a}( \pm 0,6)$ & $0,9 \mathrm{a}( \pm 0,2)$ & $0,9 \mathrm{a}( \pm 0,2)$ & $0,3 \mathrm{a}( \pm 0,1)$ & $0,3 \mathrm{a}( \pm 0,1)$ \\
\hline Ponteiros & $8,6( \pm 0,6)$ & $1,5 \mathrm{a}( \pm 0,2)$ & $1,2 \mathrm{~b}( \pm 0,2)$ & $1,0 \mathrm{a}( \pm 0,3)$ & $1,0 \mathrm{a}( \pm 0,2)$ & $0,3 \mathrm{a}( \pm 0,1)$ & $0,3 \mathrm{a}( \pm 0,1)$ \\
\hline Palhada & $9,0( \pm 0,7)$ & $2,2 \mathrm{a}( \pm 0,4)$ & $1,6 \mathrm{~b}( \pm 0,1)$ & 0,6 a $( \pm 0,1)$ & 0,6 a $( \pm 0,2)$ & $0,2 \mathrm{a}( \pm 0,1)$ & $0,2 \mathrm{a}( \pm 0,1)$ \\
\hline Total & $39,8( \pm 5,8)$ & 6,9 a $( \pm 0,8)$ & $6,1 \mathrm{a}( \pm 0,5)$ & $2,5 \mathrm{a}( \pm 0,6)$ & $2,5 \mathrm{a}( \pm 0,4)$ & $0,8 \mathrm{a}( \pm 0,1)$ & $0,8 \mathrm{a}( \pm 0,2)$ \\
\hline \multicolumn{8}{|l|}{$\mathrm{Nnm}^{5}\left(\mathrm{~kg} \cdot \mathrm{ha}^{-1}\right)$} \\
\hline Colmos & 114,9 & 85,1 & 124,3 & 29,5 & 46,1 & 29,3 & 38,2 \\
\hline Ponteiros & 68,5 & 46,8 & 48,7 & 49,9 & 59,1 & 28,2 & 37,2 \\
\hline Palhada & 41,1 & 51,2 & 57,4 & 34,4 & 46,8 & 33,3 & 41,9 \\
\hline Total & 224,5 & 183,1 & 230,4 & 113,8 & 152,0 & 90,8 & 117,3 \\
\hline
\end{tabular}

1: Desvio Padrão aparece entre parênteses. 2: Exportação nos dois tratamentos. 3: Permanece no sistema 100\% no tratamento SQ e 50\% no tratamento CQ. 4: Permanece no sistema $100 \%$ no tratamento SQ e $0 \%$ no tratamento CQ. 5: $\mathrm{Nnm}=\mathrm{Nt}-\mathrm{NdfF}$.

Cada valor é a média de quatro repetições. Os tratamentos no mesmo ano com diferentes letras são estatisticamente diferentes ao nível de probabilidade de 5\% pelo Teste $t$. 
No presente experimento, a palhada deixada na superfície do solo pode ter exercido um efeito inibitório da rebrota seja por um simples efeito físico ou por efeito alelopático, o qual pode explicar os menores rendimentos no tratamento SQ. Uma possível solução para esse problema freqüentemente observado seria espalhar os resíduos culturais nas entrelinhas, evitando que as soqueiras fiquem cobertas.

\subsection{Recuperação do nitrogênio derivado do fertilizante no sistema solo-planta}

A maior parte do nitrogênio do fertilizante foi absorvida pela cultura no primeiro ano, decrescendo a absorção nos anos seguintes de uma forma exponencial.

Na colheita da cana-planta em 1998 (ciclo 1) não foram observadas diferenças significativas entre as parcelas que iriam receber os tratamentos SQ e CQ, o que era esperado, já que ainda os tratamentos não haviam sido impostos nas respectivas parcelas. Em média, 11,4\% do NddF permaneceu no solo (inclusive sistema radicular e rizomas) e $63 \%$ foi recuperado pela parte aérea da cultura, sendo que aproximadamente $35 \%$ foi alocado aos colmos (exportação), e $28 \%$ em ponteiros e palhada (Tabelas 4 e 5). Para a cana-planta NFRec na parte aérea da planta varia entre 21 e 40\% (Takahashi, 1969; Chan \& Weng, 1983; Sampaio et al., 1984; Vallis \& Keating, 1994). Wood (1991), usando ${ }^{15} \mathrm{~N}$-uréia, observou que a cultura da cana recuperou $50 \%$ do nitrogênio do fertilizante quando a palhada foi mantida na lavoura, e menos do $40 \%$ quando ocorreu despalha a fogo.

$\mathrm{Na}$ colheita da primeira soca em 1999 (ciclo 2), o tratamento SQ apresentou maior eficiência na recuperação do NddF que o tratamento CQ $\left(28,0\right.$ e 22,1 kg.ha ${ }^{-1}$, respectivamente), sendo essa diferença estatisticamente significativa. O NFRec em SQ foi $9 \%$ superior ao recuperado em CQ (Tabela 5) No tratamento com despalha a fogo, a palhada é completamente queimada, mas os ponteiros (folhas verdes e gema apical) não totalmente. Uma avaliação dos resíduos após a queima permitiu constatar que $50 \%$ da massa seca dos ponteiros permaneceu no campo sem ser queimada, portanto, considerou-se que $50 \%$ do nitrogênio contido nos ponteiros é reciclado no sistema. No tratamento SQ, o $\mathrm{N}$ do fertilizante contido na palhada, que foi liberado e incorporado ao solo, representou praticamente $50 \%$ do $\mathrm{N}$ do fertilizante total que permaneceu no solo ao 
final do segundo ciclo da cultura. Porém, do total de nitrogênio absorvido pela planta, menos de $10 \%$ provém do NddF liberado pela palhada, o que evidencia o longo tempo para o sistema entrar em equilíbrio.

Nas colheitas da segunda soca em 2000 (ciclo 3) e da terceira soca em 2001 (ciclo 4), também foi observada maior eficiência na recuperação do NddF no sistema solo-planta em SQ em comparação com CQ, mas a diferença entre os dois tratamentos não foi significativa (Tabela 5).

$\mathrm{Na}$ colheita da quarta soca em 2002 (ciclo 5) não foi possível realizar a amostragem da planta como nos anos anteriores. Por causa de uma alta infestação de carrapatos no Campus da ESALQ foi decidido queimar todas as parcelas antes da colheita, inclusive os tratamentos sem queima. Após a queima foi realizada a amostragem do solo como nos anos anteriores. Como pode ser observado na Tabela 4, a QNddF absorvida pela cultura já na colheita de 2001 tende a zero, portanto a não inclusão dos dados da seguinte colheita (2002) não interfere significativamente no balanço de nitrogênio no sistema solo-planta.

Na Tabela 5 pode ser observado que a diferença na recuperação do NddF no sistema solo-planta sempre foi devida ao nitrogênio residual que permaneceu no solo. O sistema de colheita com ou sem queima não influenciou na QNddF absorvido pela cultura. A QNddF que permaneceu no solo sempre foi superior em SQ que em CQ, mais essa diferença apenas foi significativa no ciclo 2 e no ciclo 5. Esses resultados mostram que no tratamento com ciclagem dos resíduos (SQ) a taxa de decréscimo do NddF residual é menor da observada no tratamento com queima (CQ), o que é esperado devido à perda de $\mathrm{N}$ do sistema durante a queima dos resíduos (Figura 3).

$\mathrm{Na}$ Tabela 5, observa-se que a QNddF residual no solo aumentou significativamente do ciclo 1 para o ciclo 2. Isso é devido à decomposição dos resíduos culturais e do sistema radicular enriquecidos em ${ }^{15} \mathrm{~N}$ devido à alta absorção pelas plantas do $\mathrm{N}$ do fertilizante ocorrida no ciclo da cana-planta. Posteriormente, o NddF residual decresce de anos para ano, mas no último ciclo avaliado ainda foi detectado $\mathrm{n}$ do fertilizante no solo. 
Na maioria dos casos, a baixa eficiência de recuperação é causada pelas elevadas quantidades de nitrogênio do fertilizante que são perdidas, principalmente via volatilização (Denmead et al., 1990). A uréia é o fertilizante nitrogenado mais usado, tanto no Brasil (Cantarella, 1998), quanto na Austrália (Wood, 1991). Quando a uréia é aplicada sobre os resíduos vegetais as perdas por volatilização de amônia aumentam consideravelmente devido à atividade da urease da palhada (Trivelin et al., 1998), podendo atingir 20 a 40\% do $\mathrm{N}$ da uréia (Cantarella, 1998), sendo comuns perdas ainda superiores (Wood, 1991).

Por outro lado, as perdas por lixiviação do $\mathrm{N}$ do fertilizante foram desprezíveis, já que a incorporação do fertilizante foi lenta devido à baixa dose aplicada e ao baixo volume de precipitação ocorrido no momento da adubação. Extratores de solução do solo instalados na profundidade de $50 \mathrm{~cm}$ mostraram durante o primeiro ciclo da cultura conteúdo muito baixo de $\mathrm{N}_{-} \mathrm{NO}_{3}{ }^{-}$, do qual menos de $1 \%$ foi derivado do fertilizante (Reichardt, 1999 $)$. Em outras pesquisas em cana-de-açúcar também não foram observadas perdas por lixiviação do N do fertilizante (Padovese, 1988; Oliveira et al., 2002). Porém, Reichardt et al. (1982) observaram que $6 \mathrm{~kg} \cdot \mathrm{ha}^{-1}$ de $\mathrm{N}$ foram lixiviados durante o ciclo da cana quando o volume de precipitação foi de $1.500 \mathrm{~mm}^{-a_{n}{ }^{-1}} \mathrm{e}$ a dose de fertilizante aplicado em torno de $90 \mathrm{~kg} \cdot \mathrm{ha}^{-1}$ de N.

A recuperação relativamente alta pela cana do $\mathrm{N}$ do fertilizante no presente experimento pode ser atribuída aos seguintes fatores: (i) aplicação localizada do fertilizante na linha de plantio; (ii) ocorrência ideal de uma precipitação de 13,4 mm logo após a aplicação do fertilizante, fato que permitiu a incorporação ao solo e a distribuição do adubo dentro da zona radicular; (iii) o sulfato de amônio é uma fonte nitrogenada que sofre pouca volatilização quando comparada com a uréia; e (iv) a dose de $\mathrm{N}$ aplicada pode ser considerada de média a baixa quando comparada às utilizadas nos trabalhos que reportam valores baixos de NFRec (\%).

\footnotetext{
${ }^{1}$ Comunicação Pessoal.
} 
Tabela 5. Quantidade de nitrogênio derivado do fertilizante (QNddF, kg.ha- ${ }^{-1}$ ) e porcentagem de nitrogênio do fertilizante recuperado (NFRec, \%) no sistema solo-planta nos dois sistemas de manejo dos resíduos da cultura (1998-2002)

\begin{tabular}{|c|c|c|c|c|}
\hline \multicolumn{5}{|c|}{ Colheita 1998 (ciclo 1) } \\
\hline \multirow[t]{2}{*}{ Compartimento } & \multicolumn{2}{|c|}{ SQ } & \multicolumn{2}{|c|}{ CQ } \\
\hline & QNddF & NFRec $^{1}$ & QNddF & NFRec \\
\hline Solo $(0-50 \mathrm{~cm})$ & 8,1 & 12,8 & 6,3 & 10,0 \\
\hline Planta & 39,9 & 63,3 & 39,5 & 62,7 \\
\hline Solo + Planta & $48,0 \mathrm{a}$ & 76,1 & $45,8 \mathrm{a}$ & 72,7 \\
\hline \multicolumn{5}{|c|}{ Colheita 1999 (ciclo 2) } \\
\hline & \multicolumn{2}{|c|}{ SQ } & \multicolumn{2}{|c|}{ CQ } \\
\hline & QNddF & NFRec & QNddF & NFRec \\
\hline Solo $(0-50 \mathrm{~cm})$ & 21,1 & 33,5 & 16,0 & 25,4 \\
\hline Planta & 6,9 & 10,9 & 6,1 & 9,7 \\
\hline Solo + Planta & $28,0 \mathrm{a}$ & 44,4 & $22,1 \mathrm{~b}$ & 35,1 \\
\hline \multicolumn{5}{|c|}{ Colheita 2000 (ciclo 3) } \\
\hline & \multicolumn{2}{|c|}{ SQ } & \multicolumn{2}{|c|}{ CQ } \\
\hline & QNddF & NFRec & QNddF & NFRec \\
\hline Solo $(0-50 \mathrm{~cm})$ & 16,6 & 26,3 & 14,4 & 22,9 \\
\hline Planta & 2,5 & 4,0 & 2,5 & 4,1 \\
\hline Solo + Planta & $19,1 \mathrm{a}$ & 30,3 & $16,9 \mathrm{a}$ & 27,0 \\
\hline \multicolumn{5}{|c|}{ Colheita 2001 (ciclo 4) } \\
\hline & \multicolumn{2}{|c|}{ SQ } & \multicolumn{2}{|c|}{ CQ } \\
\hline & QNddF & NFRec & QNddF & NFRec \\
\hline Solo $(0-50 \mathrm{~cm})$ & 15,3 & 24,3 & 12,1 & 19,2 \\
\hline Planta & 0,8 & 1,3 & 0,8 & 1,3 \\
\hline Solo + Planta & $16,1 \mathrm{a}$ & 25,6 & $12,9 \mathrm{a}$ & 20,5 \\
\hline \multicolumn{5}{|c|}{ Colheita $2002(\text { ciclo } 5)^{2}$} \\
\hline & \multicolumn{2}{|c|}{ SQ } & \multicolumn{2}{|c|}{ CQ } \\
\hline & QNddF & NFRec & QNddF & NFRec \\
\hline Solo $(0-50 \mathrm{~cm})$ & $10,4 \mathrm{a}$ & 16,5 & $4,9 \mathrm{~b}$ & 7,8 \\
\hline
\end{tabular}

1: NFRec (\%): Porcentagem calculada com base nos $63 \mathrm{~kg} \cdot \mathrm{ha}^{-1}$ de $\mathrm{N}$ do fertilizante.

2: em 2002 só foi avaliado o compartimento solo.

Valores seguidos pela mesma letra dentro de cada ano (na horizontal) não apresentam diferenças significativas pelo Teste $t$ ao nível de significância de 5\%. 


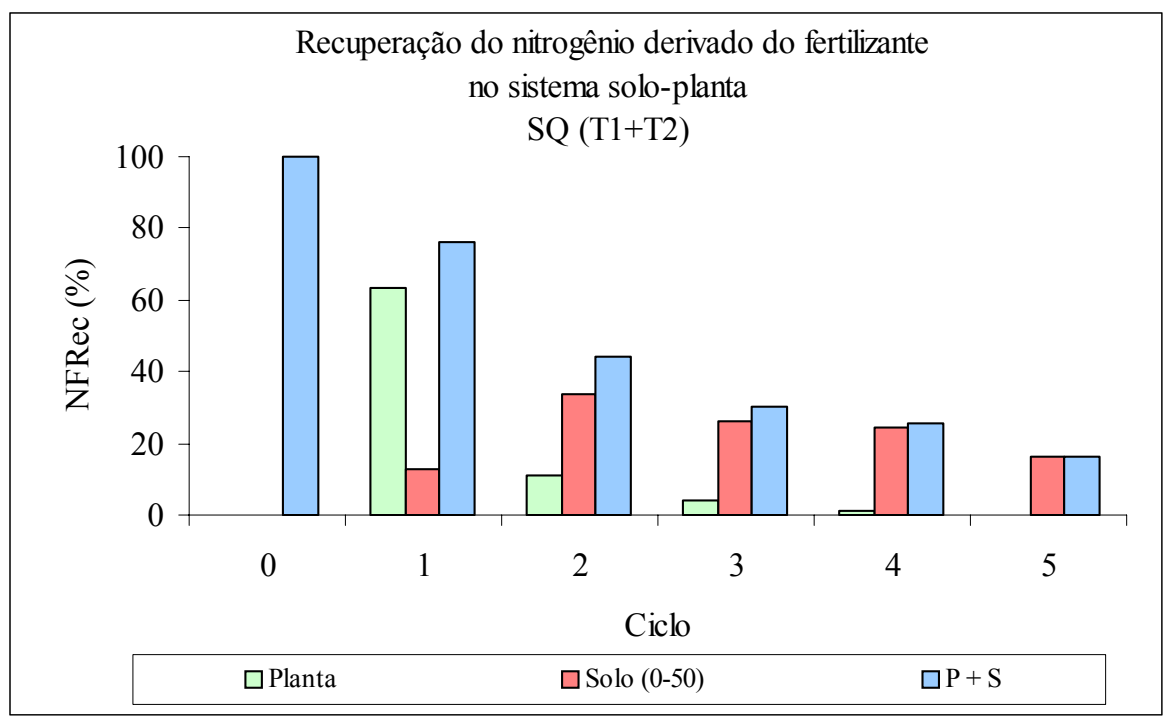

(a)

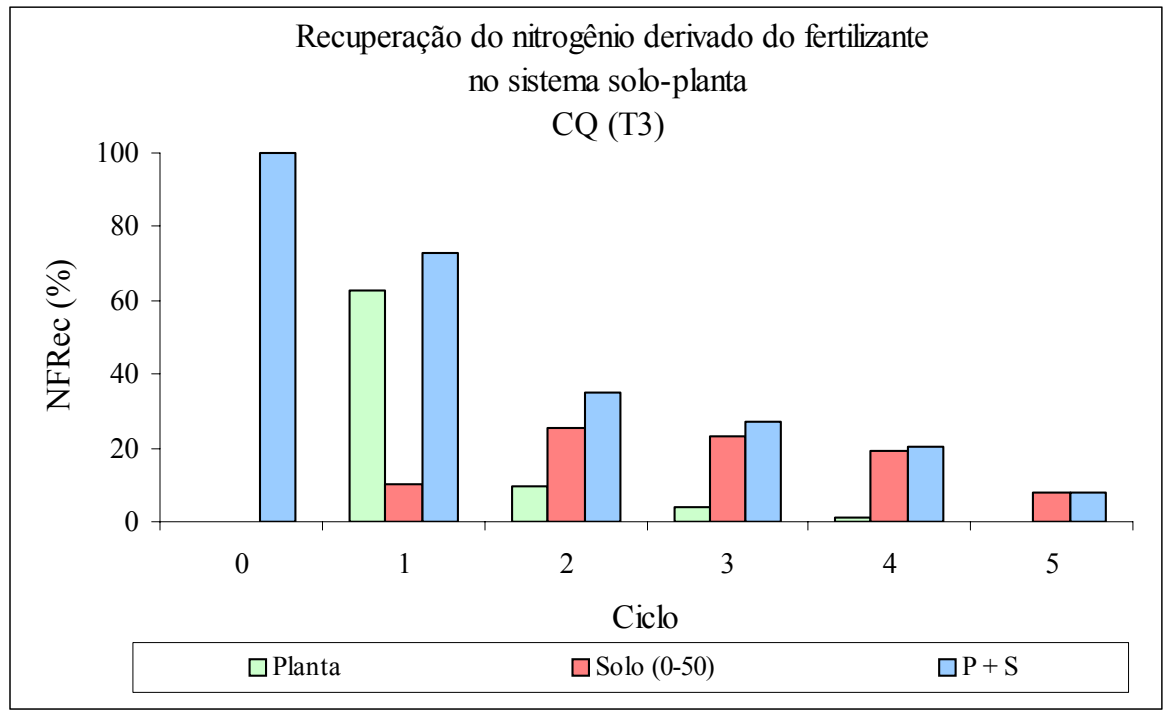

(b)

Figura 3 - Recuperação do nitrogênio derivado do fertilizante (NFRec, \%) na parte aérea da cultura (Planta), no solo até a profundidade de $50 \mathrm{~cm}$ (Solo 0-50 cm) e no sistema solo-planta $(\mathrm{P}+\mathrm{S})$ sob os sistemas de manejo dos resíduos da cultura de cana-de-açúcar: (a) sem queima (SQ) e (b) com queima (CQ), nos cinco ciclos analisados

Embora durante o primeiro ciclo da cultura a maior proporção do $\mathrm{NddF}$ fosse absorvida pelas plantas, o nitrogênio do fertilizante representa só $15 \%$ do nitrogênio 
total da planta (Tabela 4). Geralmente, cerca de $80 \%$ do nitrogênio absorvido pela canade-açúcar deriva do solo e $20 \%$ do fertilizante (Chan \& Weng, 1983; Weng \& Li, 1992; Chapman et al., 1994; Courtaillac et al., 1998).

\subsection{Os resíduos da cana como fonte de nitrogênio}

\subsubsection{Quantidade de resíduos produzidos pela cultura de cana-de-açúcar}

Na colheita da cana-planta (colheita 1998), com uma produtividade de colmos de $120 \mathrm{Mg} \mathrm{ha}^{-1}$, o total de massa de matéria seca de resíduos produzidos pela cultura durante o primeiro ciclo foi de 18,5 Mg.ha ${ }^{-1}$ correspondendo 40,6\% $\left(7,5 \mathrm{Mg}^{-h^{-1}}\right)$ à massa de matéria seca de ponteiros e 59,4\% $\left(11,0 \mathrm{Mg} \cdot \mathrm{ha}^{-1}\right)$ à da palhada.

No tratamento sem queima (SQ) todos os resíduos culturais permaneceram na superfície do solo podendo ser reciclados no sistema (Figura 4).

Nas parcelas nas que foi realizada a queima prévia à colheita (tratamento CQ), uma avaliação feita no momento da colheita manual de colmos permitiu estimar que $50 \%$ dos ponteiros não foram queimados e permaneceram sobre a superfície do solo enquanto que toda a palhada tinha sido queimada. Assim, no tratamento CQ, a massa de matéria seca de resíduos que permaneceu no sistema depois da colheita foi de cerca de 3,7 Mg.ha ${ }^{-1}$. Na Figura 5, pode-se observar a quantidade de ponteiros que permaneceram sobre a superfície do solo sem ser totalmente queimados.

A quantidade de matéria seca produzida pela cultura de cana-de-açúcar depende, entro outros fatores, do material genético. O potencial produtivo de cada variedade determinará a produtividade de colmos assim como a produção de matéria seca total.

Ripoli et al. (1991) encontraram nas variedades SP71-1406 e NA56-79, com

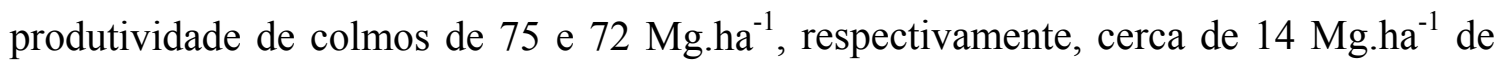
resíduos que representaram cerca de $16 \%$ do total de fitomassa produzida. Nas variedades SP71-6163 e SP70-1143, com produtividade de colmos de 75 e $88 \mathrm{Mg} \cdot \mathrm{ha}^{-1}$, respectivamente, os resíduos culturais foram da ordem de $11 \mathrm{Mg} . h a^{-1}$, ou seja, entre $11 \mathrm{e}$ $13 \%$ do total de fitomassa produzida. 


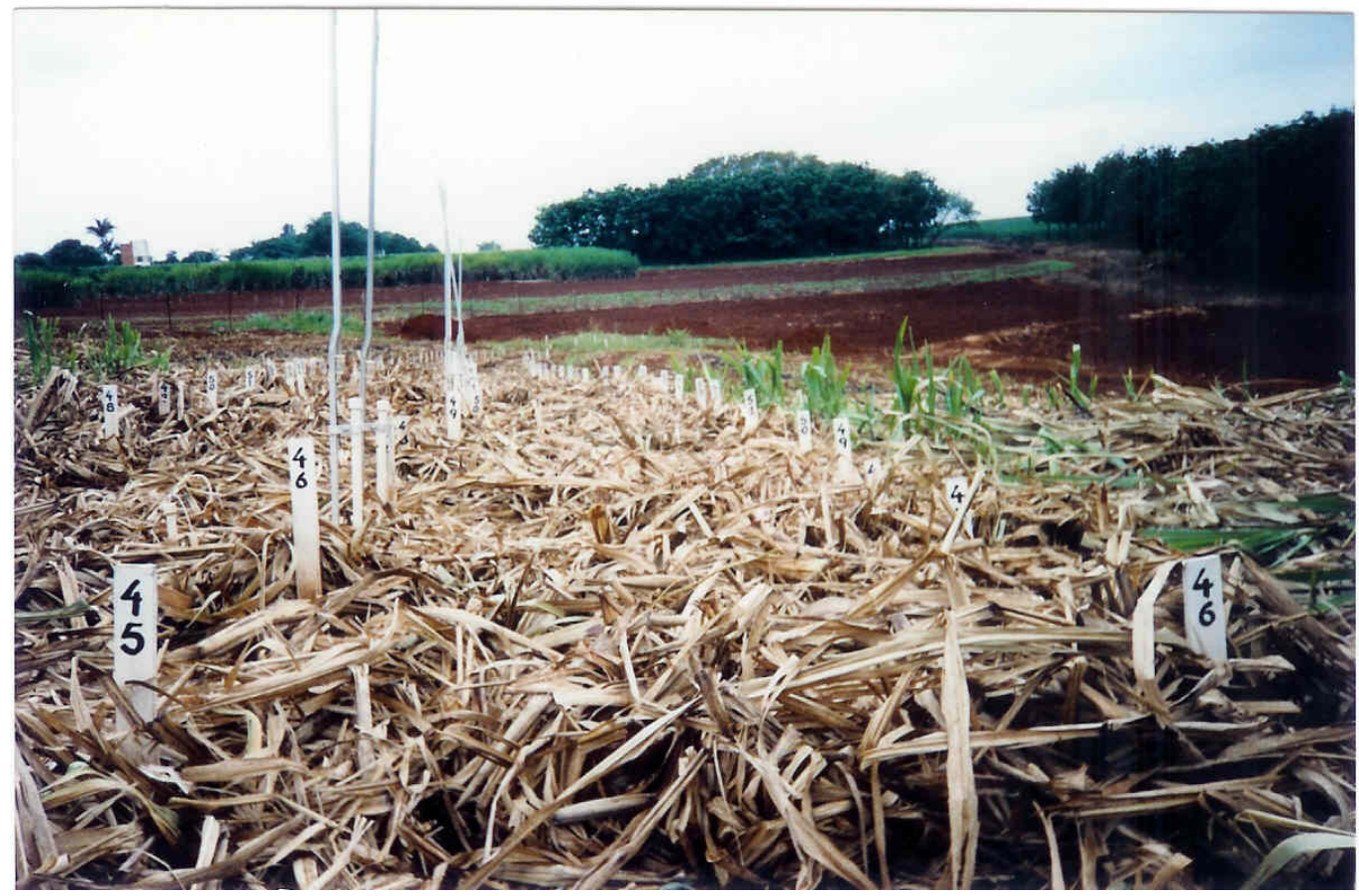

Figura 4 - Parcelas do tratamento sem queima dos resíduos (SQ) logo após a colheita da cana-planta

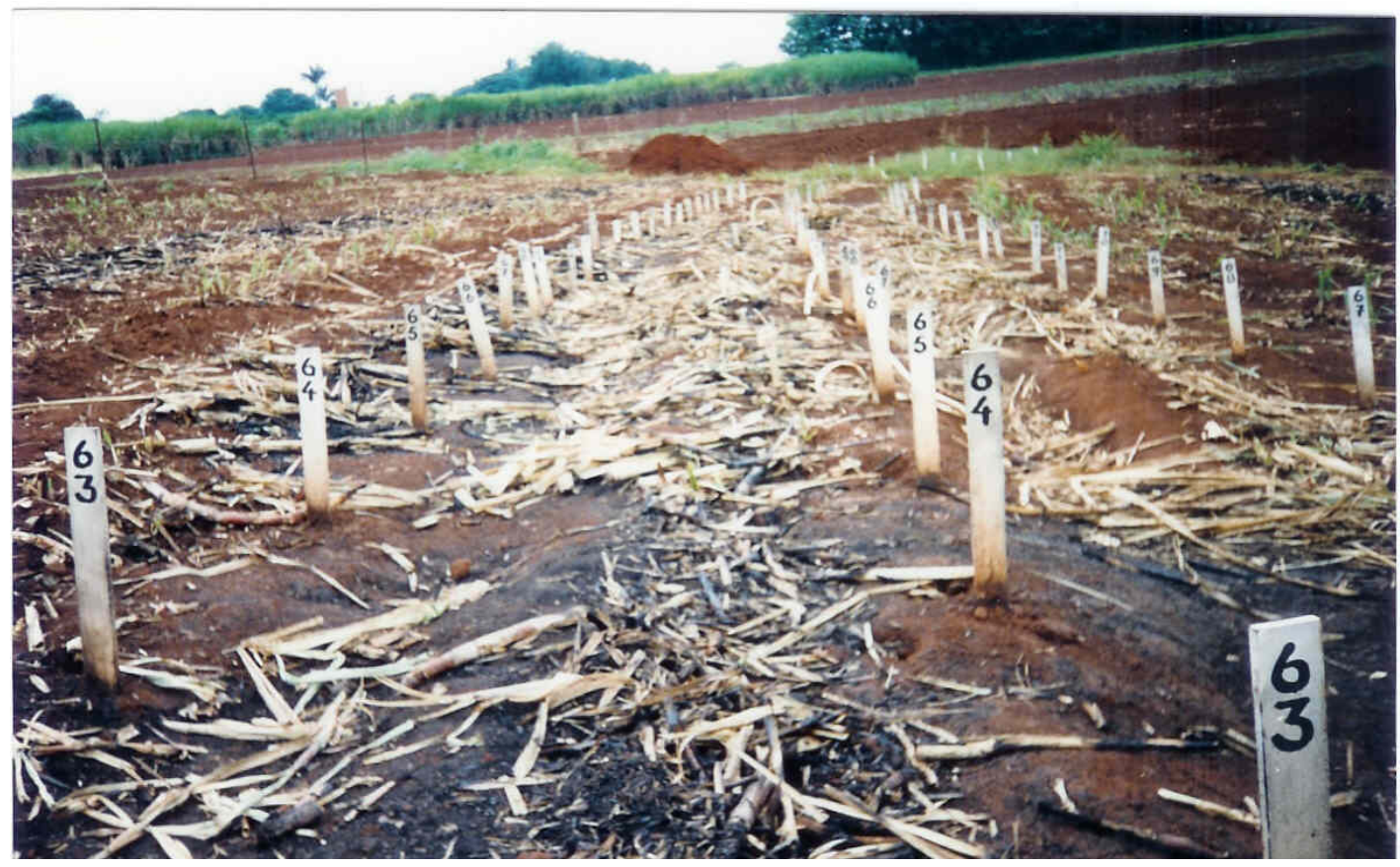

Figura 5 - Parcelas do tratamento com queima dos resíduos (CQ) logo após a colheita da cana-planta 
Abramo Filho et al. (1993) relataram na variedade SP71-6161, com produtividade de colmos de $106 \mathrm{Mg} \cdot \mathrm{ha}^{-1}$, uma quantidade de resíduos de $15 \mathrm{Mg} \cdot \mathrm{ha}^{-1}$ (12\% da fitomassa total produzida).

Os valores de fitomassa total produzida e de matéria seca de resíduos achados no presente trabalho são algo superiores aos mencionados acima. Porém, a matéria seca de resíduos representou $13 \%$ da fitomassa total produzida, valor similar aos achados pelos autores previamente citados.

\subsubsection{Recuperação no sistema solo-planta do nitrogênio contido nos resíduos da cultura}

A recuperação no sistema solo-planta do nitrogênio dos resíduos foi estudada ao longo de 4 ciclos (1999-2002), sendo NRRec de 55,0\% (69,8/127 kg.ha $\left.{ }^{-1}\right), 38,5 \%$ $\left(48,8 / 127 \mathrm{~kg} \cdot \mathrm{ha}^{-1}\right), 48,3 \%\left(61,4 / 127 \mathrm{~kg} \cdot \mathrm{ha}^{-1}\right)$ e $38,0 \%\left(48,3 / 127 \mathrm{~kg} \cdot \mathrm{ha}^{-1}\right)$ para as colheitas 1999 (ciclo 2), 2000 (ciclo 3), 2001 (ciclo 4) e 2002 (ciclo 5), respectivamente. Do total do NddR que foi incorporado ao sistema solo-planta, a maior parte (93 a 95\%) ficou imobilizada no solo persistindo no sistema ainda no final do ciclo 5 (Tabela 6).

O NddR remanescente no perfil do solo sofreu uma redistribuição vertical. Inicialmente $70 \%$ do $\mathrm{NddR}$ retido no solo se encontravam nos primeiros $15 \mathrm{~cm}$ e com o tempo aumentou seu conteúdo nas camadas sub-superficiais, principalmente na camada de 15-30 cm (Figura 6).

A liberação do nitrogênio da palhada (55\%) após um período de 12 meses observada no presente trabalho é elevada quando comparada a $20 \%$ de mineralização de nitrogênio da palhada num período de 11 meses (Oliveira et al., 1999b), e 27\% após 18 meses de permanência da palhada na lavoura (Ng Kee Kwong et al., 1987). Esses autores salientam que os resíduos de cana-de-açúcar representam uma fonte pouco significativa de $\mathrm{N}$ para a cultura quando comparada ao $\mathrm{N}$ disponível no solo.

Anualmente cerca de 3,5 kg.ha- ${ }^{-1}$ de NddR foi achado na parte aérea da cultura, o que representa aproximadamente $3 \%$ do total de $\mathrm{N}$ dos resíduos. Da adição dos resíduos em 1998 (início do ciclo 2) até o final do ciclo 4, na parte aérea da cultura foram totalizados $11,7 \mathrm{~kg} . \mathrm{ha}^{-1}$ de NddR, ou seja que o NRRec na parte aérea foi apenas de $9 \%$. 
Resultados similares de NddR e NRRec na parte aérea são similares foram achados por Gava (1999), Gava et al. (2002) e Vitti (2003).

Esses resultados refletem uma elevada imobilização do nitrogênio dos resíduos pela biomassa microbiana do solo. Por causa da baixa qualidade dos resíduos de canade-açúcar (alta relação $\mathrm{C} / \mathrm{N}$ ), durante sua decomposição predomina a imobilização do nitrogênio em detrimento da mineralização, diminuindo a sua disponibilidade para a cultura. A redução na produtividade de colmos observada no tratamento SQ (Tabela 4) evidencia a necessidade de se aumentar a dose da adubação nitrogenada quando os resíduos permanecem no sistema, o que também foi constatado por Chapman \& Haysom (1991); Thompson (1992) e Vitti (2003).

Cabe salientar que, embora os resíduos de cana não representem uma fonte de $\mathrm{N}$ importante para a cultura no curto prazo, no longo prazo eles aumentam os níveis de carbono orgânico e melhoram a estrutura do solo (Vallis et al., 1996; Blair, 2000). 
Tabela 6. Nitrogênio derivado dos resíduos (NddR) nos distintos compartimentos do sistema solo-planta

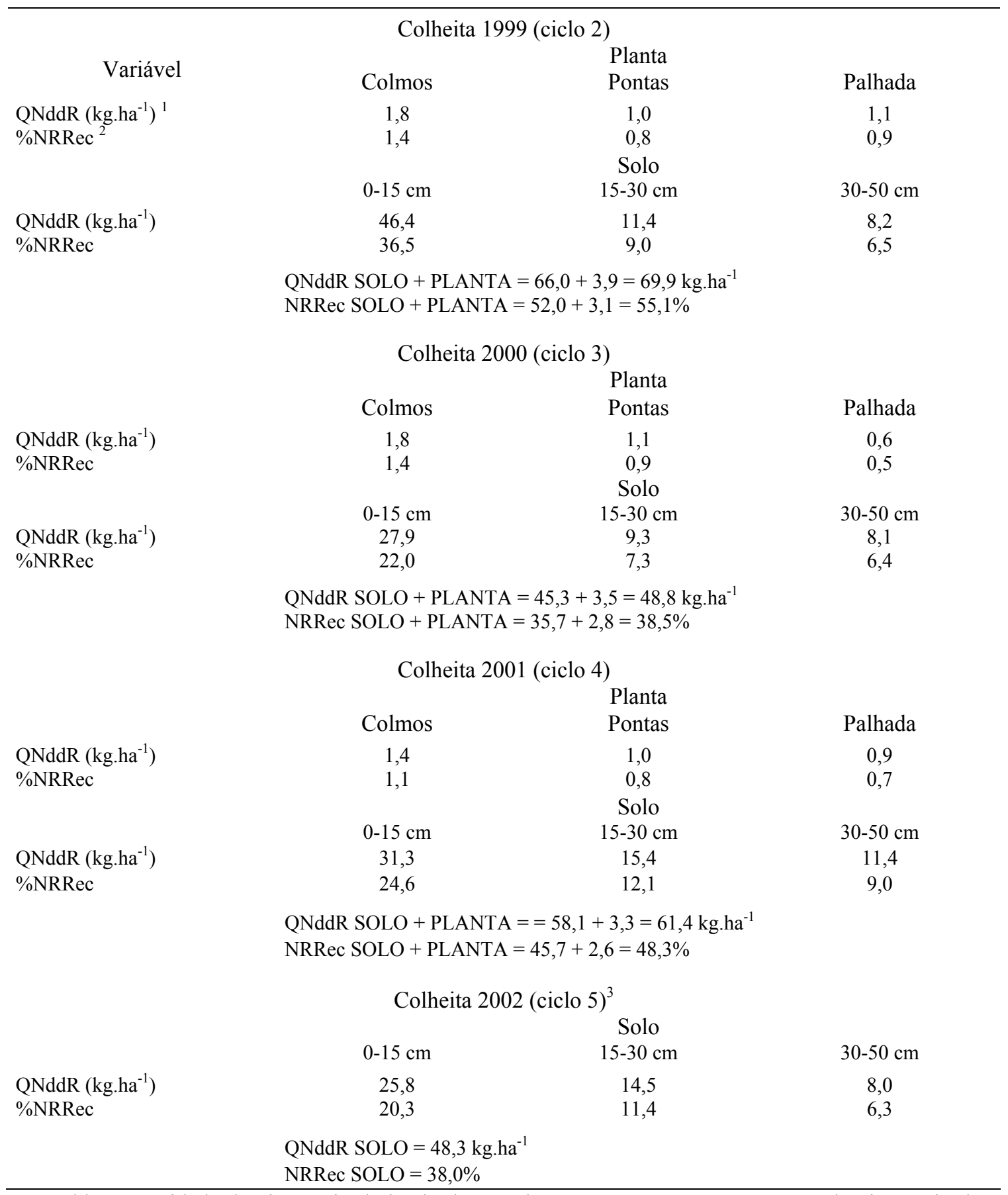

1. QNddR: quantidade de nitrogênio derivado dos resíduos. 2. \%NRRec: porcentagem de nitrogênio dos resíduos recuperado (calculado com base nos $127 \mathrm{~kg} \cdot \mathrm{ha}^{-1}$ de $\mathrm{N}$ contidos nos resíduos marcados adicionados no início do ciclo 2). 3. na colheita de 2002 foi avaliado apenas o compartimento solo. 


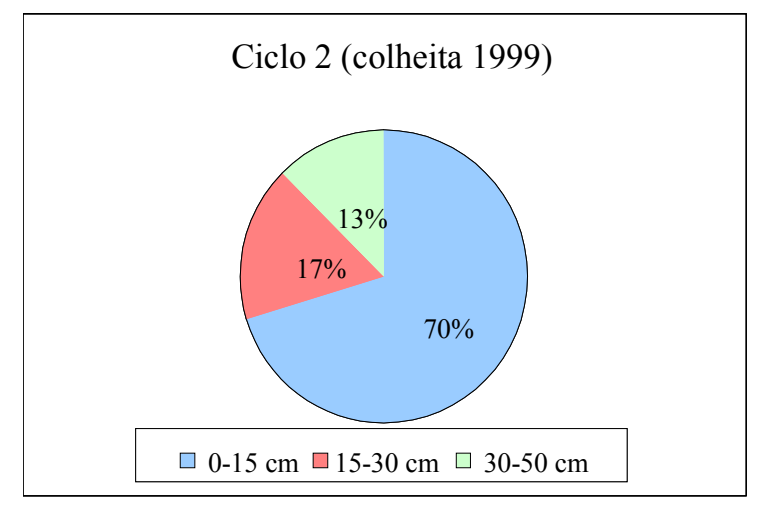

Ciclo 4 (colheita 2001)

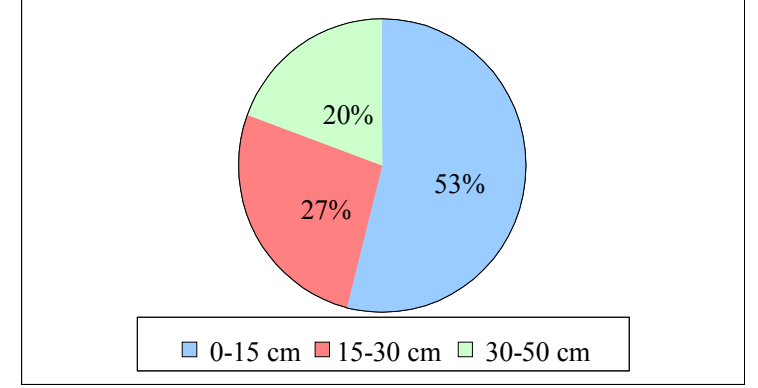

Figura 6 - Redistribuição porcentual do nitrogênio derivado dos resíduos (NddR) nas profundidades de solo nos quatro anos analisados (1999-2002)

\subsection{Distribuição do carbono e do nitrogênio nas frações granulométricas e no perfil do solo}

A recuperação das frações do solo (média dos 5 anos) foi de $98 \%$ variando entre 99,1\% em 1998 e 97,1\% em 2002. A fração pesada (Fp) apresentou valores de \%N inferiores a 0,01\%, uma ordem de grandeza menor do que as outras frações. Essa baixa concentração de $\mathrm{N}$ dificultou a precisão nas determinações analíticas, cujos resultados apresentaram altíssimos coeficientes de variação (superiores a 100\%) e, na maioria dos casos, não foi possível obter um resultado por causa da concentração de $\mathrm{N}$ estar abaixo da sensibilidade do espectrômetro de massa (abaixo do valor mínimo requerido para a análise). Portanto, Fp não foi considerada na análise dos resultados de $\mathrm{N}$ total e de ${ }^{15} \mathrm{~N}$.

Nos 5 ciclos (1998-2002) não foram detectadas diferenças significativas nos conteúdos totais de $\mathrm{C}\left(\mathrm{Mg}_{\mathrm{h}} \mathrm{ha}^{-1}\right)$ entre os dois sistemas de manejo dos resíduos 
contrastantes (CQ e SQ) (Tabelas 7 a 11). Observou-se, porém, que os conteúdos de C em SQ foram sempre ligeiramente superiores.

$\mathrm{O}$ conteúdo de $\mathrm{N}$ total apresentou comportamento similar ao $\mathrm{C}$, sendo geralmente maior em SQ do que em CQ, embora essas diferenças tenham sido estatisticamente significativas somente no último ciclo (ano 2002) para as frações Fl e Fom na profundidade $0-15 \mathrm{~cm}$, e para Fom em $30-50 \mathrm{~cm}$ (Tabelas 7 a 11).

Devido à alta variabilidade observada nos resultados de $\mathrm{C}$ e $\mathrm{N}$, pequenas variações não podem ser consideradas como devidas ao manejo; por essa razão, a grande maioria das comparações de médias nas (Tabelas 7 a 11) confirmou a hipótese de igualdade. As diferenças significativas observadas em Fl e Fom em 0-15 cm no ano 2002 poderiam refletir o efeito acumulativo da reciclagem de $\mathrm{N}$ em SQ e/ou da maior perda do $\mathrm{N}$ do solo em $\mathrm{CQ}$, mas essa tendência não se reflete no conteúdo de $\mathrm{N}$ total do solo, o qual não apresentou diferenças significativas entre os tratamentos.

Em geral, os conteúdos de $\mathrm{C}$ e $\mathrm{N}$ apresentaram valores crescentes com a diminuição do tamanho de partícula seguindo a ordem Fsa $>$ Fom $>$ Fl. Observou-se também que a relação $\mathrm{C} / \mathrm{N}$ diminui na medida em que o tamanho de partícula é menor.

A fração $\mathrm{Fl}$ teve elevados teores de $\mathrm{C}$ variando entre 15 e $25 \%$, mas, devido a sua baixa proporção no total do solo $(<1 \%)$, contribui com $3 \%$ do conteúdo total do C e $1 \%$ do $\mathrm{N}$ total. A fração Fom contém em média $23 \%$ do carbono total e $21 \%$ do $\mathrm{N}$ total. Essas duas frações granulométricas superiores a $53 \mu \mathrm{m}$, as quais somam uma quarta parte do carbono total, atuam como reservatório da matéria orgânica utilizada pela biomassa microbiana como fonte de energia, sendo que os compostos orgânicos estáveis liberados pelos microorganismos durante o processo de transformação dessa matéria orgânica agem como agentes de ligação das frações mais finas contribuindo à agregação do solo (Angers et al., 1997). A fração Fsa $(<53 \mu \mathrm{m})$ apresentou, em média, 74\% do carbono e $78 \%$ do nitrogênio total contido no solo, o que corrobora seu importante papel como fonte e destino de $\mathrm{N}$ no sistema. 
Tabela 7. Distribuição porcentual das frações granulométricas do solo, conteúdo de carbono e conteúdo de nitrogênio nas frações de solo nas profundidades 0-15; 15-30 e 30-50 cm e nos tratamentos sem queima (SQ) e com queima (CQ) dos resíduos da colheita da cana-de-açúcar. Ano 1998

\begin{tabular}{|c|c|c|c|c|c|c|c|}
\hline \multirow{2}{*}{ Variável } & \multirow{2}{*}{ Fração do solo } & \multicolumn{2}{|c|}{------------------ 0-15 ----------------- } & \multicolumn{2}{|c|}{------------------ 15-30 ------------------ } & \multicolumn{2}{|c|}{----------------- 30-50 ----------------- } \\
\hline & & SQ & $\mathrm{CQ}$ & SQ & $\mathrm{CQ}$ & SQ & CQ \\
\hline \multirow{4}{*}{$\begin{array}{l}\text { \% da fração na } \\
\text { amostra de solo }\end{array}$} & Fl & $0,23 \mathrm{a}( \pm 0,13)^{1}$ & $0,21 \mathrm{a}( \pm 0,11)$ & $0,17 \mathrm{a}( \pm 0,03)$ & $0,15 \mathrm{a}( \pm 0,03)$ & $0,17 \mathrm{a}( \pm 0,05)$ & $0,20 \mathrm{a}( \pm 0,19)$ \\
\hline & $\mathrm{Fp}$ & 3,92 a $( \pm 1,71)$ & $5,00 \mathrm{a}( \pm 2,89)$ & $3,59 \mathrm{a}( \pm 1,31)$ & $4,27 \mathrm{a}( \pm 0,39)$ & 5,08 a $( \pm 2,84)$ & $4,76 \mathrm{a}( \pm 1,38)$ \\
\hline & Fom & $34,87 \mathrm{a}( \pm 2,64)$ & $34,85 \mathrm{a}( \pm 4,21)$ & $32,37 \mathrm{a}( \pm 2,41)$ & 33,33 a $( \pm 3,24)$ & $31,22 \mathrm{a}( \pm 2,37)$ & $33,46 \mathrm{a}( \pm 1,16)$ \\
\hline & Fsa & 59,46 a $( \pm 3,21)$ & $58,80 \mathrm{a}( \pm 4,44)$ & 62,83 a $( \pm 3,67)$ & $60,92 \mathrm{a}( \pm 3,17)$ & $62,12 \mathrm{a}( \pm 4,59)$ & $61,02 \mathrm{a}( \pm 1,32)$ \\
\hline \multirow[t]{4}{*}{$\% \mathrm{C}$} & Fl & $22,10 \mathrm{a}( \pm 5,08)$ & $20,00 \mathrm{a}( \pm 5,61)$ & $19,83 \mathrm{a}( \pm 2,91)$ & $21,60 \mathrm{a}( \pm 1,04)$ & $22,33 \mathrm{a}( \pm 8,85)$ & $15,81 \mathrm{a}( \pm 8,71)$ \\
\hline & $\mathrm{Fp}$ & $0,43 \mathrm{a}( \pm 0,19)$ & $0,28 \mathrm{a}( \pm 0,13)$ & 0,52 a $( \pm 0,09)$ & 0,36 a $( \pm 0,25)$ & 0,43 a $( \pm 0,09)$ & $0,39 \mathrm{a}( \pm 0,13)$ \\
\hline & Fom & $1,01 \mathrm{a}( \pm 0,03)$ & 0,98 a $( \pm 0,09)$ & 0,86 a $( \pm 0,08)$ & $0,80 \mathrm{a}( \pm 0,10)$ & $0,75 \mathrm{a}( \pm 0,12)$ & $0,78 \mathrm{a}( \pm 0,10)$ \\
\hline & Fsa & $1,90 \mathrm{a}( \pm 0,02)$ & 1,85 a $( \pm 0,08)$ & $1,92 \mathrm{a}( \pm 0,05)$ & 1,88 a $( \pm 0,14)$ & $1,55 \mathrm{a}( \pm 0,08)$ & 1,52 a $( \pm 0,12)$ \\
\hline \multirow[t]{5}{*}{$\mathrm{C}\left(\mathrm{Mg} \cdot \mathrm{ha}^{-1}\right)$} & $\mathrm{Fl}$ & $1,00 \mathrm{a}( \pm 0,27)$ & $0,85 \mathrm{a}( \pm 0,22)$ & $0,77 \mathrm{a}( \pm 0,16)$ & $0,74 \mathrm{a}( \pm 0,14)$ & $1,10 \mathrm{a}( \pm 0,50)$ & $0,92 \mathrm{a}( \pm 0,27)$ \\
\hline & $\mathrm{Fp}$ & $0,34 \mathrm{a}( \pm 0,36)$ & $0,28 \mathrm{a}( \pm 0,18)$ & $0,42 \mathrm{a}( \pm 0,16)$ & $0,35 \mathrm{a}( \pm 0,22)$ & 0,63 a $( \pm 0,33)$ & $0,54 \mathrm{a}( \pm 0,15)$ \\
\hline & Fom & 7,13 a $( \pm 0,68)$ & 6,91 a $( \pm 1,33)$ & $6,32 \mathrm{a}( \pm 1,02)$ & $6,05 \mathrm{a}( \pm 1,28)$ & 6,79 a $( \pm 1,52)$ & 7,56 a $( \pm 0,96)$ \\
\hline & Fsa & 22,88 a $( \pm 1,44)$ & $22,01 \mathrm{a}( \pm 1,42)$ & $27,38 \mathrm{a}( \pm 1,77)$ & 25,99 a $( \pm 0,86)$ & $27,90 \mathrm{a}( \pm 1,71)$ & 26,88 a $( \pm 1,76)$ \\
\hline & Total & $31,35 \mathrm{a}( \pm 1,30)$ & $30,05 \mathrm{a}( \pm 1,50)$ & 34,89 a $( \pm 1,71)$ & 33,13 a $( \pm 2,77)$ & 36,42 a $( \pm 1,29)$ & 35,90 a $( \pm 2,69)$ \\
\hline \multirow[t]{4}{*}{$\% \mathrm{~N}$ total } & $\mathrm{Fl}$ & $0,776 \mathrm{a}( \pm 0,216)$ & $0,714 \mathrm{a}( \pm 0,235)$ & 0,615 a $( \pm 0,136)$ & $0,699 \mathrm{a}( \pm 0,068)$ & 0,485 a $( \pm 0,104)$ & $0,404 \mathrm{a}( \pm 0,194)$ \\
\hline & $\mathrm{Fp}$ & nd & nd & nd & nd & nd & nd \\
\hline & Fom & $0,070 \mathrm{a}( \pm 0,007)$ & $0,065 \mathrm{a}( \pm 0,010)$ & $0,059 \mathrm{a}( \pm 0,013)$ & $0,051 \mathrm{a}( \pm 0,008)$ & $0,057 \mathrm{a}( \pm 0,009)$ & $0,050 \mathrm{a}( \pm 0,006)$ \\
\hline & Fsa & 0,160 a $( \pm 0,010)$ & 0,152 a $( \pm 0,016)$ & $0,160 \mathrm{a}( \pm 0,015)$ & $0,151 \mathrm{a}( \pm 0,010)$ & $0,125 \mathrm{a}( \pm 0,008)$ & 0,119 a $( \pm 0,009)$ \\
\hline \multirow[t]{5}{*}{$\mathrm{N}$ total $\left(\mathrm{kg} \cdot \mathrm{ha}^{-1}\right)$} & $\mathrm{Fl}$ & $36,1 \mathrm{a}( \pm 15,2)$ & $30,3 \mathrm{a}( \pm 7,92)$ & $23,7 \mathrm{a}( \pm 7,54)$ & $23,8 \mathrm{a}( \pm 3,40)$ & 23,9 a $( \pm 6,8)$ & $23,4 \mathrm{a}( \pm 6,47)$ \\
\hline & $\mathrm{Fp}$ & - & - & - & - & - & - \\
\hline & Fom & 493,9 a $( \pm 81,8)$ & 458,4 a $( \pm 123,4)$ & $433,4 \mathrm{a}( \pm 119,5)$ & 385,8 a $( \pm 87,9)$ & 519,6 a $( \pm 116,0)$ & 484,8 a $( \pm 67,7)$ \\
\hline & Fsa & $1925,1 \mathrm{a}( \pm 200,5)$ & $1808,5 \mathrm{a}( \pm 131,1)$ & $2281,5 \mathrm{a}( \pm 297,0)$ & $2087,7 \mathrm{a}( \pm 56,4)$ & 2258,8 a $( \pm 298,0)$ & 2104,3 a $( \pm 118,5)$ \\
\hline & Total & 2455,1 a $( \pm 159,4)$ & 2297,2 a $( \pm 196,7)$ & 2738,6 a $( \pm 292,9)$ & 2497,3 a $( \pm 198,6)$ & $2791,3 \mathrm{a}( \pm 205,7)$ & 2612,5 a $( \pm 177,3)$ \\
\hline
\end{tabular}

1: Desvio Padrão aparece entre parênteses. nd: não determinado. Fl: fração leve (200 -2000 $\mu$ m), com resíduos orgânicos grossos; Fp: fração mineral pesada (200 a $2000 \mu \mathrm{m})$; Fom: fração organo-mineral (53 a $200 \mu \mathrm{m})$; Fsa: fração organo-mineral $(<53 \mu \mathrm{m})$. Cada valor é a média de quatro repetições. Os tratamentos no mesmo ano com diferentes letras são estatisticamente diferentes ao nível de probabilidade de $5 \%$ pelo Teste $t$. 
Tabela 8. Distribuição porcentual das frações granulométricas do solo, conteúdo de carbono e conteúdo de nitrogênio nas frações de solo nas profundidades 0-15; 15-30 e 30-50 cm e nos tratamentos sem queima (SQ) e com queima (CQ) dos resíduos da colheita da cana-de-açúcar. Ano 1999

\begin{tabular}{|c|c|c|c|c|c|c|c|}
\hline \multirow{2}{*}{ Variável } & \multirow{2}{*}{ Fração do solo } & \multicolumn{2}{|c|}{------------------- 0-15 ----------------- } & \multicolumn{2}{|c|}{----------------- 15-30 ----------------- } & \multicolumn{2}{|c|}{----------------- 30-50 ---------------- } \\
\hline & & SQ & $\mathrm{CQ}$ & SQ & CQ & SQ & CQ \\
\hline \multirow{4}{*}{$\begin{array}{l}\text { \% da fração na } \\
\text { amostra de solo }\end{array}$} & Fl & $0,69 \mathrm{a}( \pm 0,27)^{1}$ & $0,58 \mathrm{a}( \pm 0,22)$ & $0,22 \mathrm{a}( \pm 0,10)$ & $0,19 \mathrm{a}( \pm 0,07)$ & $0,10 \mathrm{a}( \pm 0,04)$ & $0,08 \mathrm{a}( \pm 0,04)$ \\
\hline & $\mathrm{Fp}$ & 8,16 a $( \pm 3,28)$ & 9,91 a $( \pm 0,69)$ & 5,66 a $( \pm 1,70)$ & 7,16 a $( \pm 0,99)$ & $7,94 \mathrm{a}( \pm 4,85)$ & $5,39 \mathrm{a}( \pm 0,52)$ \\
\hline & Fom & $32,93 \mathrm{a}( \pm 6,65)$ & $35,10 \mathrm{a}( \pm 3,72)$ & $34,84 \mathrm{a}( \pm 1,99)$ & $32,54 \mathrm{a}( \pm 5,44)$ & $32,05 \mathrm{a}( \pm 7,67)$ & $36,48 \mathrm{a}( \pm 5,53)$ \\
\hline & Fsa & 56,03 a $( \pm 5,62)$ & 53,15 a $( \pm 2,99)$ & 57,67 a $( \pm 3,70)$ & 58,58 a $( \pm 4,77)$ & 58,35 a $( \pm 9,60)$ & 56,20 a $( \pm 6,76)$ \\
\hline \multirow[t]{4}{*}{$\% \mathrm{C}$} & $\mathrm{Fl}$ & $19,80 \mathrm{a}( \pm 6,26)$ & $21,03 \mathrm{a}( \pm 4,30)$ & $24,33 \mathrm{a}( \pm 2,09)$ & $22,45 \mathrm{a}( \pm 3,57)$ & $21,45 \mathrm{a}( \pm 4,30)$ & 21,68 a $( \pm 6,30)$ \\
\hline & $\mathrm{Fp}$ & $0,47 \mathrm{a}( \pm 0,26)$ & $0,22 \mathrm{a}( \pm 0,05)$ & $0,27 \mathrm{a}( \pm 0,09)$ & $0,24 \mathrm{a}( \pm 0,07)$ & $0,29 \mathrm{a}( \pm 0,15)$ & $0,21 \mathrm{a}( \pm 0,04)$ \\
\hline & Fom & $1,24 \mathrm{a}( \pm 0,18)$ & 1,09 a $( \pm 0,06)$ & 1,06 a $( \pm 0,19)$ & 0,93 a $( \pm 0,09)$ & $1,21 \mathrm{a}( \pm 0,51)$ & $0,80 \mathrm{a}( \pm 0,11)$ \\
\hline & Fsa & $1,60 \mathrm{a}( \pm 0,38)$ & 1,66 a $( \pm 0,07)$ & $1,94 \mathrm{a}( \pm 0,50)$ & $1,67 \mathrm{a}( \pm 0,13)$ & 1,31 a $( \pm 0,28)$ & 1,18 a $( \pm 0,16)$ \\
\hline \multirow[t]{5}{*}{$\mathrm{C}\left(\mathrm{Mg} \cdot \mathrm{ha}^{-1}\right)$} & $\mathrm{Fl}$ & $2,76 \mathrm{a}( \pm 1,35)$ & $2,47 \mathrm{a}( \pm 0,56)$ & $1,21 \mathrm{a}( \pm 0,48)$ & $0,97 \mathrm{a}( \pm 0,30)$ & $0,62 \mathrm{a}( \pm 0,27)$ & $0,50 \mathrm{a}( \pm 0,24)$ \\
\hline & $\mathrm{Fp}$ & $0,78 \mathrm{a}( \pm 0,68)$ & $0,44 \mathrm{a}( \pm 0,05)$ & $0,35 \mathrm{a}( \pm 0,21)$ & $0,39 \mathrm{a}( \pm 0,11)$ & $0,67 \mathrm{a}( \pm 0,18)$ & $0,33 \mathrm{a}( \pm 0,09)$ \\
\hline & Fom & 8,26 a $( \pm 1,67)$ & $7,74 \mathrm{a}( \pm 0,97)$ & $8,38 \mathrm{a}( \pm 1,89)$ & 6,87 a $( \pm 0,89)$ & $11,24 \mathrm{a}( \pm 7,80)$ & 8,46 a $( \pm 1,73)$ \\
\hline & Fsa & $18,14 \mathrm{a}( \pm 4,77)$ & $17,85 \mathrm{a}( \pm 1,02)$ & 25,39 a $( \pm 5,31)$ & $22,20 \mathrm{a}( \pm 1,43)$ & 22,15 a $( \pm 3,19)$ & $19,22 \mathrm{a}( \pm 3,00)$ \\
\hline & Total & $29,94 \mathrm{a}( \pm 4,99)$ & $28,50 \mathrm{a}( \pm 0,94)$ & 35,33 a $( \pm 7,10)$ & 30,43 a $( \pm 1,35)$ & 34,68 a $( \pm 7,98)$ & 28,51 a $( \pm 3,98)$ \\
\hline \multirow[t]{4}{*}{$\% \mathrm{~N}$ total } & $\mathrm{Fl}$ & $0,811 \mathrm{a}( \pm 0,108)$ & $0,846 \mathrm{a}( \pm 0,127)$ & $0,802 \mathrm{a}( \pm 0,039)$ & $0,813 \mathrm{a}( \pm 0,045)$ & $0,587 \mathrm{a}( \pm 0,050)$ & $0,636 \mathrm{a}( \pm 0,159)$ \\
\hline & $\mathrm{Fp}$ & nd $^{1}$ & nd & nd & nd & nd & nd \\
\hline & Fom & $0,100 \mathrm{a}( \pm 0,017)$ & 0,081 a $( \pm 0,008)$ & $0,069 \mathrm{a}( \pm 0,007)$ & $0,072 \mathrm{a}( \pm 0,007)$ & $0,077 \mathrm{a}( \pm 0,015)$ & $0,067 \mathrm{a}( \pm 0,013)$ \\
\hline & Fsa & 0,148 a $( \pm 0,034)$ & $0,153 \mathrm{a}( \pm 0,003)$ & 0,158 a $( \pm 0,016)$ & 0,143 a $( \pm 0,008)$ & $0,125 \mathrm{a}( \pm 0,028)$ & $0,115 \mathrm{a}( \pm 0,004)$ \\
\hline \multirow[t]{5}{*}{$\mathrm{N}$ total $\left(\mathrm{kg} \cdot \mathrm{ha}^{-1}\right)$} & $\mathrm{Fl}$ & $113,2 \mathrm{a}( \pm 41,9)$ & 99,3 a $( \pm 28,1)$ & $40,0 \mathrm{a}( \pm 17,0)$ & 35,1 a $( \pm 12,2)$ & 17,0 a $( \pm 7,6)$ & $14,7 \mathrm{a}( \pm 9,3)$ \\
\hline & $\mathrm{Fp}$ & - & - & - & - & - & - \\
\hline & Fom & $666,3 \mathrm{a}( \pm 99,1)$ & 575,3 a $( \pm 109,8)$ & 545,6 a $( \pm 83,7)$ & $531,7 \mathrm{a}( \pm 80,4)$ & $715,2 \mathrm{a}( \pm 251,3)$ & $708,3 \mathrm{a}( \pm 186,6)$ \\
\hline & Fsa & 1678,0 a $( \pm 159,3)$ & $1645,5 \mathrm{a}( \pm 172,9)$ & 2067,9 a $( \pm 187,9)$ & $1941,0 \mathrm{a}( \pm 183,8)$ & $2113,7 \mathrm{a}( \pm 278,8)$ & $1873,0 \mathrm{a}( \pm 245,1)$ \\
\hline & Total & $2457,5 \mathrm{a}( \pm 443,2)$ & $2320,1 \mathrm{a}( \pm 67,7)$ & $2653,5 \mathrm{a}( \pm 185,0)$ & $2507,8 \mathrm{a}( \pm 56,2)$ & 2845,9 a $( \pm 452,3)$ & $2596,0 \mathrm{a}( \pm 243,6)$ \\
\hline
\end{tabular}

1: Desvio Padrão aparece entre parênteses. nd: não determinado. Fl: fração leve (200 -2000 $\mu$ m), com resíduos orgânicos grossos; Fp: fração mineral pesada (200 a $2000 \mu \mathrm{m})$; Fom: fração organo-mineral (53 a $200 \mu \mathrm{m})$; Fsa: fração organo-mineral $(<53 \mu \mathrm{m})$. Cada valor é a média de quatro repetições. Os tratamentos no mesmo ano com diferentes letras são estatisticamente diferentes ao nível de probabilidade de $5 \%$ pelo Teste $t$. 
Tabela 9. Distribuição porcentual das frações granulométricas do solo, conteúdo de carbono e conteúdo de nitrogênio nas frações de solo nas profundidades 0-15; 15-30 e 30-50 cm e nos tratamentos sem queima (SQ) e com queima (CQ) dos resíduos da colheita da cana-de-açúcar. Ano 2000

\begin{tabular}{|c|c|c|c|c|c|c|c|}
\hline \multirow{2}{*}{ Variável } & \multirow{2}{*}{ Fração do solo } & \multicolumn{2}{|c|}{------------------ 0-15 ----------------- } & \multicolumn{2}{|c|}{------------------ 15-30 ------------------ } & \multicolumn{2}{|c|}{----------------- 30-50 ----------------- } \\
\hline & & SQ & $\mathrm{CQ}$ & SQ & $\mathrm{CQ}$ & SQ & CQ \\
\hline \multirow{4}{*}{$\begin{array}{l}\text { \% da fração na } \\
\text { amostra de solo }\end{array}$} & Fl & $0,35 \mathrm{a}( \pm 0,12)^{1}$ & $0,47 \mathrm{a}( \pm 0,24)$ & $0,16 \mathrm{a}( \pm 0,07)$ & $0,19 \mathrm{a}( \pm 0,08)$ & $0,08 \mathrm{a}( \pm 0,02)$ & $0,11 \mathrm{a}( \pm 0,04)$ \\
\hline & $\mathrm{Fp}$ & 2,65 a $( \pm 1,52)$ & $4,45 \mathrm{a}( \pm 3,00)$ & $3,64 \mathrm{a}( \pm 0,84)$ & $3,64 \mathrm{a}( \pm 1,28)$ & $3,22 \mathrm{a}( \pm 2,35)$ & 3,16 a $( \pm 1,44)$ \\
\hline & Fom & $32,23 \mathrm{a}( \pm 4,23)$ & $33,03 \mathrm{a}( \pm 2,59)$ & $29,34 \mathrm{a}( \pm 3,15)$ & $33,44 \mathrm{a}( \pm 7,35)$ & $33,76 \mathrm{a}( \pm 7,36)$ & $33,76 \mathrm{a}( \pm 6,05)$ \\
\hline & Fsa & $62,00 \mathrm{a}( \pm 5,42)$ & 59,69 a $( \pm 6,45)$ & $64,70 \mathrm{a}( \pm 2,98)$ & 59,71 a $( \pm 9,00)$ & $62,12 \mathrm{a}( \pm 10,47)$ & 60,58 a $( \pm 6,84)$ \\
\hline \multirow[t]{4}{*}{$\% \mathrm{C}$} & Fl & $22,00 \mathrm{a}( \pm 3,66)$ & $16,05 \mathrm{a}( \pm 7,27)$ & $27,93 \mathrm{a}( \pm 9,68)$ & $19,35 \mathrm{a}( \pm 6,39)$ & $26,38 \mathrm{a}( \pm 9,17)$ & $20,34 \mathrm{a}( \pm 9,87)$ \\
\hline & $\mathrm{Fp}$ & $0,15 \mathrm{a}( \pm 0,04)$ & $0,14 \mathrm{a}( \pm 0,02)$ & $0,15 \mathrm{a}( \pm 0,02)$ & $0,14 \mathrm{a}( \pm 0,02)$ & 0,18 a $( \pm 0,04)$ & $0,17 \mathrm{a}( \pm 0,04)$ \\
\hline & Fom & $1,02 \mathrm{a}( \pm 0,10)$ & 0,99 a $( \pm 0,20)$ & $0,83 \mathrm{a}( \pm 0,11)$ & $0,84 \mathrm{a}( \pm 0,05)$ & 0,79 a $( \pm 0,13)$ & $0,75 \mathrm{a}( \pm 0,13)$ \\
\hline & Fsa & 1,96 a $( \pm 0,05)$ & 1,91 a $( \pm 0,13)$ & $1,84 \mathrm{a}( \pm 0,13)$ & $1,94 \mathrm{a}( \pm 0,12)$ & $1,53 \mathrm{a}( \pm 0,18)$ & 1,43 a $( \pm 0,22)$ \\
\hline \multirow[t]{5}{*}{$\mathrm{C}\left(\mathrm{Mg} \cdot \mathrm{ha}^{-1}\right)$} & $\mathrm{Fl}$ & $1,56 \mathrm{a}( \pm 0,66)$ & $1,53 \mathrm{a}( \pm 0,40)$ & $1,01 \mathrm{a}( \pm 0,26)$ & $0,83 \mathrm{a}( \pm 0,10)$ & $0,61 \mathrm{a}( \pm 0,24)$ & $0,65 \mathrm{a}( \pm 0,29)$ \\
\hline & $\mathrm{Fp}$ & $0,08 \mathrm{a}( \pm 0,07)$ & $0,13 \mathrm{a}( \pm 0,08)$ & $0,12 \mathrm{a}( \pm 0,03)$ & $0,12 \mathrm{a}( \pm 0,05)$ & $0,17 \mathrm{a}( \pm 0,13)$ & $0,16 \mathrm{a}( \pm 0,11)$ \\
\hline & Fom & 6,65 a $( \pm 1,53)$ & $6,62 \mathrm{a}( \pm 1,75)$ & $5,53 \mathrm{a}( \pm 1,18)$ & $6,37 \mathrm{a}( \pm 1,48)$ & 7,73 a $( \pm 2,69)$ & $7,34 \mathrm{a}( \pm 2,58)$ \\
\hline & Fsa & $24,59 \mathrm{a}( \pm 2,00)$ & $23,07 \mathrm{a}( \pm 1,04)$ & $27,02 \mathrm{a}( \pm 1,29)$ & 26,29 a $( \pm 3,94)$ & $27,54 \mathrm{a}( \pm 6,05)$ & 25,10 a $( \pm 1,99)$ \\
\hline & Total & 32,88 a $( \pm 1,65)$ & 31,35 a $( \pm 1,59)$ & 33,49 a $( \pm 1,89)$ & 33,61 a $( \pm 2,70)$ & 36,05 a $( \pm 5,89)$ & 33,26 a $( \pm 3,51)$ \\
\hline \multirow[t]{4}{*}{$\% \mathrm{~N}$ total } & $\mathrm{Fl}$ & $0,716 \mathrm{a}( \pm 0,248)$ & $0,520 \mathrm{a}( \pm 0,133)$ & $0,514 \mathrm{a}( \pm 0,156)$ & 0,448 a $( \pm 0,189)$ & $0,480 \mathrm{a}( \pm 0,239)$ & $0,420 \mathrm{a}( \pm 0,176)$ \\
\hline & $\mathrm{Fp}$ & nd $^{1}$ & nd & nd & nd & nd & nd \\
\hline & Fom & $0,074 \mathrm{a}( \pm 0,015)$ & $0,062 \mathrm{a}( \pm 0,019)$ & $0,060 \mathrm{a}( \pm 0,015)$ & $0,052 \mathrm{a}( \pm 0,010)$ & $0,059 \mathrm{a}( \pm 0,015)$ & $0,053 \mathrm{a}( \pm 0,012)$ \\
\hline & Fsa & 0,163 a $( \pm 0,006)$ & 0,161 a $( \pm 0,016)$ & $0,150 \mathrm{a}( \pm 0,018)$ & $0,149 \mathrm{a}( \pm 0,012)$ & $0,122 \mathrm{a}( \pm 0,020)$ & $0,110 \mathrm{a}( \pm 0,012)$ \\
\hline \multirow[t]{5}{*}{$\mathrm{N}$ total $\left(\mathrm{kg} \mathrm{ha}^{-1}\right)$} & $\mathrm{Fl}$ & 50,7 a $( \pm 6,4)$ & $49,5 \mathrm{a}( \pm 17,5)$ & $18,7 \mathrm{a}( \pm 8,0)$ & $19,3 \mathrm{a}( \pm 4,3)$ & $11,1 \mathrm{a}( \pm 5,5)$ & $13,4 \mathrm{a}( \pm 4,2)$ \\
\hline & $\mathrm{Fp}$ & - & - & - & - & - & - \\
\hline & Fom & 482,6 a $( \pm 158,8)$ & 414,4 a $( \pm 153,5)$ & 399,5 a $( \pm 129,6)$ & 394,6 a $( \pm 133,1)$ & 577,2 a $( \pm 256,8)$ & 518,5 a $( \pm 203,04)$ \\
\hline & Fsa & 2044,9 a $( \pm 149,6)$ & 1944,6 a $( \pm 123,6)$ & 2202,5 a $( \pm 191,0)$ & $2019,1 \mathrm{a}( \pm 169,0)$ & 2196,3 a $( \pm 585,8)$ & $1931,7 \mathrm{a}( \pm 149,8)$ \\
\hline & & $2578,2( \pm 222,8)$ & $2396,4( \pm 261,2)$ & 2620,7 a $( \pm 292,4)$ & 2433,0 a $( \pm 187,7)$ & 2784,6 a $( \pm 565,9)$ & 2463,1 a $( \pm 184,4)$ \\
\hline
\end{tabular}

1: Desvio Padrão aparece entre parênteses. nd: não determinado. Fl: fração leve (200 -2000 $\mu$ m), com resíduos orgânicos grossos; Fp: fração mineral pesada (200 a $2000 \mu \mathrm{m})$; Fom: fração organo-mineral (53 a $200 \mu \mathrm{m})$; Fsa: fração organo-mineral $(<53 \mu \mathrm{m})$. Cada valor é a média de quatro repetições. Os tratamentos no mesmo ano com diferentes letras são estatisticamente diferentes ao nível de probabilidade de $5 \%$ pelo Teste $t$. 
Tabela 10. Distribuição porcentual das frações granulométricas do solo, conteúdo de carbono e conteúdo de nitrogênio nas frações de solo nas profundidades 0-15; 15-30 e 30-50 cm e nos tratamentos sem queima (SQ) e com queima (CQ) dos resíduos da colheita da cana-de-açúcar. Ano 2001

\begin{tabular}{|c|c|c|c|c|c|c|c|}
\hline \multirow{2}{*}{ Variável } & \multirow{2}{*}{ Fração do solo } & \multicolumn{2}{|c|}{------------------ 0-15 ----------------- } & \multicolumn{2}{|c|}{----------------- 15-30 ----------------- } & \multicolumn{2}{|c|}{----------------- 30-50 ---------------- } \\
\hline & & SQ & $\mathrm{CQ}$ & SQ & CQ & SQ & CQ \\
\hline \multirow{4}{*}{$\begin{array}{l}\text { \% da fração na } \\
\text { amostra de solo }\end{array}$} & Fl & $0,41 \mathrm{a}( \pm 0,20)^{1}$ & $0,37 \mathrm{a}( \pm 0,12)$ & $0,20 \mathrm{a}( \pm 0,03)$ & $0,15 \mathrm{a}( \pm 0,02)$ & $0,15 \mathrm{a}( \pm 0,06)$ & $0,13 \mathrm{a}( \pm 0,03)$ \\
\hline & $\mathrm{Fp}$ & $2,49 \mathrm{a}( \pm 1,91)$ & $2,29 \mathrm{a}( \pm 1,23)$ & 1,85 a $( \pm 0,11)$ & $1,22 \mathrm{a}( \pm 0,63)$ & $1,37 \mathrm{a}( \pm 0,27)$ & $1,35 \mathrm{a}( \pm 0,59)$ \\
\hline & Fom & $31,86 \mathrm{a}( \pm 4,62)$ & $32,43 \mathrm{a}( \pm 3,73)$ & $31,68 \mathrm{a}( \pm 4,16)$ & $31,46 \mathrm{a}( \pm 2,64)$ & $33,79 \mathrm{a}( \pm 2,63)$ & 32,22 a $( \pm 6,84)$ \\
\hline & Fsa & 63,63 a $( \pm 2,29)$ & 62,98 a $( \pm 3,14)$ & 64,31 a $( \pm 3,44)$ & 64,65 a $( \pm 3,43)$ & 59,22 a $( \pm 5,43)$ & 63,26 a $( \pm 9,30)$ \\
\hline \multirow[t]{4}{*}{$\% \mathrm{C}$} & $\mathrm{Fl}$ & $23,43 \mathrm{a}( \pm 5,17)$ & $24,75 \mathrm{a}( \pm 2,20)$ & $16,85 \mathrm{a}( \pm 4,38)$ & $18,48 \mathrm{a}( \pm 4,45)$ & $13,55 \mathrm{a}( \pm 1,15)$ & $15,45 \mathrm{a}( \pm 3,06)$ \\
\hline & $\mathrm{Fp}$ & $0,23 \mathrm{a}( \pm 0,19)$ & $0,12 \mathrm{a}( \pm 0,05)$ & $0,07 \mathrm{a}( \pm 0,02)$ & $0,07 \mathrm{a}( \pm 0,05)$ & $0,38 \mathrm{a}( \pm 0,27)$ & $0,11 \mathrm{a}( \pm 0,03)$ \\
\hline & Fom & $1,20 \mathrm{a}( \pm 0,41)$ & $0,94 \mathrm{a}( \pm 0,18)$ & $0,89 \mathrm{a}( \pm 0,16)$ & $0,77 \mathrm{a}( \pm 0,09)$ & 1,06 a $( \pm 0,35)$ & $0,67 \mathrm{a}( \pm 0,17)$ \\
\hline & Fsa & $2,02 \mathrm{a}( \pm 1,13)$ & $2,07 \mathrm{a}( \pm 0,15)$ & $1,90 \mathrm{a}( \pm 0,11)$ & 1,86 a $( \pm 0,11)$ & 1,29 a $( \pm 0,37)$ & 1,39 a $( \pm 0,06)$ \\
\hline \multirow[t]{5}{*}{$\mathrm{C}\left(\mathrm{Mg} \cdot \mathrm{ha}^{-1}\right)$} & $\mathrm{Fl}$ & $1,94 \mathrm{a}( \pm 0,85)$ & $1,85 \mathrm{a}( \pm 0,78)$ & $0,76 \mathrm{a}( \pm 0,20)$ & $0,63 \mathrm{a}( \pm 0,22)$ & $0,59 \mathrm{a}( \pm 0,19)$ & $0,58( \pm 0,07)$ \\
\hline & $\mathrm{Fp}$ & $0,12 \mathrm{a}( \pm 0,05)$ & $0,06 \mathrm{a}( \pm 0,01)$ & $0,03 \mathrm{a}( \pm 0,02)$ & $0,02 \mathrm{a}( \pm 0,01)$ & 0,15 a $( \pm 0,09)$ & $0,04 \mathrm{a}( \pm 0,02)$ \\
\hline & Fom & $7,74 \mathrm{a}( \pm 1,12)$ & 6,17 a $( \pm 1,56)$ & $6,40 \mathrm{a}( \pm 1,80)$ & 5,50 a $( \pm 0,98)$ & $10,38 \mathrm{a}( \pm 4,16)$ & 6,26 a $( \pm 2,85)$ \\
\hline & Fsa & 26,01 a $( \pm 2,38)$ & 26,38 a $( \pm 1,93)$ & $27,73 \mathrm{a}( \pm 2,20)$ & 27,29 a $( \pm 0,69)$ & 22,14 a $( \pm 6,34)$ & 25,48 a $( \pm 3,44)$ \\
\hline & Total & $35,81 \mathrm{a}( \pm 2,55)$ & 34,46 a $( \pm 3,52)$ & $34,92 \mathrm{a}( \pm 1,82)$ & 33,44 a $( \pm 1,86)$ & 33,26 a $( \pm 6,34)$ & 32,36 a $( \pm 6,34)$ \\
\hline \multirow[t]{4}{*}{$\% \mathrm{~N}$ total } & $\mathrm{Fl}$ & $0,679 \mathrm{a}( \pm 0,230)$ & $0,637 \mathrm{a}( \pm 0,073)$ & $0,384 \mathrm{a}( \pm 0,180)$ & $0,378 \mathrm{a}( \pm 0,066)$ & $0,365 \mathrm{a}( \pm 0,121)$ & $0,394 \mathrm{a}( \pm 0,162)$ \\
\hline & $\mathrm{Fp}$ & nd $^{1}$ & nd & nd & nd & nd & nd \\
\hline & Fom & $0,085 \mathrm{a}( \pm 0,008)$ & $0,072 \mathrm{a}( \pm 0,013)$ & $0,075 \mathrm{a}( \pm 0,026)$ & 0,063 a $( \pm 0,016)$ & $0,070 \mathrm{a}( \pm 0,016)$ & $0,061 \mathrm{a}( \pm 0,012)$ \\
\hline & Fsa & 0,176 a $( \pm 0,006)$ & 0,171 a $( \pm 0,011)$ & $0,155 \mathrm{a}( \pm 0,006)$ & $0,152 \mathrm{a}( \pm 0,005)$ & $0,124 \mathrm{a}( \pm 0,037)$ & $0,112 \mathrm{a}( \pm 0,007)$ \\
\hline \multirow[t]{5}{*}{$\mathrm{N}$ total $\left(\mathrm{kg} \cdot \mathrm{ha}^{-1}\right)$} & $\mathrm{Fl}$ & 56,3 a $( \pm 23,7)$ & $47,7 \mathrm{a}( \pm 20,6)$ & 17,4 a $( \pm 6,4)$ & 12,9 a $( \pm 4,8)$ & 15,9 a $( \pm 11,1)$ & $14,8 \mathrm{a}( \pm 1,2)$ \\
\hline & $\mathrm{Fp}$ & - & - & - & - & - & - \\
\hline & Fom & $548,0 \mathrm{a}( \pm 111,8)$ & 472,5 a $( \pm 193,4)$ & 539,2 a $( \pm 271,0)$ & $449,8 \mathrm{a}( \pm 139,8)$ & $685,5 \mathrm{a}( \pm 201,5)$ & 569,6 a $( \pm 214,5)$ \\
\hline & Fsa & $2266,1 \mathrm{a}( \pm 121,6)$ & $2179,2 \mathrm{a}( \pm 156,6)$ & $2262,2 \mathrm{a}( \pm 107,0)$ & $2232,9 \mathrm{a}( \pm 164,0)$ & 2128,1 a $( \pm 616,0)$ & 2053,3 a $( \pm 297,9)$ \\
\hline & Total & $2870,4 \mathrm{a}( \pm 124,8)$ & $2699,4 \mathrm{a}( \pm 232,3)$ & $2818,8 \mathrm{a}( \pm 168,5)$ & 2695,6 a $( \pm 211,8)$ & 2829,5 a $( \pm 635,1)$ & $2637,7 \mathrm{a}( \pm 173,0)$ \\
\hline
\end{tabular}

1: Desvio Padrão aparece entre parênteses. nd: não determinado. Fl: fração leve (200 -2000 $\mu \mathrm{m})$, com resíduos orgânicos grossos; Fp: fração mineral pesada (200 a $2000 \mu \mathrm{m})$; Fom: fração organo-mineral (53 a $200 \mu \mathrm{m})$; Fsa: fração organo-mineral $(<53 \mu \mathrm{m})$. Cada valor é a média de quatro repetições. Os tratamentos no mesmo ano com diferentes letras são estatisticamente diferentes ao nível de probabilidade de $5 \%$ pelo Teste $t$. 
Tabela 11. Distribuição porcentual das frações granulométricas do solo, conteúdo de carbono e conteúdo de nitrogênio nas frações de solo nas profundidades 0-15; 15-30 e 30-50 cm e nos tratamentos sem queima (SQ) e com queima (CQ) dos resíduos da colheita da cana-de-açúcar. Ano 2002

\begin{tabular}{|c|c|c|c|c|c|c|c|}
\hline \multirow{2}{*}{ Variável } & \multirow{2}{*}{ Fração do solo } & \multicolumn{2}{|c|}{ |------------------ 0 0-15 ------------------ } & \multicolumn{2}{|c|}{----------------- 15-30 ----------------- } & \multicolumn{2}{|c|}{----------------- 30-50 ----------------- } \\
\hline & & SQ & $\mathrm{CQ}$ & SQ & CQ & SQ & CQ \\
\hline \multirow{4}{*}{$\begin{array}{l}\text { \% da fração na } \\
\text { amostra de solo }\end{array}$} & Fl & $0,35 \mathrm{a}( \pm 0,11)^{1}$ & $0,26 \mathrm{a}( \pm 0,08)$ & 0,15 a $( \pm 0,05)$ & $0,12 \mathrm{a}( \pm 0,04)$ & $0,05 \mathrm{a}( \pm 0,04)$ & $0,03 \mathrm{a}( \pm 0,01)$ \\
\hline & $\mathrm{Fp}$ & $4,35 \mathrm{a}( \pm 0,39)$ & 3,85 a $( \pm 1,93)$ & 3,65 a $( \pm 0,47)$ & $3,82 \mathrm{a}( \pm 1,31)$ & 3,48 a $( \pm 1,22)$ & $3,20 \mathrm{a}( \pm 1,35)$ \\
\hline & Fom & 40,88 a $( \pm 1,18)$ & $36,12 \mathrm{a}( \pm 4,84)$ & 36,95 a $( \pm 1,30)$ & $36,64 \mathrm{a}( \pm 3,90)$ & $39,80 \mathrm{a}( \pm 1,93)$ & $34,75 \mathrm{~b}( \pm 2,34)$ \\
\hline & Fsa & $52,94 \mathrm{a}( \pm 1,21)$ & 57,60 a $( \pm 5,67)$ & 56,11 a $( \pm 1,66)$ & 57,18 a $( \pm 3,92)$ & $52,88 \mathrm{~b}( \pm 0,84)$ & 58,60 a $( \pm 2,85)$ \\
\hline \multirow[t]{4}{*}{$\% \mathrm{C}$} & $\mathrm{Fl}$ & 18,08 a $( \pm 4,98)$ & $18,29 \mathrm{a}( \pm 4,26)$ & $14,94 \mathrm{a}( \pm 1,79)$ & 16,26 a $( \pm 3,27)$ & $14,78 \mathrm{a}( \pm 2,12)$ & $16,67 \mathrm{a}( \pm 2,22)$ \\
\hline & $\mathrm{Fp}$ & $0,10 \mathrm{a}( \pm 0,01)$ & $0,10 \mathrm{a}( \pm 0,02)$ & $0,08 \mathrm{a}( \pm 0,01)$ & $0,10 \mathrm{a}( \pm 0,03)$ & $0,08 \mathrm{a}( \pm 0,01)$ & $0,07 \mathrm{a}( \pm 0,01)$ \\
\hline & Fom & $1,22 \mathrm{a}( \pm 0,08)$ & 1,18 a $( \pm 0,10)$ & $1,04 \mathrm{a}( \pm 0,09)$ & $0,93 \mathrm{a}( \pm 0,13)$ & $0,90 \mathrm{a}( \pm 0,07)$ & $0,82 \mathrm{~b}( \pm 0,04)$ \\
\hline & Fsa & $2,16 \mathrm{a}( \pm 0,08)$ & $2,12 \mathrm{a}( \pm 0,10)$ & 1,89 a $( \pm 0,07)$ & $1,88 \mathrm{a}( \pm 0,09)$ & 1,48 a $( \pm 0,05)$ & $1,40 \mathrm{~b}( \pm 0,06)$ \\
\hline \multirow{5}{*}{$\mathrm{C}\left(\mathrm{t}, \mathrm{ha}^{-1}\right)$} & $\mathrm{Fl}$ & $1,28 \mathrm{a}( \pm 0,37)$ & $0,96 \mathrm{a}( \pm 0,25)$ & $0,51 \mathrm{a}( \pm 0,22)$ & $0,44 \mathrm{a}( \pm 0,15)$ & $0,21 \mathrm{a}( \pm 0,15)$ & $0,14 \mathrm{a}( \pm 0,07)$ \\
\hline & $\mathrm{Fp}$ & $0,09 \mathrm{a}( \pm 0,01)$ & $0,08 \mathrm{a}( \pm 0,04)$ & $0,07 \mathrm{a}( \pm 0,01)$ & $0,09 \mathrm{a}( \pm 0,06)$ & $0,08 \mathrm{a}( \pm 0,03)$ & $0,06 \mathrm{a}( \pm 0,03)$ \\
\hline & Fom & $10,01 \mathrm{a}( \pm 0,73)$ & $8,62 \mathrm{a}( \pm 1,60)$ & 8,72 a $( \pm 0,80)$ & $7,73 \mathrm{a}( \pm 1,90)$ & $10,38 \mathrm{a}( \pm 1,18)$ & $8,26 \mathrm{~b}( \pm 0,76)$ \\
\hline & Fsa & 23,13 a $( \pm 0,58)$ & $24,70 \mathrm{a}( \pm 2,94)$ & $24,07 \mathrm{a}( \pm 1,18)$ & $24,40 \mathrm{a}( \pm 2,41)$ & 22,68 a $( \pm 0,99)$ & 23,78 a $( \pm 1,00)$ \\
\hline & Total & 34,51 a $( \pm 1,39)$ & $34,36 \mathrm{a}( \pm 1,62)$ & $33,37 \mathrm{a}( \pm 1,83)$ & 32,66 a $( \pm 1,61)$ & 33,35 a $( \pm 1,26)$ & 32,24 a $( \pm 1,97)$ \\
\hline \multirow[t]{4}{*}{$\% \mathrm{~N}$ total } & $\mathrm{Fl}$ & 0,823 a $( \pm 0,187)$ & $0,634 \mathrm{~b}( \pm 0,101)$ & $0,660 \mathrm{a}( \pm 0,132)$ & $0,597 \mathrm{a}( \pm 0,040)$ & $0,465 \mathrm{a}( \pm 0,315)$ & $0,534 \mathrm{a}( \pm 0,371)$ \\
\hline & $\mathrm{Fp}$ & nd $^{1}$ & & nd & & & nd \\
\hline & Fom & $0,091 \mathrm{a}( \pm 0,004)$ & $0,074 \mathrm{~b}( \pm 0,007)$ & $0,078 \mathrm{a}( \pm 0,012)$ & 0,068 a $( \pm 0,007)$ & $0,070 \mathrm{a}( \pm 0,004)$ & 0,066 a $( \pm 0,005)$ \\
\hline & Fsa & $0,174 \mathrm{a}( \pm 0,009)$ & 0,173 a $( \pm 0,007)$ & $0,162 \mathrm{a}( \pm 0,015)$ & 0,158 a $( \pm 0,007)$ & $0,121 \mathrm{a}( \pm 0,012)$ & $0,110 \mathrm{a}( \pm 0,005)$ \\
\hline \multirow[t]{5}{*}{$\mathrm{N}$ total $\left(\mathrm{kg} \cdot \mathrm{ha}^{-1}\right)$} & $\mathrm{Fl}$ & $58,3 \mathrm{a}( \pm 11,5)$ & $33,4 \mathrm{~b}( \pm 6,8)$ & $22,5 \mathrm{a}( \pm 8,5)$ & $16,26 \mathrm{a}( \pm 4,6)$ & $6,7 \mathrm{a}( \pm 3,1)$ & $4,6 \mathrm{a}( \pm 2,5)$ \\
\hline & $\mathrm{Fp}$ & - & - & - & - & - & - \\
\hline & Fom & $752,8 \mathrm{a}( \pm 42,8)$ & $540,9 \mathrm{~b}( \pm 111,0)$ & 654,1 a $( \pm 98,6)$ & 565,5 a $( \pm 123,4)$ & $807,4 \mathrm{a}( \pm 79,8)$ & $664,7 \mathrm{~b}( \pm 81,8)$ \\
\hline & Fsa & 1864,0 a $( \pm 107,3)$ & 2016,4 a $( \pm 188,7)$ & 2062,9 a $( \pm 155,9)$ & 2050,4 a $( \pm 123,4)$ & 1854,3 a $( \pm 206,5)$ & 1868,1 a $( \pm 84,5)$ \\
\hline & Total & 2675,1 a $( \pm 102,3)$ & $2590,7 \mathrm{a}( \pm 193,9)$ & $2739,5 \mathrm{a}( \pm 254,6)$ & 2632,2 a $( \pm 192,8)$ & 2668,4 a $( \pm 189,8)$ & $2537,4 \mathrm{a}( \pm 120,0)$ \\
\hline
\end{tabular}

1: Desvio Padrão aparece entre parênteses. nd: não determinado. Fl: fração leve (200 -2000 $\mu$ m), com resíduos orgânicos grossos; Fp: fração mineral pesada (200 a $2000 \mu \mathrm{m})$; Fom: fração organo-mineral (53 a $200 \mu \mathrm{m})$; Fsa: fração organo-mineral (< $53 \mu \mathrm{m})$. Cada valor é a média de quatro repetições. Os tratamentos no mesmo ano com diferentes letras são estatisticamente diferentes ao nível de probabilidade de $5 \%$ pelo Teste $t$. 
Em relação à distribuição vertical, observou-se que os teores e os conteúdos de C e de $\mathrm{N}$ decresceram com a profundidade, e apresentaram redistribuição similar entre as frações do solo em todas as profundidades. Proporcionalmente, o conteúdo de $\mathrm{N}$ decresce mais que o de $\mathrm{C}$; portanto, a relação $\mathrm{C} / \mathrm{N}$ decresce com a profundidade.

Vários estudos foram feitos sobre a dinâmica da decomposição do material orgânico remanescente logo após a colheita da cultura de cana-de-açúcar (Blair et al., 1998; Skjemstadt et al., 1999; Blair, 2000) e de outras culturas (Rasmussen et al., 1980; Chan et al., 2002; Collins et al., 1992; Campbell \& Zentner 1993). Esses estudos têm demonstrado a importância desses resíduos como fontes de carbono orgânico para o solo.

É importante observar que tanto a duração do experimento quanto a profundidade de solo estudada são duas variáveis primordiais para se detectar diferenças no carbono e nitrogênio do solo entre os dois sistemas de manejo dos resíduos. Provavelmente a duração do presente experimento não tenha sido suficientemente longa para se detectar diferenças significativas na quantidade e distribuição de $\mathrm{C}$ e $\mathrm{N}$ total no solo. $\mathrm{O}$ fato de a camada superficial ter sido de 0 a $15 \mathrm{~cm}$ pode ter diluído possíveis diferenças ocorridas nos primeiros centímetros do solo.

\subsection{Distribuição do nitrogênio derivado do fertilizante nas frações granulométricas e no perfil do solo}

Após 5 anos de aplicado o ${ }^{15} \mathrm{~N}$-fertilizante, ainda foi detectada a presença de nitrogênio derivado do fertilizante ( $\mathrm{NddF}$ ) no solo nos dois sistemas de manejo.

O NddF se distribuiu nas frações do solo similarmente ao nitrogênio total, na seguinte ordem Fsa $>$ Fom $>$ FL, e seu conteúdo diminuiu em profundidade (Tabelas 7 a 11 e Figura 7). O conteúdo de NddF no solo aumentou do primeiro para o segundo ciclo e logo foi decrescendo com o tempo.

A quantidade de NddF retido no compartimento solo $(0-50 \mathrm{~cm})$ apenas apresentou diferenças significativas entre os tratamentos SQ e CQ nos ciclos 2 e 5 (colheitas de 1999 e 2002), sendo que nesses anos o conteúdo de NddF no tratamento SQ foi $5 \mathrm{~kg} \cdot \mathrm{ha}^{-1}$ superior ao achado no tratamento CQ (Tabela 12). No ciclo 2, a 
diferença entre os tratamentos foi devida principalmente à contribuição da $\mathrm{Fl}$ em SQ, a qual apresentou conteúdo de NddF superior ao da Fom na profundidade $0-15 \mathrm{~cm}$, fato não observado em nenhum outro ciclo.

A decomposição, durante o ciclo correspondente à primeira soca (ciclo 2), dos resíduos da colheita de 1998 (colheita da cana-planta - ciclo 1) enriquecidos com ${ }^{15} \mathrm{~N}$ devido à alta absorção do $\mathrm{N}$ do fertilizante durante o primeiro ano (Tabelas 4 e 5), explicaria o aumento do NddF observado no ciclo 2 em ambos os sistemas, mas significativamente superior em SQ (Figura 7). Também a decomposição do material vegetal subterrâneo morto, constituído por raízes e rizomas mortos provenientes do ciclo anterior (ciclo 1), durante o qual tinham absorvido importantes quantidades de nitrogênio do fertilizante, deve ter contribuído ao aumento do NddF do ciclo 1 para o ciclo 2 .

No ciclo 4, a diferença foi devida à diminuição do NddF da Fsa, mais acentuada em CQ do que em SQ e observada em todas a profundidades do solo (Figura 7). Essa perda mais pronunciada de NddF em CQ poderia ser o início do processo de deterioração da estrutura dos microagregados induzido pelas repetidas queimas e que afeta a produção por parte dos microorganismos do solo de compostos que irão estabilizar as partículas mais finas (Chan et al., 2002). Porém, não tendo sido observadas mudanças significativas nos conteúdos totais de carbono e de nitrogênio, essa hipótese não pode ser sustentada por este trabalho. Também, esse fato sugere a necessidade de ter no Brasil mais experimentos de cana-de-açúcar de longa duração para o estudo de mudanças induzidas pelo manejo dos resíduos. 
Tabela 12. Distribuição nas frações de solo do N derivado do fertilizante (NddF) nas profundidades 0-15; 15-30 e 30-50 cm e nos tratamentos sem queima (SQ) e com queima (CQ) dos resíduos da colheita da cana-de-açúcar. Período 1998-2002

\begin{tabular}{|c|c|c|c|c|c|c|c|}
\hline \multirow{2}{*}{ Ano } & \multirow{2}{*}{$\begin{array}{l}\text { Profundidade } \\
\text { do solo }(\mathrm{cm})\end{array}$} & \multicolumn{2}{|c|}{ Fl } & \multicolumn{2}{|c|}{ Fom } & \multicolumn{2}{|c|}{ Fsa } \\
\hline & & SQ & $\mathrm{CQ}$ & SQ & $\mathrm{CQ}$ & SQ & $\mathrm{CQ}$ \\
\hline & & & & & $a^{-1}$ & 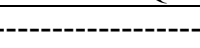 & 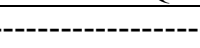 \\
\hline \multirow[t]{4}{*}{1998} & $0-15$ & $0,60( \pm 0,29)$ & $0,29( \pm 0,15)$ & $0,70( \pm 0,11)$ & $0,53( \pm 0,17)$ & $2,56( \pm 0,54)$ & $2,09( \pm 0,32)$ \\
\hline & $15-30$ & $0,34( \pm 0,11)$ & $0,24( \pm 0,06)$ & $0,43( \pm 0,13)$ & $0,36( \pm 0,09)$ & $1,78( \pm 0,54)$ & $1,45( \pm 0,31)$ \\
\hline & $30-50$ & $0,21( \pm 0,19)$ & $0,20( \pm 0,03)$ & $0,27 \mathrm{a}( \pm 0,02)$ & $0,24 \mathrm{a}( \pm 0,01)$ & $1,13( \pm 0,33)$ & $0,83( \pm 0,09)$ \\
\hline & Total & $1,15( \pm 0,50)$ & $0,73( \pm 0,21)$ & $1,40( \pm 0,18)$ & $1,13( \pm 0,22)$ & $5,47( \pm 0,53)$ & $4,37( \pm 0,43)$ \\
\hline \multirow[t]{4}{*}{1999} & $0-15$ & $4,23( \pm 0,59)$ & $1,80( \pm 0,84)$ & $2,55( \pm 0,70)$ & $1,93( \pm 0,37)$ & $6,35( \pm 0,45)$ & $5,81( \pm 0,89)$ \\
\hline & $15-30$ & $0,78( \pm 0,26)$ & $0,53( \pm 0,27)$ & $1,00( \pm 0,10)$ & $0,82( \pm 0,30)$ & $3,07( \pm 0,62)$ & $2,55( \pm 0,34)$ \\
\hline & $30-50$ & $0,38( \pm 0,03)$ & $0,24( \pm 0,16)$ & $0,83( \pm 0,26)$ & $0,62( \pm 0,20)$ & $1,93( \pm 0,49)$ & $1,68( \pm 0,47)$ \\
\hline & Total & $5,38( \pm 0,63)$ & $2,57( \pm 0,61)$ & $4,38( \pm 0,93)$ & $3,37( \pm 0,78)$ & $11,35( \pm 1,00)$ & $10,04( \pm 1,38)$ \\
\hline \multirow[t]{4}{*}{2000} & $0-15$ & $1,19( \pm 0,23)$ & $0,69( \pm 0,28)$ & $2,58( \pm 0,94)$ & $1,43( \pm 0,80)$ & $6,31( \pm 1,99)$ & $5,52( \pm 1,16)$ \\
\hline & $15-30$ & $0,14( \pm 0,09)$ & $0,25( \pm 0,04)$ & $0,70( \pm 0,12)$ & $0,81( \pm 0,24)$ & $2,51( \pm 0,41)$ & $2,53( \pm 0,43)$ \\
\hline & $30-50$ & $0,09( \pm 0,05)$ & $0,15( \pm 0,10)$ & $0,57( \pm 0,21)$ & $0,75( \pm 0,49)$ & $2,34( \pm 1,24)$ & $2,04( \pm 0,90)$ \\
\hline & Total & $1,42( \pm 0,33)$ & $1,09( \pm 0,22)$ & $3,85( \pm 1,12)$ & $2,99( \pm 0,49)$ & $11,15( \pm 3,01)$ & $10,09( \pm 0,61)$ \\
\hline \multirow[t]{4}{*}{2001} & $0-15$ & $0,75( \pm 0,23)$ & $0,65( \pm 0,40)$ & $1,34( \pm 0,22)$ & $1,02( \pm 0,08)$ & $5,94( \pm 0,90)$ & $5,16( \pm 1,15)$ \\
\hline & $15-30$ & $0,18( \pm 0,04)$ & $0,18( \pm 0,08)$ & $0,77( \pm 0,22)$ & $0,55( \pm 0,25)$ & $2,94( \pm 0,54)$ & $2,22( \pm 0,44)$ \\
\hline & $30-50$ & $0,17( \pm 0,08)$ & $0,13( \pm 0,06)$ & $0,70( \pm 0,15)$ & $0,54( \pm 0,25)$ & $2,44( \pm 0,66)$ & $1,61( \pm 0,86)$ \\
\hline & Total & $1,10( \pm 0,31)$ & $0,97( \pm 0,48)$ & $2,82( \pm 0,35)$ & $2,11( \pm 0,19)$ & $11,32( \pm 1,78)$ & $8,99( \pm 1,89)$ \\
\hline \multirow[t]{4}{*}{2002} & $0-15$ & $0,40( \pm 0,16)$ & $0,13( \pm 0,06)$ & $1,25( \pm 0,25)$ & $0,93( \pm 0,17)$ & $4,13( \pm 0,55)$ & $2,45( \pm 0,40)$ \\
\hline & $15-30$ & $0,14( \pm 0,04)$ & $0,03( \pm 0,01)$ & $0,91( \pm 0,08)$ & $0,23( \pm 0,02)$ & $1,91( \pm 0,12)$ & $0,65( \pm 0,04)$ \\
\hline & $30-50$ & $0,05( \pm 0,03)$ & $0,01\left( \pm 4 \cdot 10^{-3}\right)$ & $0,47( \pm 0,04)$ & $0,12\left( \pm 4.10^{-3}\right)$ & $1,15( \pm 0,17)$ & $0,40( \pm 0,03)$ \\
\hline & Total & $0,59( \pm 0,17)$ & $0,16( \pm 0,07)$ & $2,63( \pm 0,34)$ & $1,28( \pm 0,22)$ & $7,19( \pm 0,67)$ & $3,50( \pm 0,44)$ \\
\hline
\end{tabular}

1: Desvio Padrão aparece entre parênteses. Fl: fração leve (200 -2000 $\mu \mathrm{m})$, com resíduos orgânicos grossos; Fp: fração mineral pesada (200 a 2000 um); Fom: fração organo-mineral (53 a $200 \mu \mathrm{m})$; Fsa: fração organo-mineral $(<53 \mu \mathrm{m})$. Cada valor é a média de quatro repetições. 


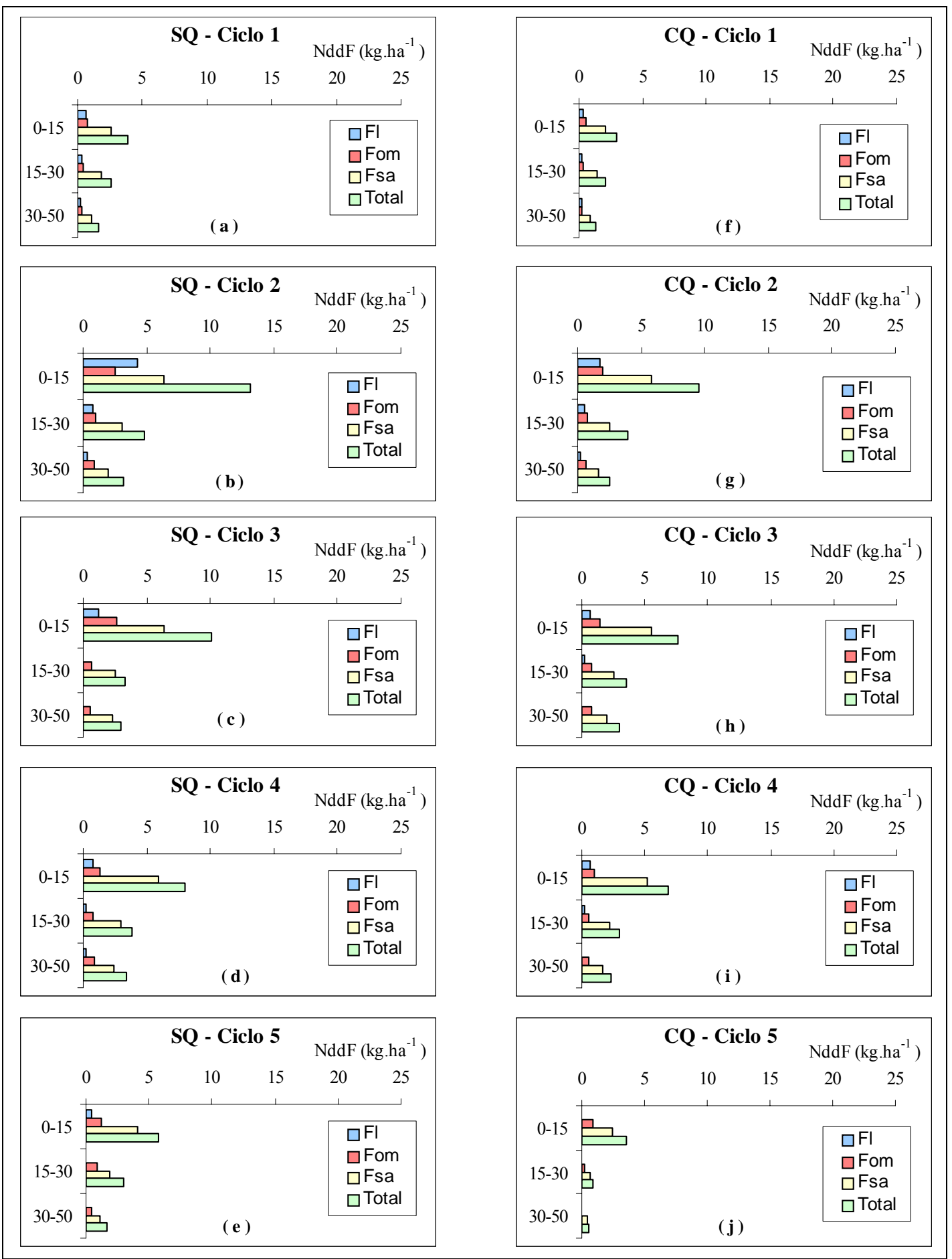

Figura 7 - Distribuição do nitrogênio derivado do fertilizante (NddF) nas frações do solo e nas camadas de solo durante os cinco ciclos analisados (1998-2002) 


\subsection{Distribuição do nitrogênio derivado dos resíduos da cultura nas frações granulométricas e no perfil do solo}

A recuperação do nitrogênio contido nos resíduos culturais da cana-de-açúcar foi avaliada durante quatro ciclos, iniciando na colheita da primeira cana-soca em 1999, um ano após de ter sido aplicados nas parcelas do tratamento T2 os resíduos marcados com ${ }^{15} \mathrm{~N}$ provenientes de T1. No item 4.3 foi analisada a recuperação do NddR no sistema solo-planta, considerando o compartimento solo dividido nas camadas 0-15, 15-30 e 30$50 \mathrm{~cm}$ de profundidade. Neste item será discutida a retenção do NddR no solo analisando sua distribuição nas frações granulométricas e como elas se distribuíram no perfil do solo.

Em geral, a distribuição do NddR nas frações do solo apresentou a seguinte ordem Fsa $>$ Fom $>$ Fl, nas três profundidades e nos quatro ciclos (Tabela 13 e Figura 8).

Apenas na primeira avaliação, realizada após 12 meses da disposição dos resíduos sobre a superfície do solo (ciclo 2), foi observada maior quantidade de NddR na Fl do que em Fsa e Fom na profundidade de 0-15 cm (Figura 8a). A F1 é composta por materiais grosseiros em estádios iniciais de decomposição, os que no ciclo 2 provinham dos resíduos marcados com ${ }^{15} \mathrm{~N}$, o que explica seu alto contudo de NddR. Devido a que a absorção do NddR pela cultura foi baixa $\left(3 \mathrm{~kg} \cdot \mathrm{ha}^{-1} \cdot \mathrm{ano}^{-1}\right)$ o enriquecimento isotópico dos resíduos diminuiu nas sucessivas colheitas o que explicaria a queda na quantidade de ${ }^{15} \mathrm{~N}$ na $\mathrm{Fl}$ nos ciclos posteriores.

Como já foi mencionado para o $\mathrm{NddF}$, durante o ciclo correspondente à primeira soca (ciclo 2), ocorreu a decomposição dos resíduos culturais, das raízes e dos rizomas enriquecidos com ${ }^{15} \mathrm{~N}$ devido à alta absorção do $\mathrm{N}$ do fertilizante durante o primeiro ano (Tabelas 4 e 5). Isso explicaria o alto conteúdo de NddR na Fl observado no ciclo 2, o qual nos anos seguintes diminui consideravelmente (Tabela 13 e Figura 8). 
Tabela 13. Distribuição nas frações de solo do $\mathrm{N}$ derivado dos resíduos (NddR) nas profundidades $0-15 ; 15-30$ e $30-50 \mathrm{~cm}$ e nos tratamentos sem queima (SQ) e com queima (CQ) dos resíduos da colheita da cana-de-açúcar. Período 19992002

\begin{tabular}{|c|c|c|c|c|}
\hline Ano & $\begin{array}{l}\text { Profundidade } \\
\text { do solo }(\mathrm{cm})\end{array}$ & $\mathrm{Fl}$ & Fom & Fsa \\
\hline \multirow[t]{4}{*}{1999} & $0-15$ & $20,25( \pm 2,85)$ & $7,81( \pm 3,62)$ & $18,11( \pm 3,81)$ \\
\hline & $15-30$ & $2,55( \pm 0,96)$ & $2,45( \pm 0,75)$ & $6,37( \pm 1,05)$ \\
\hline & $30-50$ & $1,49( \pm 0,56)$ & $2,19( \pm 0,93)$ & $4,54( \pm 0,41)$ \\
\hline & Total & $24,29( \pm 3,75)$ & $12,45( \pm 4,18)$ & $29,02( \pm 3,73)$ \\
\hline \multirow[t]{4}{*}{2000} & $0-15$ & $3,84( \pm 1,28)$ & $8,33( \pm 4,05)$ & $15,71( \pm 4,75)$ \\
\hline & $15-30$ & $0,24( \pm 0,08)$ & $2,00( \pm 0,45)$ & $7,04( \pm 1,19)$ \\
\hline & $30-50$ & $0,19( \pm 0,09)$ & $1,62( \pm 0,30)$ & $6,26( \pm 1,17)$ \\
\hline & Total & $4,27( \pm 1,36)$ & $11,95( \pm 4,51)$ & $29,01( \pm 2,51)$ \\
\hline \multirow[t]{4}{*}{2001} & $0-15$ & $2,91( \pm 0,77)$ & $5,36( \pm 1,65)$ & $23,05( \pm 3,28)$ \\
\hline & $15-30$ & $0,73( \pm 0,18)$ & $3,09( \pm 1,08)$ & $11,58( \pm 0,83)$ \\
\hline & $30-50$ & $0,48( \pm 0,23)$ & $1,39( \pm 0,64)$ & $9,49( \pm 0,69)$ \\
\hline & Total & $4,12( \pm 0,90)$ & $9,84( \pm 2,61)$ & $44,13( \pm 2,65)$ \\
\hline \multirow[t]{4}{*}{2002} & $0-15$ & $1,40( \pm 0,19)$ & $4,10( \pm 0,56)$ & $20,38( \pm 3,76)$ \\
\hline & $15-30$ & $0,58( \pm 0,20)$ & $4,62( \pm 0,35)$ & $9,32( \pm 0,95)$ \\
\hline & $30-50$ & $0,40( \pm 0,27)$ & $2,15( \pm 0,20)$ & $5,40( \pm 1,39)$ \\
\hline & Total & $2,34( \pm 0,35)$ & $10,87( \pm 0,93)$ & $35,10( \pm 5,20)$ \\
\hline
\end{tabular}

1: Desvio Padrão aparece entre parênteses. Fl: fração leve (200 -2000 $\mu \mathrm{m})$, com resíduos orgânicos grossos; Fp: fração mineral pesada (200 a $2000 \mu \mathrm{m})$; Fom: fração organo-mineral (53 a $200 \mu \mathrm{m})$; Fsa: fração organo-mineral $(<53 \mu \mathrm{m})$. Cada valor é a média de quatro repetições. 

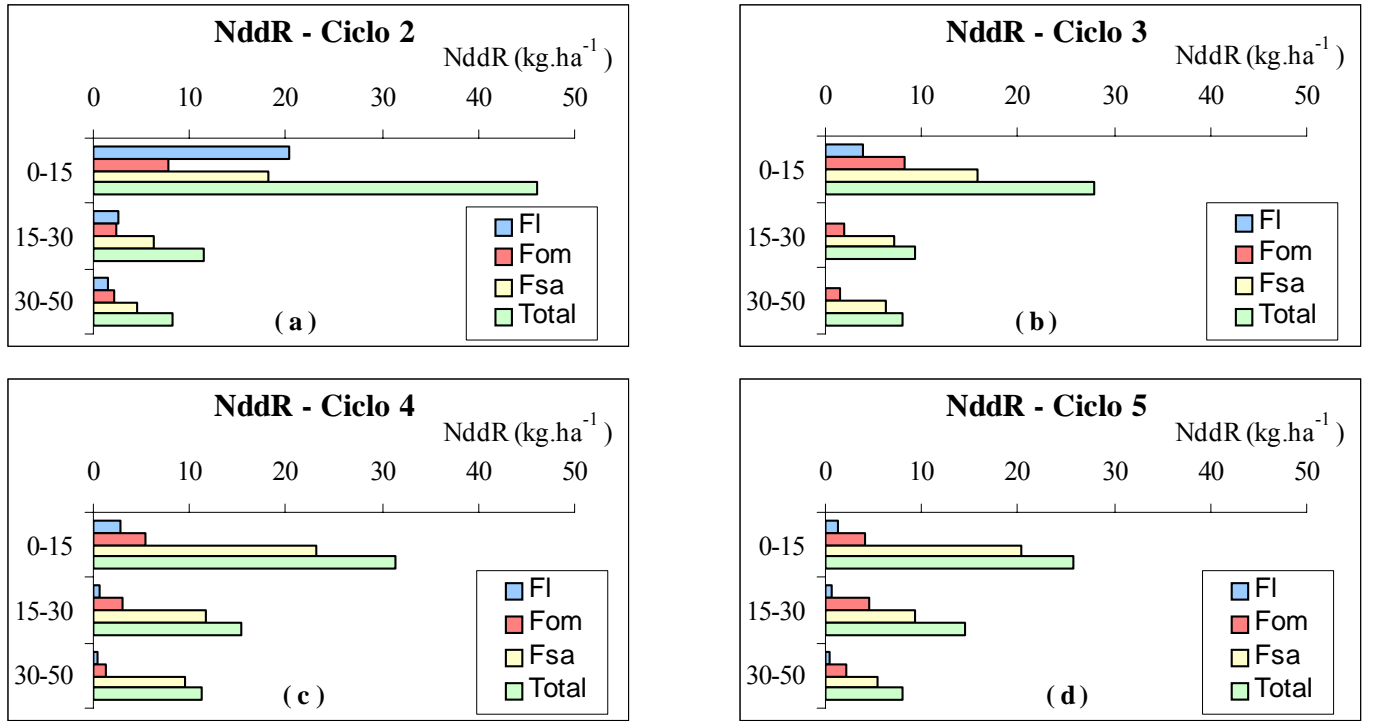

Figura 8 - Distribuição do nitrogênio derivado dos resíduos (NddR) nas frações do solo e nas camadas de solo durante os quatro ciclos analisados (1999-2002)

\subsection{Modelo descritivo da dinâmica do nitrogênio adicionado ao sistema solo- planta via fertilizante}

De acordo com o modelo proposto e com os resultados experimentais obtidos, foram determinados os parâmetros empíricos através de análise de regressão. Para tal, foi utilizado o programa computacional Table Curve, onde foram obtidas as curvas de porcentagem de recuperação do nitrogênio do fertilizante (\%NFRec), denominada recuperação relativa do nitrogênio do fertilizante $\left(\mathrm{N}_{\mathrm{k}, \mathrm{j}}\right)$ no sistema solo-planta e no compartimento planta para os tratamentos com queima $(C Q=T 3)$ e sem queima $(\mathrm{SQ}=\mathrm{T} 1+\mathrm{T} 2)$.

Nas Tabelas 14 e 15, são apresentados os parâmetros do modelo, o coeficiente de determinação $\left(\mathrm{r}^{2}\right)$ e o valor $\mathrm{F}$ para os tratamentos $\mathrm{SQ}$ e $\mathrm{CQ}$, referentes à recuperação do nitrogênio do fertilizante no sistema solo-planta e no compartimento planta, respectivamente.

No início do experimento, no instante da adubação $(\mathrm{j}=0)$, todo o $\mathrm{N}$ aplicado se encontra no sistema solo-planta $\left(\mathrm{N}_{3, \mathrm{j}}=100 \%\right)$ sendo nulas as perdas do $\mathrm{NddF}$ do sistema $\left(\mathrm{Nl}_{3, j}=0\right)$. Nesse momento, todo o NddF do sistema se encontra no compartimento solo 
$\left(\mathrm{N}_{1, j}=100 \%\right)$. A partir do momento em que a cultura desenvolve seu sistema radicular e começa a absorção de N, o NddF se redistribui entre os compartimento planta e solo, atingindo um valor máximo na planta e um valor mínimo no solo no instante $\mathrm{j}=1$.

$\mathrm{O} \mathrm{NddF}$ no sistema apresenta comportamento estritamente decrescente (pois $\lim _{j \rightarrow \infty} N_{3, j}=A_{3}$ ) (Tabela 14 e Figura 9). As curvas de recuperação do nitrogênio adicionado no sistema solo-planta para SQ (Figura 9a) e para CQ (Figura 9b) apresentam a mesma tendência, porém foram observadas maiores taxas de decréscimos quando os resíduos foram queimados, fato expresso pelo coeficiente $\mathrm{B}_{3}$ (Tabela 14) o qual é maior em CQ.

No início, no instante da adubação $(\mathrm{j}=0)$, o $\mathrm{NddF}$ na planta é nulo $\left(\mathrm{N}_{2, \mathrm{j}}=0 \%\right)$. Durante o primeiro ciclo $(0<\mathrm{j} \leq 1)$ ocorreu uma elevada absorção pela planta do nitrogênio do fertilizante prontamente disponível até atingir um máximo $\left(A_{2}\right)$ em $j=1$. Nos anos seguintes, a taxa de perda de nitrogênio na planta aumentou fazendo com que o NddF atinja um mínimo (pois $\lim _{j \rightarrow \infty} N_{2, j}=0$ ). A taxa de perda $\left(\frac{d N_{2, j}}{d j}\right)$ no compartimento planta $(\mathrm{k}=2)$ foi maior no sistema $\mathrm{CQ}\left(\mathrm{B}_{2}=5,411\right)$ do que em $\mathrm{SQ}$ $\left(\mathrm{B}_{2}=4,781\right)$ (Tabela 15, Figura 10).

No instante da adubação $(\mathrm{j}=0)$, o total do $\mathrm{NddF}$ se encontrava no compartimento solo, sendo $N_{1, j}=100 \%$ (Figura 11). Durante o ciclo da cana-planta $(0<j \leq 1)$, o solo perdeu NddF por causa da alta taxa de absorção pela planta, $\mathrm{N}_{1, \mathrm{j}}$ atingindo um valor mínimo em $\mathrm{j}=1$. Posteriormente, no segundo ciclo, correspondente à primeira cana-soca $(1<j \leq 2)$, ocorreu ganho de NddF no solo, o que se explica pela alta taxa de absorção pela cultura durante o ciclo anterior. Como a cultura durante o ciclo da cana planta absorveu grande quantidade de $\mathrm{NddF}$, as raízes ativas no primeiro ano, agora em processo de decomposição e os resíduos que permanecem no sistema seriam as fontes enriquecidas em ${ }^{15} \mathrm{~N}$ que contribuíram com o aumento do NddF no solo. Nos anos subseqüentes ocorreu sempre perda de $\mathrm{NddF}$ tanto na planta quanto no solo.

Conseqüentemente, as perdas de $\mathrm{NddF}$ no sistema são descritas por uma função estritamente crescente $\left(\lim _{j \rightarrow \infty} N l_{3, j}=100\right)$ (Figura 12). 
Tabela 14. Parâmetros do modelo referentes à porcentagem do nitrogênio derivado do fertilizante recuperado no sistema solo-planta $(k=3)$ nos tratamentos SQ (sem queima) e CQ (com queima)

\begin{tabular}{|c|c|c|c|}
\hline \multicolumn{4}{|c|}{ Modelo: $\hat{N}_{3, j}=A_{3}+\frac{100-A_{3}}{1+B_{3} \cdot j^{C_{3}}}$} \\
\hline \multicolumn{4}{|c|}{ Tratamento SQ } \\
\hline Parâmetro & Valor & $\mathrm{r}^{2}$ & $\mathrm{~F}$ \\
\hline $\mathrm{A}_{3}$ & 10,79983142 & 0,997 & 529,2 \\
\hline $\mathrm{B}_{3}$ & 0,376803317 & & \\
\hline $\mathrm{C}_{3}$ & 2,053764007 & & \\
\hline \multicolumn{4}{|c|}{ Tratamento CQ } \\
\hline Parâmetro & Valor & $r^{2}$ & $\mathrm{~F}$ \\
\hline $\mathrm{A}_{3}$ & 4,338644333 & 0,989 & 133,9 \\
\hline $\mathrm{B}_{3}$ & 0,430859451 & & \\
\hline $\mathrm{C}_{3}$ & 2,013271652 & & \\
\hline
\end{tabular}

$\mathrm{Na}$ análise de comparação (Figura 13), ficou constatado que o modelo proposto representa bem o comportamento do fenômeno em função dos coeficientes de determinação $\left(\mathrm{r}^{2}\right)$ e angular, os quais foram de 0,9999; 0,9998; 0,9998 e 0,9998 e 0,$9999 ; 0,0,9998 ; 0,0,9998$ e $0,0,9998$, respectivamente para o compartimento planta $(\mathrm{k}=2)$ nos sistemas SQ e CQ e para o sistema solo-planta $(\mathrm{k}=3)$ nos sistemas SQ e CQ. 
Tabela 15. Parâmetros do modelo referentes à porcentagem do nitrogênio derivado do fertilizante recuperado no compartimento planta $(\mathrm{k}=2)$ nos tratamentos SQ (sem queima) e CQ (com queima)

\begin{tabular}{|c|c|c|c|}
\hline \multicolumn{4}{|c|}{ Modelo: $\hat{N_{2, j}}=A_{2} \cdot j,(0 \leq \mathrm{j}<1)$} \\
\hline Parâmetro & \multicolumn{2}{|l|}{ Valor } & \\
\hline \multicolumn{4}{|c|}{ Tratamento SQ } \\
\hline \multirow[t]{2}{*}{$\mathrm{A}_{2}$} & 63,3325775 & & \\
\hline & \multicolumn{2}{|c|}{ Tratamento CQ } & \\
\hline \multirow[t]{3}{*}{$\mathrm{A}_{2}$} & \multicolumn{2}{|l|}{62,69921441} & \\
\hline & \multicolumn{3}{|c|}{ Modelo: $\hat{N}_{2, j}=\frac{A_{2}}{1+B_{2} \cdot(j-1)^{C_{2}}},(\mathrm{j} \geq 1)$} \\
\hline & \multicolumn{2}{|c|}{ Tratamento SQ } & \\
\hline Parâmetro & Valor & $r^{2}$ & $\mathrm{~F}$ \\
\hline $\mathrm{A}_{2}$ & 63,3325775 & 0,999 & 3172,7 \\
\hline $\mathrm{B}_{2}$ & 4,781019113 & & \\
\hline \multirow[t]{2}{*}{$\mathrm{C}_{2}$} & 1,794916203 & & \\
\hline & \multicolumn{2}{|c|}{ Tratamento CQ } & \\
\hline Parâmetro & Valor & $\mathrm{r}^{2}$ & $\mathrm{~F}$ \\
\hline $\mathrm{A}_{2}$ & 62,69921441 & 0,999 & 1926,8 \\
\hline $\mathrm{B}_{2}$ & 5,411143327 & & \\
\hline $\mathrm{C}_{2}$ & 1,613746224 & & \\
\hline
\end{tabular}

Pelas estimativas do modelo, em uma situação hipotética em que a cultura permaneça em sucessivos ciclos de cana-soca e sem nenhum tipo de perturbação do sistema (cultivo, renovação do canavial, remoção do solo, por exemplo), após de 30 anos ter-se-á que o NddF na planta seria praticamente nulo (algo em torno de 0,04\%) e, portanto, todo o NddF do sistema solo-planta se encontraria no solo, sendo $11,0 \%$ no sistema SQ e 4,6\% no sistema CQ (Figura 9). 


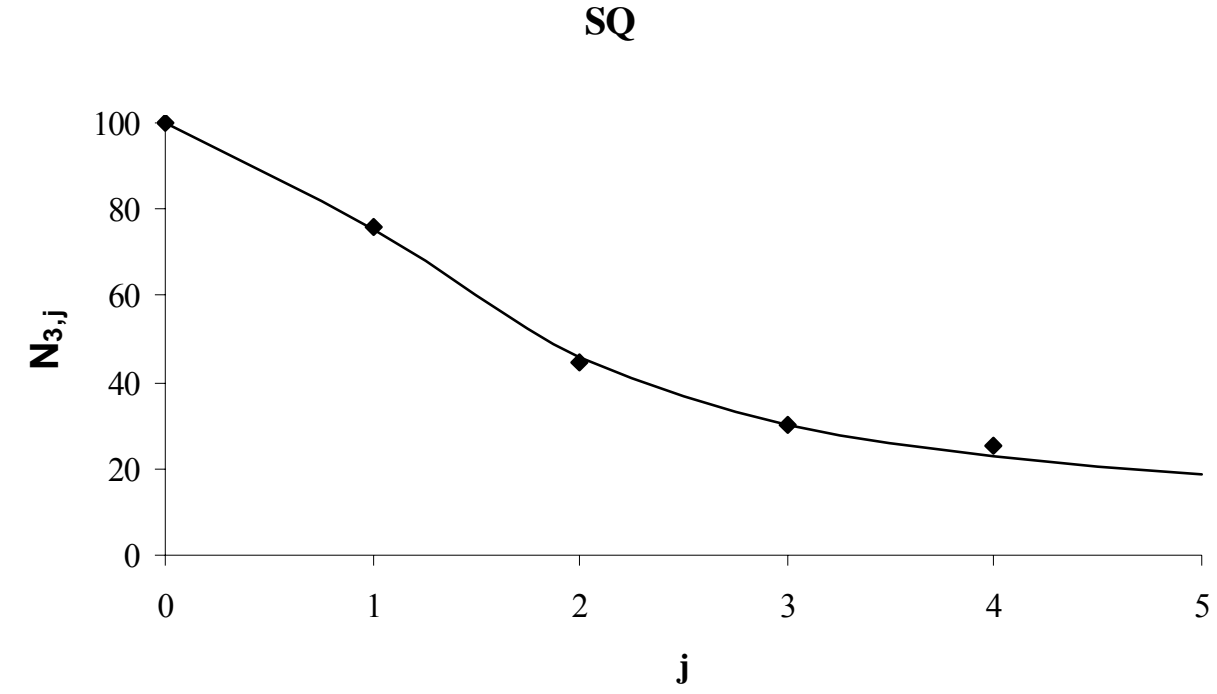

(a)

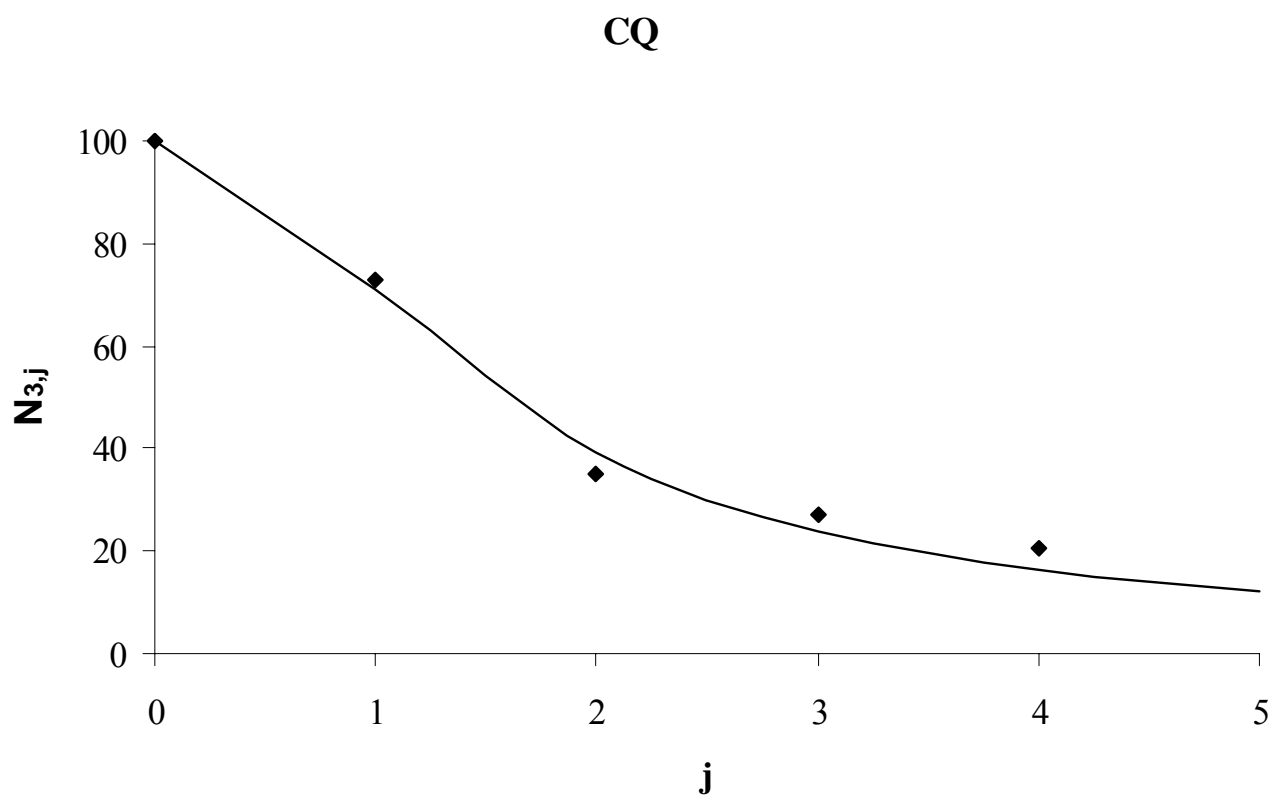

(b)

Figura 9 - Quantidade relativa de nitrogênio do fertilizante recuperado no sistema soloplanta $\left(\mathrm{N}_{3, j}\right)$ nos sistemas de manejo dos resíduos da cultura de cana-deaçúcar (a) sem queima (SQ) e (b) com queima (CQ), desde o plantio da cana-planta em $1997(j=0)$ até a colheita da quarta cana-soca em $2002(j=5)$. Valores observados ( $\square)$; valores estimados (-) 
SQ

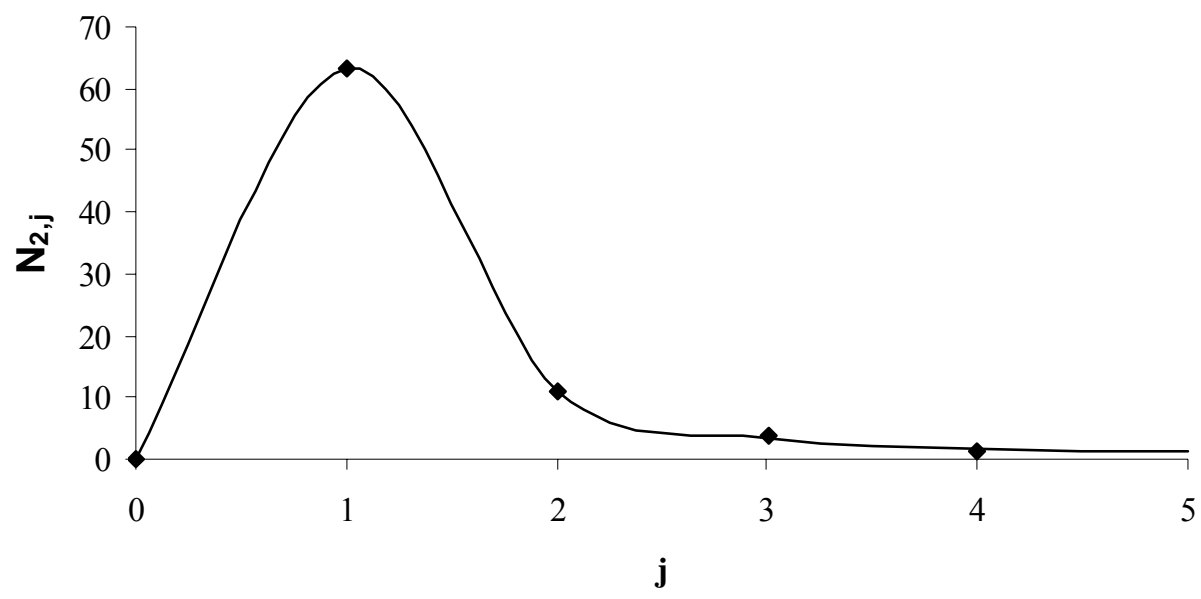

(a)

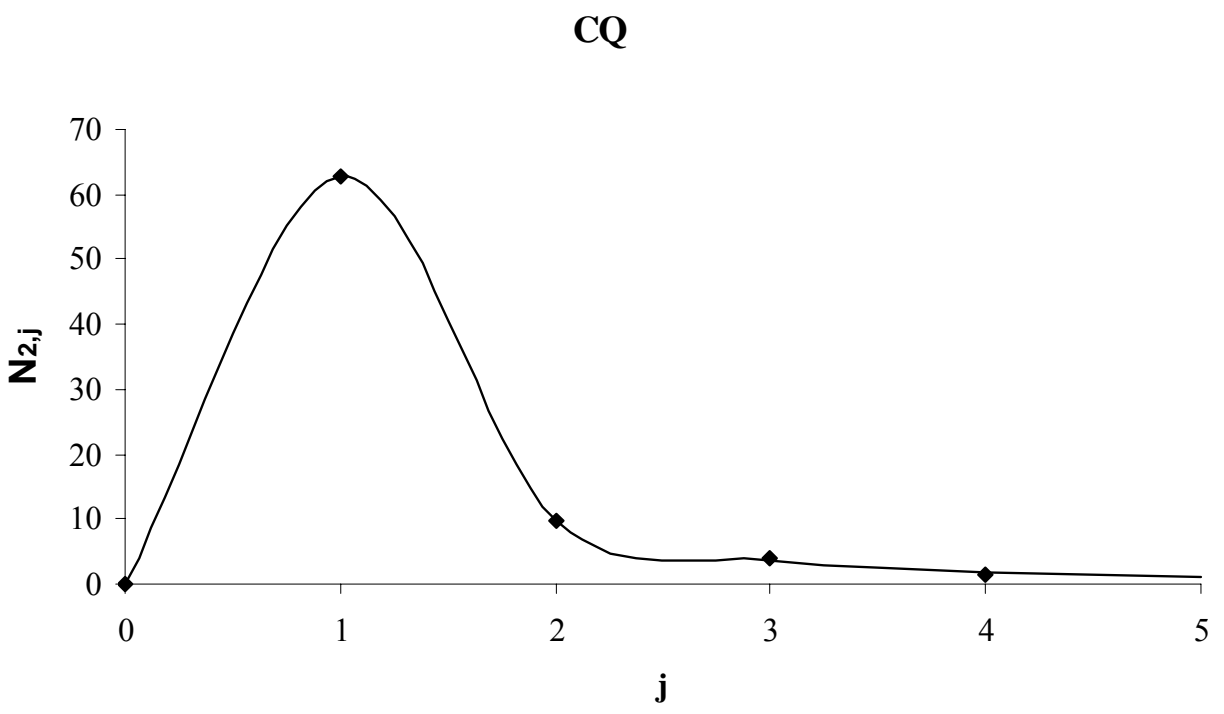

(b)

Figura 10 - Quantidade relativa de nitrogênio do fertilizante recuperado na planta $\left(\mathrm{N}_{2, \mathrm{j}}\right)$ nos sistemas de manejo dos resíduos da cultura de cana-de-açúcar (a) sem queima (SQ) e (b) com queima (CQ), desde o plantio da cana-planta em $1997(j=0)$ até a colheita da quarta cana-soca em $2002(j=5)$. Valores observados ( $\mathbf{\square})$; valores estimados (-) 


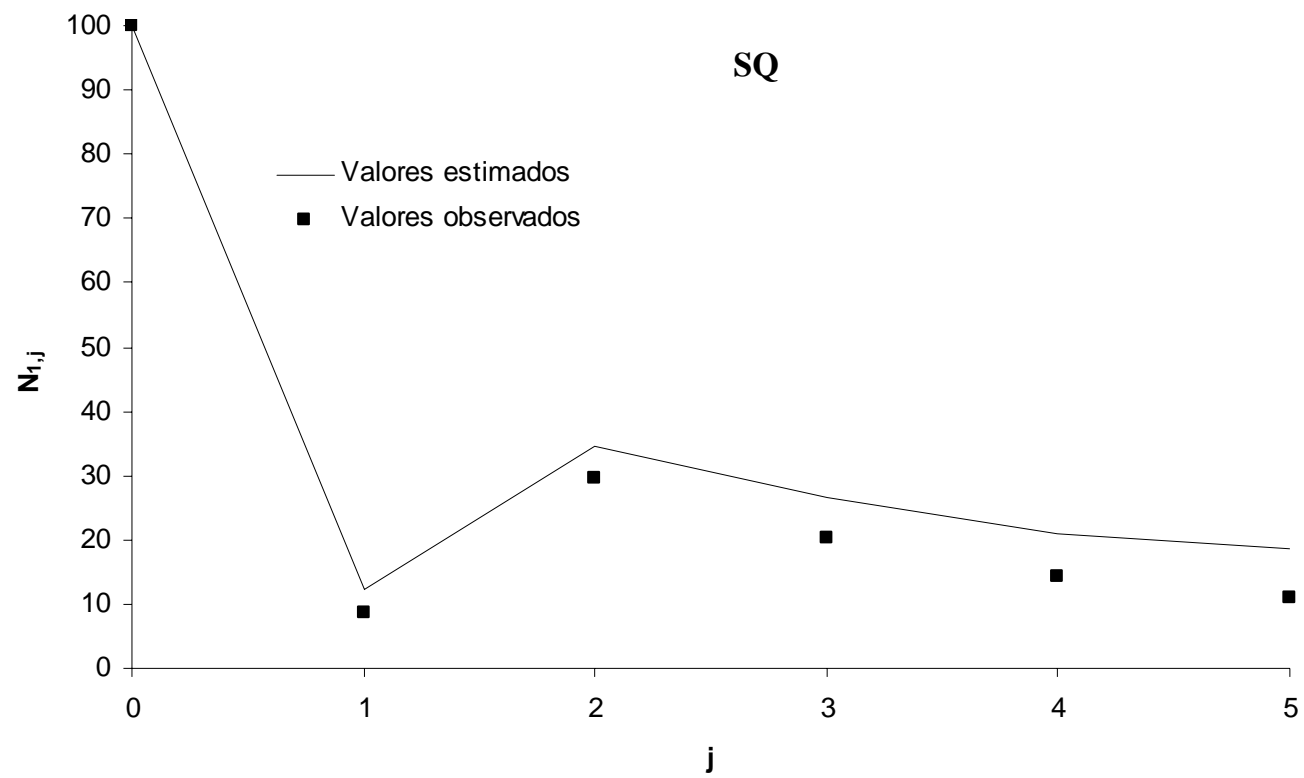

(a)

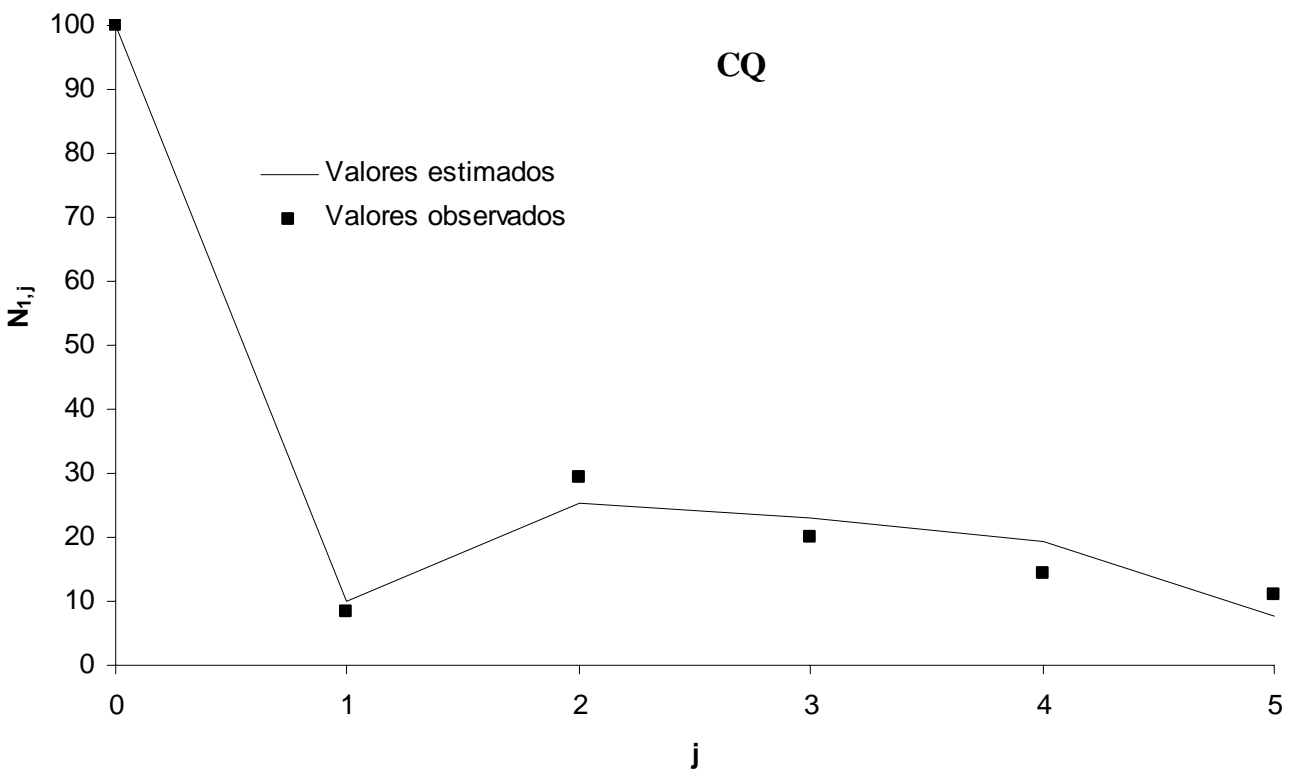

(b)

Figura 11 - Quantidade relativa de nitrogênio do fertilizante recuperado no solo $\left(\mathrm{N}_{1, \mathrm{j}}\right)$ nos sistemas de manejo dos resíduos da cultura de cana-de-açúcar (a) sem queima (SQ) e (b) com queima (CQ), desde o plantio da cana-planta em $1997(j=0)$ até a colheita da quarta cana-soca em $2002(j=5)$. Valores observados ( $\mathbf{\square})$; valores estimados (-) 


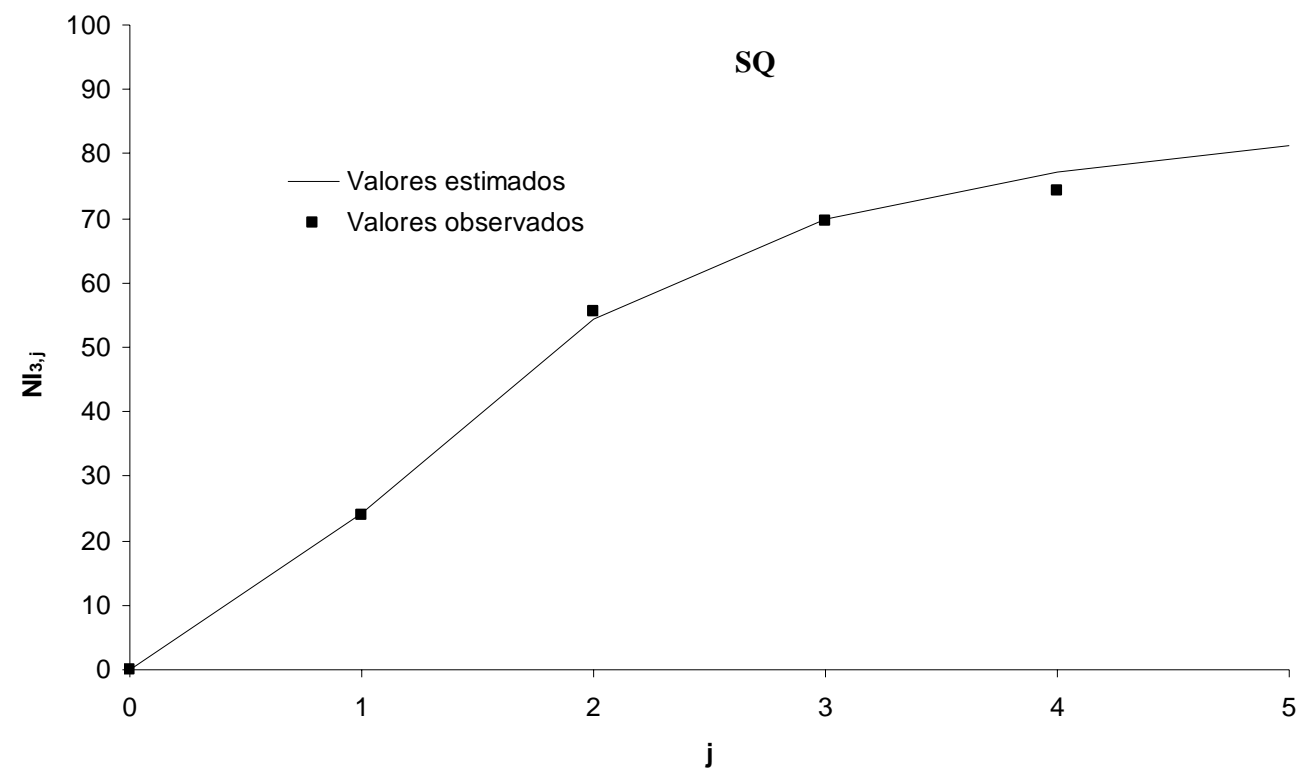

(a)

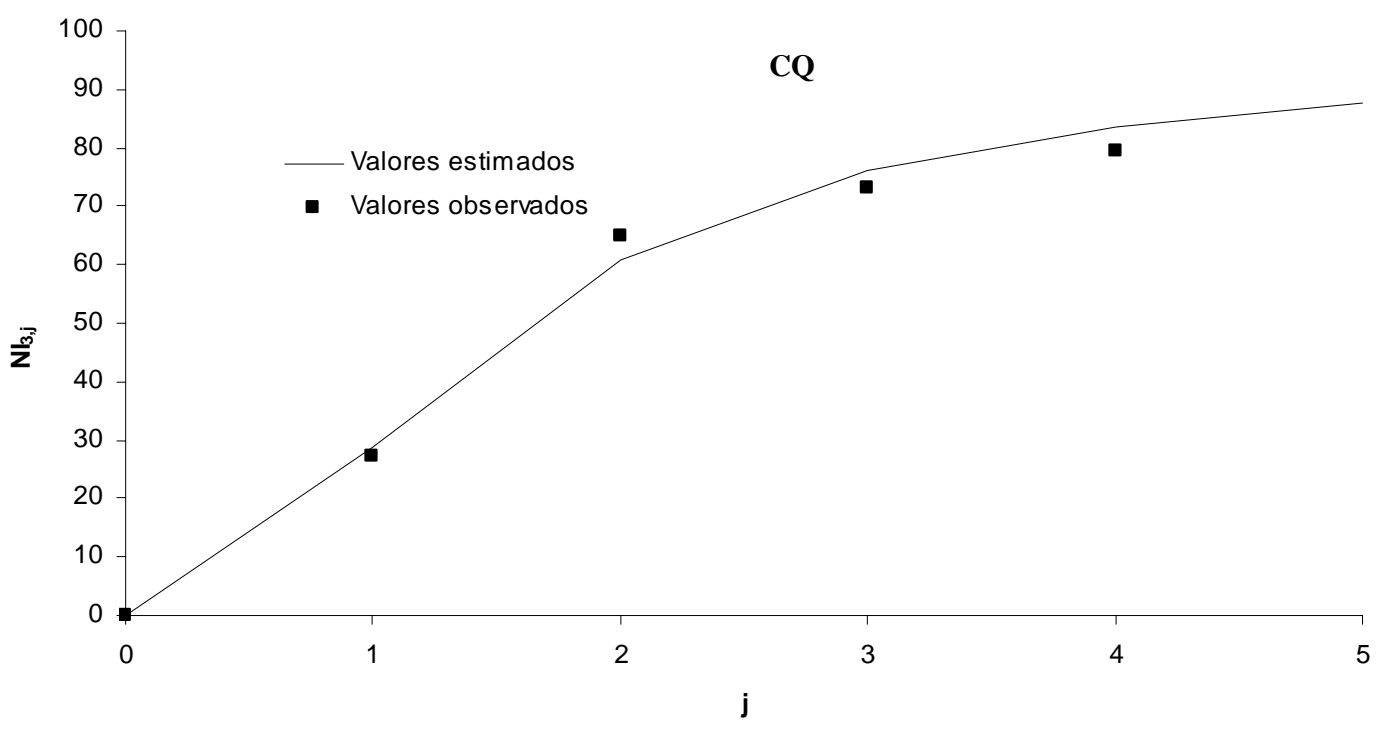

(b)

Figura 12 - Quantidade relativa de perdas de nitrogênio do fertilizante no sistema soloplanta $\left(\mathrm{Nl}_{3, j}\right)$ utilizando manejo dos resíduos da cultura de cana-de-açúcar (a) sem queima (SQ) e (b) com queima (CQ), desde o plantio de cana-planta em $1997(j=0)$ até a colheita da terceira cana-soca em $2002(j=5)$. Valores observados ( $\mathbf{\square})$; valores estimados (-) 

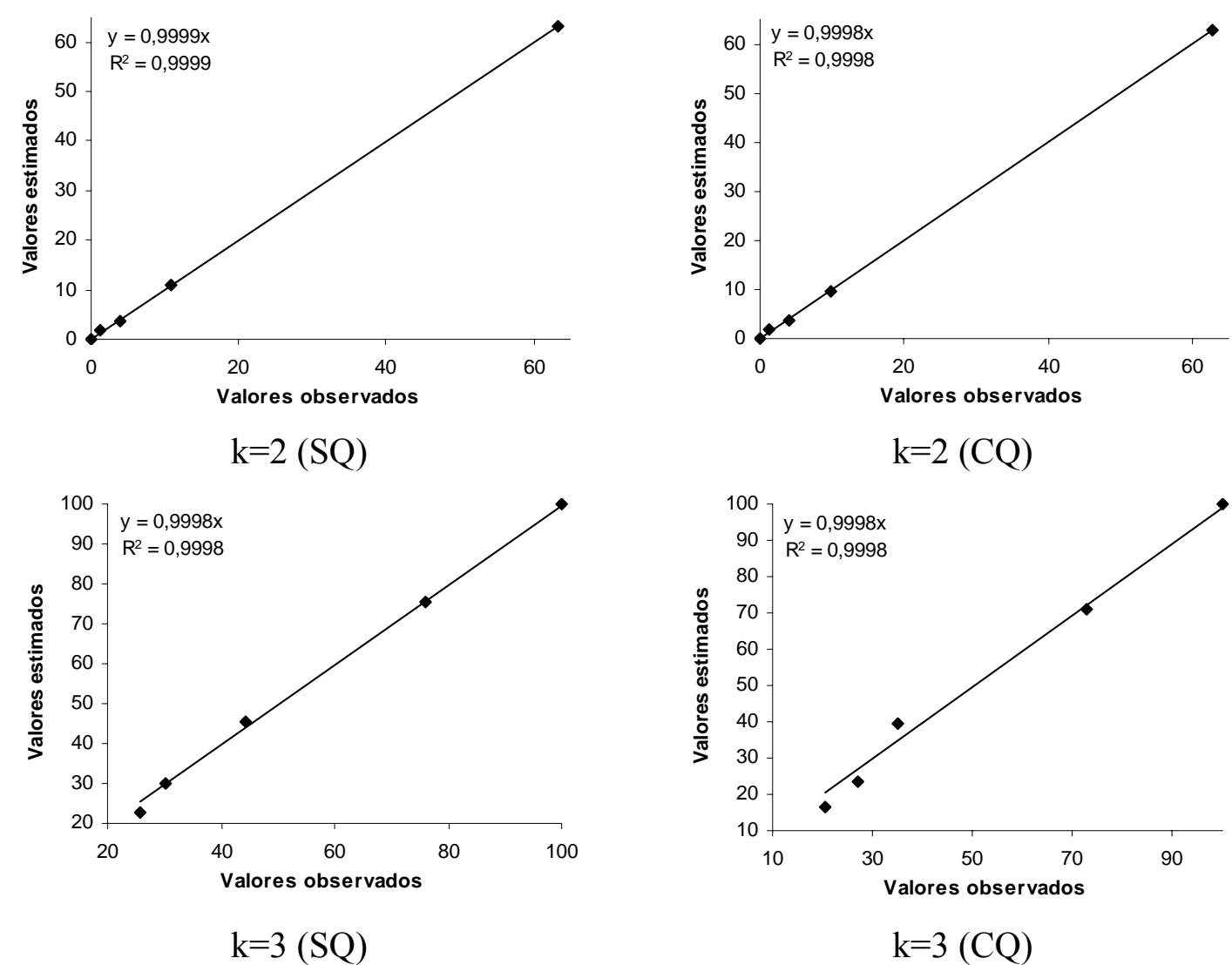

Figura 13 - Análise de comparação entre os resultados experimentais (valores observados) e dos modelos propostos (valores estimados) de nitrogênio derivado do fertilizante no compartimento planta $(\mathrm{k}=2)$ e no sistema soloplanta $(\mathrm{k}=3)$ utilizando manejo do resíduo da cultura de cana-de-açúcar sem queima (SQ) e com queima (CQ)

Foi realizada a representação gráfica do balanço de NddF no sistema SQ (Figura 14) e no sistema CQ (Figura 15) para os valores definidos com base nos resultados experimentais (A) e os valores definidos com base nas estimativas do modelo (B).

Pode ser observada diminuição do NddF no compartimento planta a partir de $\mathrm{j}=1$, sendo semelhante nos dois sistemas de manejo.

No solo, após a primeira cana-soca $(1<\mathrm{j} \leq 2)$, o $\mathrm{NddF}$ vai diminuindo a medida que o tempo passa, sendo o NddF remanescente superior em SQ. Conseqüentemente, as perdas de NddF do sistema solo-planta aumentam, sendo superiores no sistema CQ. 
SQ
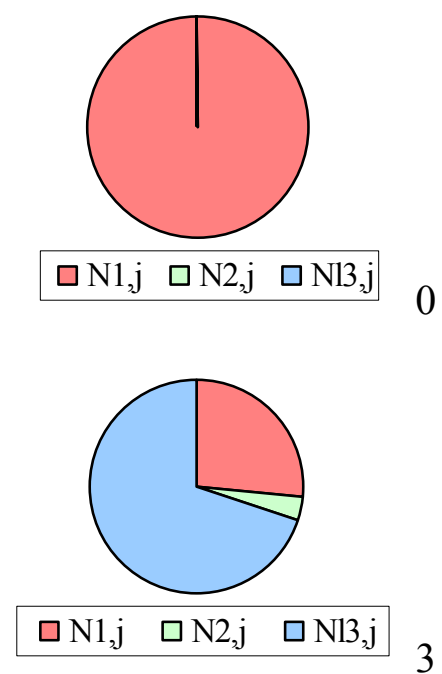

SQ
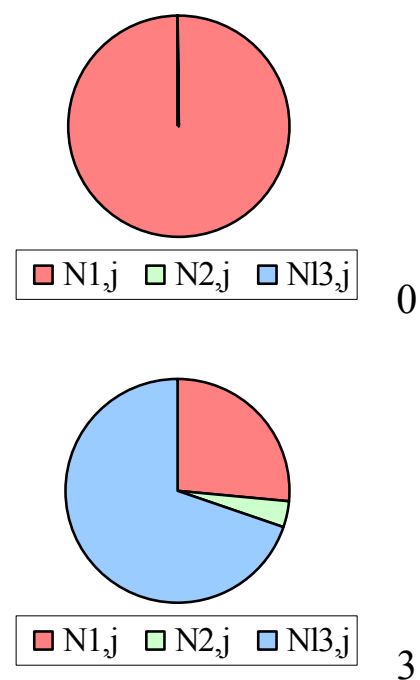

A
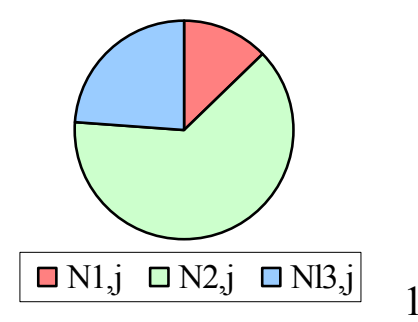

$\square \mathrm{N} 1, \mathrm{j} \quad \square \mathrm{N} 2, \mathrm{j} \quad \square \mathrm{N13,j} \quad 2$

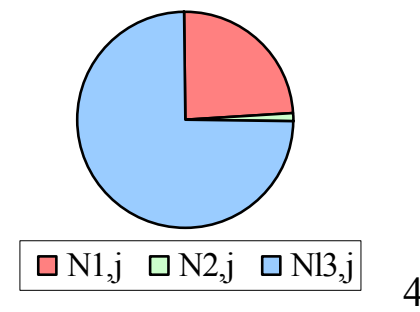

B
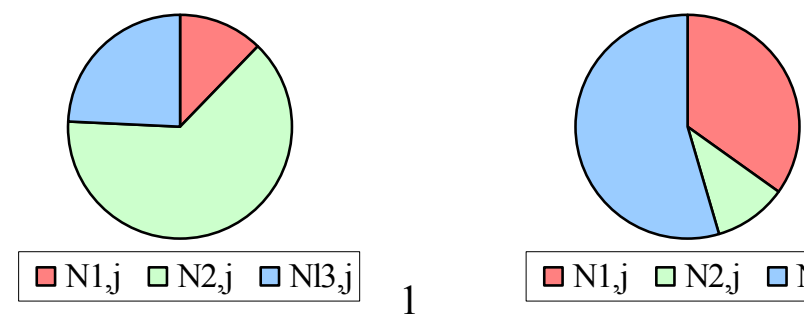

$\square \mathrm{N} 1, \mathrm{j} \quad \square \mathrm{N} 2, \mathrm{j} \quad \square \mathrm{N} 13, \mathrm{j}$

2
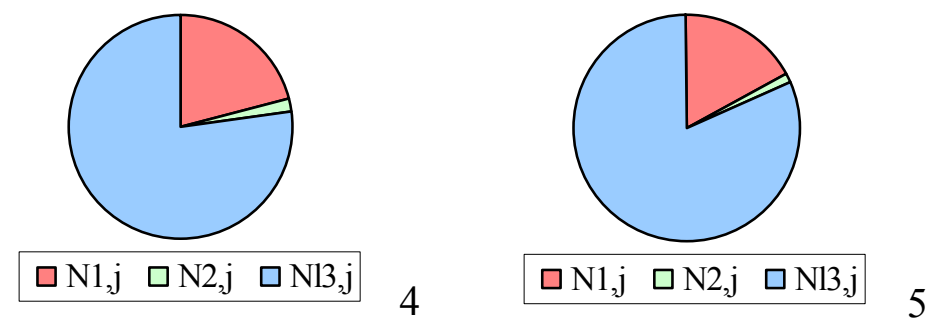

Figura 14 - Balanço de nitrogênio derivado do fertilizante no sistema solo-planta, especificando os compartimentos solo $\left(\mathrm{N}_{1, \mathrm{j}}\right)$ e planta $\left(\mathrm{N}_{2, \mathrm{j}}\right)$ e as perdas $\left(\mathrm{Nl}_{3, \mathrm{j}}\right)$, utilizando manejo do resíduo da cultura de cana-de-açúcar sem queima (SQ) nos anos 0 (plantio em 1997), 1 (colheita de cana-planta em 1998), 2 (colheita da primeira cana-soca em 1999), 3 (colheita da segunda cana-soca em 2000), 4 (colheita da terceira cana-soca em 2001) e 5 (colheita da quarta cana-soca em 2002): (A) valores definidos com base nos resultados experimentais, e (B) valores definidos com base nas estimativas do modelo 
CQ

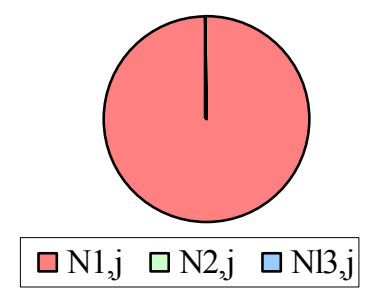

A

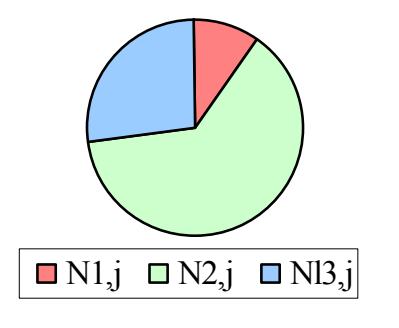

1

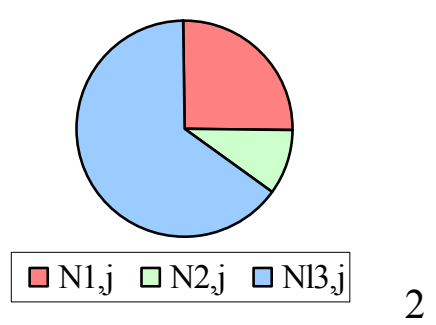

2

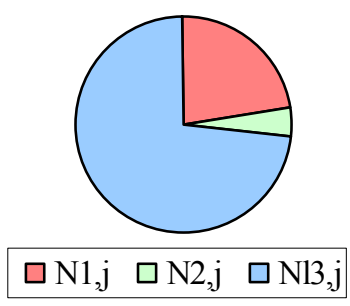

$\mathbf{C Q}$

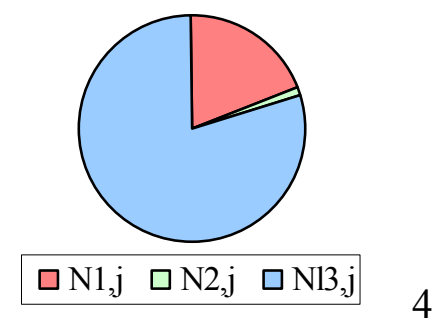

B
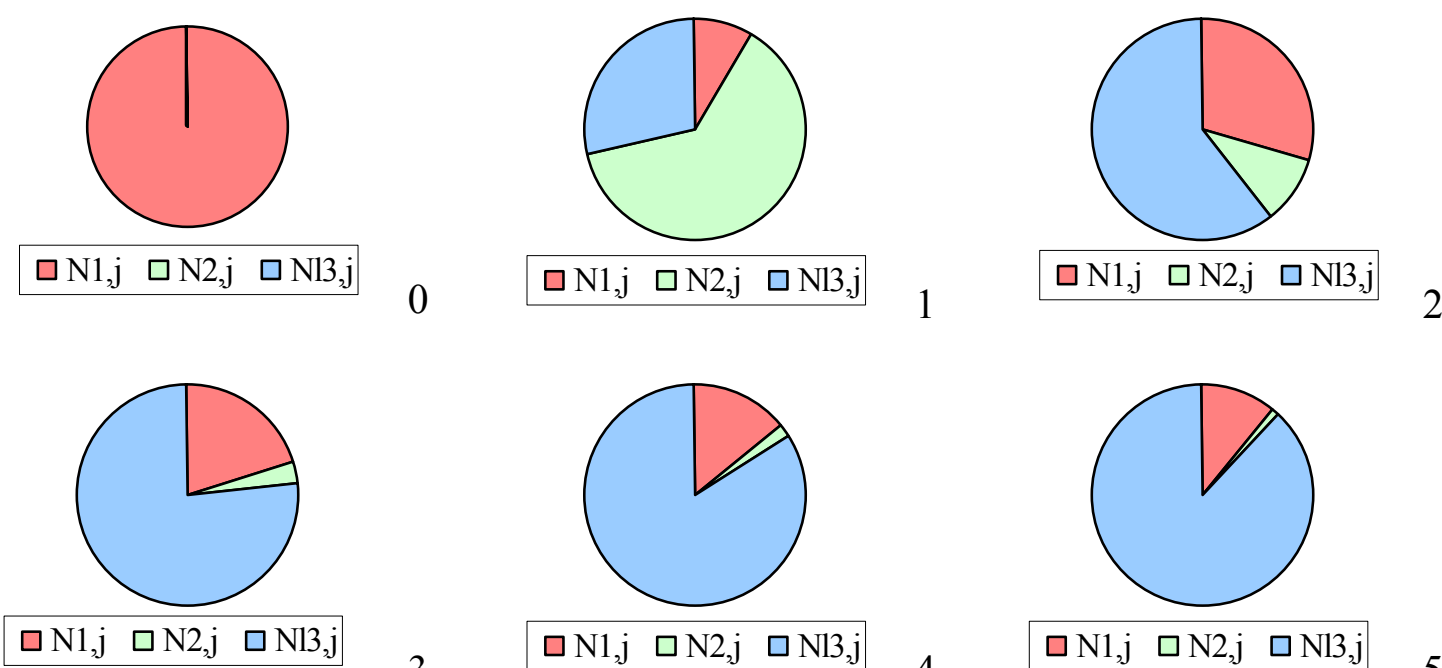

0
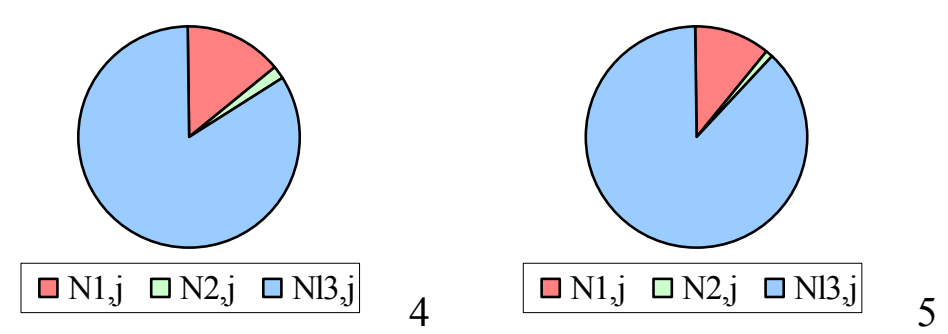

Figura 15 - Balanço de nitrogênio derivado do fertilizante no sistema solo-planta, especificando os compartimentos solo $\left(\mathrm{N}_{1, \mathrm{j}}\right)$ e planta $\left(\mathrm{N}_{2, \mathrm{j}}\right)$ e as perdas $\left(\mathrm{Nl}_{3, \mathrm{j}}\right)$, utilizando manejo do resíduo da cultura de cana-de-açúcar com queima (CQ) nos anos 0 (plantio em 1997), 1 (colheita de cana-planta em 1998), 2 (colheita da primeira cana-soca em 1999), 3 (colheita da segunda cana-soca em 2000), 4 (colheita da terceira cana-soca em 2001) e 5 (colheita da quarta cana-soca em 2002): (A) valores definidos com base nos resultados experimentais, e (B) valores definidos com base nas estimativas do modelo 
Com base nas estimativas do modelo, foi realizado o balanço de NddF para as colheitas da quinta $(\mathrm{j}=6)$, sexta $(\mathrm{j}=7)$ e sétima $(\mathrm{j}=8)$ cana-soca (Figura 16). Observa-se que o NddF no compartimento solo no sistema SQ é sempre superior ao do sistema CQ.

SQ

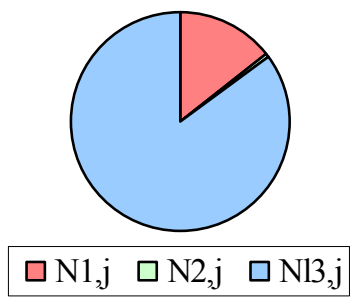

ano 6

CQ

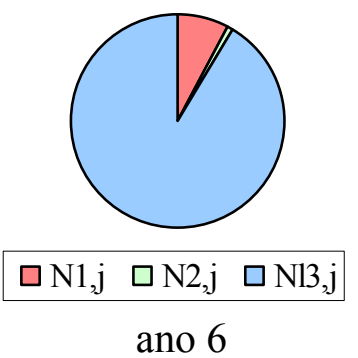

B

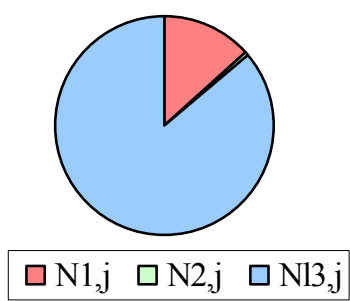

ano 7

B

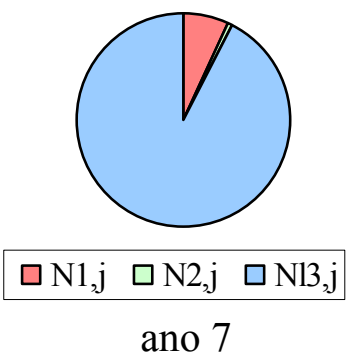

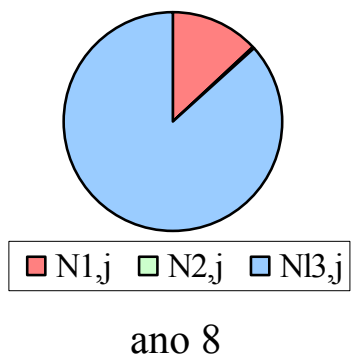

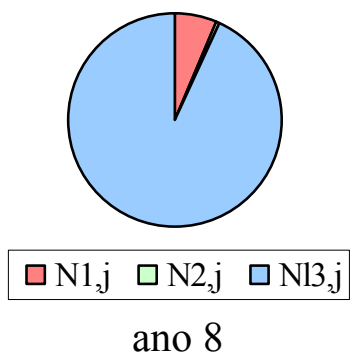

Figura 16 - Balanço de nitrogênio derivado do fertilizante no sistema solo-planta, especificando os compartimentos solo $\left(\mathrm{N}_{1, \mathrm{j}}\right)$ e planta $\left(\mathrm{N}_{2, \mathrm{j}}\right)$ e as perdas $\left(\mathrm{Nl}_{3, \mathrm{j}}\right)$, utilizando manejo do resíduo da cultura de cana-de-açúcar sem queima (SQ) e com queima (CQ). Previsão para os anos 6 (colheita da quinta cana-soca em 2003), 7 (colheita da sexta cana-soca em 2004), e 8 (colheita da sétima cana-soca em 2005): (B) valores definidos com base nas estimativas do modelo

\subsection{Considerações finais}

A adoção da colheita sem queima dos resíduos é, sem dúvida, uma prática de manejo necessária para a conservação do recurso solo e para a qualidade do ambiente. As práticas de manejo que não contemplam a reciclagem do material orgânico através 
dos resíduos das culturas, como é o caso da queima, ou que incorporam os resíduos vegetais ao solo favorecendo sua rápida mineralização (sistemas de cultivos tradicionais com revolvimento do solo), precisam ser substituídas por práticas que permitam um manejo mais racional e sustentável do sistema agrícola através do tratamento adequado dos resíduos das culturas, deixando-os na superfície do solo, e permitindo assim, a sua lenta incorporação à matéria orgânica do solo pelo processo de transformação microbiana.

Sendo que as recomendações de manejo da cana-de-açúcar foram formuladas com base no sistema tradicional de colheita com queima dos resíduos, muitas delas precisam ser reformuladas pensando na colheita de cana verde como um sistema diferente ao tradicional, com características muito semelhantes ao sistema de plantio direto usado para culturas anuais. Isso se evidencia na necessidade de aumentar as doses da adubação nitrogenada já que o elevado conteúdo de carbono da palhada de cana-deaçúcar é uma fonte rica em energia para aumentar a atividade dos microorganismos do solo, resultando na imobilização do nitrogênio mineral.

Sendo a matéria orgânica responsável por variações importantes nas propriedades físicas, químicas e biológicas do solo, ela se constitui em um dos parâmetros mais aceitos para a avaliação da sustentabilidade de um determinado uso da terra ou manejo do solo. Por esse motivo, faz-se necessário acrescentar as pesquisas sobre manejos alternativos da cana que aproveitem as vantagens de manter os resíduos da cultura no sistema.

É importante observar que a duração do experimento (fator temporal) e a profundidade de solo estudada (fator espacial) são duas variáveis decisivas para detectar diferenças no carbono e nitrogênio do solo entre os sistemas de manejo com e sem queima dos resíduos. Provavelmente a duração do presente experimento não tenha sido suficientemente longa como para detectar as possíveis diferenças na quantidade e distribuição de $\mathrm{C}$ e $\mathrm{N}$ total no solo. Além disso, o fato das mensurações terem sido feitas na camada superficial de 0 a $15 \mathrm{~cm}$, pode ter mascarado as diferenças ocorridas na camada mais superficial (primeiros centímetros do solo), onde geralmente ocorre as 
mudanças induzidas pelo manejo dos resíduos, principalmente durante os primeiros anos de implantação do sistema. 


\section{CONCLUSÕES}

A retenção no sistema dos resíduos de cana-de-açúcar promoveu uma redução média de $18 \%$ na produtividade de colmos em relação ao tratamento com queima prévia à colheita. A produtividade de colmos nas quatro canas-soca foi significativamente inferior $(\mathrm{p}<0,05)$ no sistema sem queima dos resíduos.

O potencial de reciclagem de nitrogênio no sistema de colheita sem queima dos resíduos culturais foi em média de $83,3 \mathrm{~kg} \cdot \mathrm{ha}^{-1} \cdot \mathrm{ano}^{-1}$, correspondendo a $65 \%$ do total de nitrogênio contido na parte aérea da cultura.

O potencial de perdas de nitrogênio no sistema de colheita com queima dos resíduos foi em média de $74 \mathrm{~kg} \cdot \mathrm{ha}^{-1} \cdot \mathrm{ano}^{-1}$, correspondendo a $85 \%$ do nitrogênio da parte aérea. Essa quantidade de nitrogênio perdido para a atmosfera representou $75 \%$ do total de nitrogênio contido nos resíduos.

Até o final do primeiro ciclo da cultura (colheita da cana-planta), em média, 74\% do nitrogênio do fertilizante foi recuperado no sistema solo-planta, sendo que a maior parte $(63 \%)$ encontrava-se na parte aérea da cultura.

O nitrogênio do fertilizante recuperado na parte aérea da cultura decresceu exponencialmente com o tempo. Na colheita da terceira cana-soca, na planta foi recuperado apenas $1,3 \%$ (menos de $\left.1 \mathrm{~kg} \cdot \mathrm{ha}^{-1}\right)$.

Nos dois sistemas de manejo (com e sem queima dos resíduos) o nitrogênio derivado do fertilizante no solo aumentou do primeiro ano (cana-planta) para o segundo ano (primeira cana-soca). Porém, foi significativamente superior $(\mathrm{p}<0,05)$ quando os resíduos culturais não foram queimados.

A recuperação pelo sistema solo-planta do nitrogênio derivado dos resíduos durante os quatro ciclos de cana-soca foi em média de $45 \%$ (76 kg.ha ${ }^{-1}$ ), dos quais, em 
torno de $95 \%$ ficaram imobilizados no solo, permanecendo no sistema ainda no final da colheita de 2002, quatro anos depois da disposição dos resíduos nas parcelas.

Não foram constatadas diferenças significativas entre os sistemas de manejo com queima e sem queima no conteúdo de carbono orgânico total do solo durante os cinco anos do experimento. Porém, os conteúdos de carbono foram sempre superiores no sistema sem queima dos resíduos.

Os conteúdos de carbono e nitrogênio nas frações granulométricas do solo apresentaram valores crescentes com a diminuição do tamanho de partícula seguindo a seguinte ordem: Fsa $>$ Fom $>$ Fl. Mais de $70 \%$ do carbono e do nitrogênio do solo encontraram-se na fração Fsa. 


\section{REFERÊNCIAS BIBLIOGRÁFICAS}

ABRAMO FILHO, J.; MATSUOKA, S.; SPERANDIO, M.L.; RODRIGUES, C.D.; MARCHETTI, L.L. Resíduos da colheita mecanizada de cana crua. Álcool \& Açúcar, n.67, p.23-25, 1993.

ALBRECHT, A.; RANGON, L.; BARRET, P. Effet de la matiére organique sur la stabilité structurale et la détachabilité d'un Vertisol et d'un Ferrisol (Martinique). Cahiers ORSTOM, Série Pédologie, v.27, p.121-133, 1992.

ALEXANDER, M.I.H. Introduction to soil microbiology. 4 ed. New York: John Wiley, 1977. 472p.

ALLISON, L.E. Organic carbon. In: BLACK, C.A. (Ed.). Methods of soil analysis. Madison: American Society of Agronomy, 1965. p.1367-1378.

ANGERS, D.A.; RECOUS, S.; AITA, C. Fate of carbon and nitrogen in water-stable aggregates during decomposition of wheat straw in situ. European Journal of Soil Science, v. 48, p.295-300, 1997.

AXMANN, H.; ZAPATA, F. Stable and radioactive isotopes. In: HARDARSON, G. (Ed.). Use of nuclear techniques in studies of soil-plant relationships. Vienna: IAEA, 1990. p.9-34 (Training Course Series, 2).

BALESDENT, J.; PETRAUD, J.P.; FELLER, C. Effet des ultrasons sur la distribution granulométrique des mattiéres organiques des sols. Science du Sol, v.29, p.95-106, 1991.

BALL-COELHO, B.; TIESSEN, H.; STEWART, J.W.B.; SALCEDO, I.H.; SAMPAIO, E.V.S.B. Residue management effects on sugarcane yield and soil properties in Northeastern Brazil. Agronomy Journal, v.85, p.1004-1008, 1993. 
BARRIE, A.; PROSSER, J.S. Automated analysis of light-element stable isotopes by isotope mass spectrometry. In: BOUTTON, W.T.; YAMASAKI, S. (Ed.). Mass spectrometry of soils. New York: Marcel Dekker, 1996. p.1-47.

BIEDERBECK, V.O.; CAMPBELL, C.A.; BOWREN, K.E.; SCHNITZER, M.; MCIVER, R.N. Effect of burning cereal straw on soil properties and grain yields in Saskatchewan. Soil Science Society of America Journal, v.44, p.103-111, 1980.

BLAIR, N. Impact of cultivation and sugar-cane green trash management on carbon fractions and aggregate stability for a Chromic Luvisol in Queensland, Australia. Soil and Tillage Research, v.55, p.183-191, 2000.

BLAIR, G.J.; CHAPMAN, L.; WHITBREAD, A.M.; BALL-COELHO, B.; LARSEN, P.; TIESSEN, H. Soil carbon changes resulting from sugarcane trash management at two locations in Queensland, Australia, and in North-East Brazil. Australian Journal of Soil Research, v.36, p.873-881, 1998.

BOERNER, R.E.J. Fire and nutrient cycling in temperate ecosystems. Bioscience, v.32, p.187-192, 1982.

BRADY, N.C. Natureza e propriedades dos solos. 7.ed. Rio de Janeiro: Freitas Bastos, 1989. $878 \mathrm{p}$.

BREMNER, J.M. Isotope-ratio analysis of nitrogen in nitrogen-15 tracer investigations. In: BLACK, C.A. (Ed.). Methods of soil analysis. Part. 2. Madison: American Society of Agronomy, 1965. p.1256-1286.

CAMPBELL, C.A.; ZENTNER, R.P. Soil organic matter as influenced by crop rotations and fertilization. Soil Science Society of America Journal, v.57, p.1034-1040, 1993.

CAMPOS, D. de C. Potencialidade do sistema de colheita sem queima da cana-deaçúcar para o seqüestro de carbono. Piracicaba, 2003. 103p. Tese (Doutorado) Escola Superior de Agricultura “Luiz de Queiroz”, Universidade de São Paulo.

CANTARELLA, H. Adubação nitrogenada em sistema de cana crua. STAB Açúcar, Álcool e Subprodutos, v.16, n.4, p.21-22, 1998. 
CARNAÚBA, B.A.A. Eficiência de utilização e efeito residual da uréia- ${ }^{15} \mathrm{~N}$ em cana-deaçúcar (Saccharum spp), em condições de campo. Piracicaba, 1989. 193p. Dissertação (Mestrado) - Escola Superior de Agricultura "Luiz de Queiroz", Universidade de São Paulo.

CARVALHO, G.J.; ANDRADE, L.A.B.; ANJOS, I.A.; FIGUEIREDO, P.A.M. Efeito dos restos culturais da colheita, com e sem queima prévia, na rebrota e rendimento de soqueiras de cana-de-açúcar. STAB Açúcar, Álcool e Subprodutos, v.15, n.1, p.27, 1996. /Apresentado ao 6. Congresso Nacional da STAB, Maceió, 1996 - Resumo.

CERRI, C.C.; EDUARDO, B.P.; PICCOLO, M.C. Métodos de análises em matéria orgânica do solo. Piracicaba: Centro de Energia Nuclear na Agricultura - USP, 1990. $78 \mathrm{p}$.

CHAN, Y.; WENG, T. Use of ${ }^{15} \mathrm{~N}$ to study the efficacy of nitrogen for sugarcane; nitrogen recovery on spring planting cane. Taiwan Sugar, v.50, n.5, p.161-164, 1983.

CHAN, K.Y.; HEENAN, D.P.; OATES, A. Soil carbon fractions and relationship to soil quality under different tillage and stubble management. Soil and Tillage Research, v.63, p.133-139, 2002.

CHAPMAN, L.S.; HAYSOM, M.B.C. Nitrogen fertilisation for field with sugar cane crop residues. In: AUSTRALIAN SOCIETY OF SUGAR CANE TECHNOLOGISTS, 13., Bundaberg, 1991. Proceedings. Bundaberg: Watson Ferguson, 1991. p.53-58.

CHAPMAN, L.S.; HAYSOM, M.B.C.; SAFFIGNA, P.G. The recovery of ${ }^{15} \mathrm{~N}$ from labelled urea fertilizer in crop components of sugarcane and in soil profiles. Australian Journal of Agricultural Research, v.45, p.1577-1585, 1994.

CHRISTENSEN, B.T. Decomposability of organic matter in particle size fractions from field soils with straw incorporation. Soil Biology and Biochemistry, v.19, n.4, p.429435, 1987.

CHRISTENSEN, B.T. Physical fractionation of soil and organic matter in primary particle size and density separates. Advances in Soil Science, v.20, p.1-87, 1992. 
COLLINS, H.P.; RASMUSSEN, P.E.; DOUGLAS JR., C.L. Crop rotation and residue management effects on soil carbon and microbial dynamics. Soil Science Society of America Journal, v.56, p.783-788, 1992.

COURTAILLAC, N.; BARAN, R.; OLIVER, R.; CASABIANCA, H.; GANRY, F. Efficiency of nitrogen fertilizer in the sugarcane-vertisol system in Guadeloupe according to growth and ratoon age of the cane. Nutrient Cycling in Agroecosystems, v.52, p.9-17, 1998.

CZIMCZIK, C.L.; PRESTON, C.M.; SCHMIDT, M.W.I.; SCHULZE, E.D. How surface fire in Siberian Scots pine forests affects soil organic carbon in the forest floor: Stocks, molecular structure, and conversion to black carbon (charcoal). Global Biogeochemical Cycles, v.17, p.1-14, 2003.

DELGADO, A.A. Os efeitos da queima dos canaviais. STAB-Açúcar, Álcool e Subprodutos, v.3, n.6, p.42-45, 1985.

DENMEAD, O.T.; FRENEY J.R.; JACKSON A.V.; SMITH, J.W.B.; SAFFIGNA, P.G.; D, A.W.; CHAPMAN, L.S. Volatilization of ammonium from urea and ammonium sulfate applied to sugarcane trash in north Queensland. In: CONFERENCE OF THE AUSTRALIAN SOCIETY OF SUGAR CANE TECHNOLOGISTS, Brisbane, 1990. Proceedings. Brisbane: Watson Ferguson, 1990. p.38-43.

DOURADO NETO, D.; TIMM, L.C.; OLIVEIRA, J.C.M.; REICHARDT, K.; BACCHI, O.O.S.; TOMINAGA, T.T.; CÁSSARO, F.A.M. State-space approach for the analysis of soil water content and temperature in a sugarcane crop. Scientia Agricola, v.56, p.1215-1221, 1999.

EMPRESA BRASILEIRA DE PESQUISA AGROPECUÁRIA. Centro nacional e pesquisa de solo. Sistema brasileiro de classificação de solos. Rio de Janeiro, 1999. 412p.

EVANS, J.O. Soil as sludge assimilators. Compost Science, v.14, n.6, p.16-21, 1973. 
FARONI, C.E.; VITTI, A.C.; GAVA, G.J.C.; MANZONI, C.S.; PENATTI, C.P.; TRIVELIN, P.C.O. Degradação da palhada $\left({ }^{15} \mathrm{~N}\right)$ de cana-de-açúcar em dois anos consecutivos (compact disc). In: CONGRESSO BRASILEIRO DE CIÊNCIA DO SOLO, 19; Ribeirão Preto, 2003. Anais. Ribeirão Preto: Sociedade Brasileira de Ciência do Solo, 2003.

FELLER, C. Une méthode de fractionement granulometrique de la matière organique des sols. Applicacion aux sols tropicaux a textures grossières, très pauvres en humus. Cahiers ORSTOM, Série Pédologie, v.17, n.4, p.339-346, 1979.

FELLER, C. Organic inputs, soil organic matter and functional soil organic compartments in low activity clay soils in tropical zones. In: MULONGOY, K.; MERCKX, R. (Ed.). Soil organic matter dynamics and sustainability of tropical agriculture. Chichester: John Wiley, 1993. p.77-88.

FELLER, C. La matière organique dans le sols tropicaux à argiles 1:1. Recherche de compartiments organiques fonctionnels. Une approche granulométrique. Strasbourg, 1994. 393p. Thèse (Doctorate) - Universitè Strasbourg.

FELLER, C.; BEARE, M.H. Physical control of soil organic matter dynamics in the tropics. Geoderma, v.79, p.69-116, 1997.

FNP CONSULTORIA \& AGRO-INFORMATIVO. AGRIANUAL 2004: anuário da agricultura brasileira. São Paulo, 2003. 496p.

FURLANI NETO, V.L.; RIPOLI, T.C.; VILLA NOVA, N.A. Biomassa de cana-deaçúcar: energia contida no palhiço remanescente de colheita mecânica. STABAçúcar, Álcool e Subprodutos, v.15, n.4, p.24-27, 1997.

GAVA, G.J.C. Utilização do nitrogênio da uréia $\left({ }^{15} \mathrm{~N}\right)$ e da palhada $\left({ }^{15} \mathrm{~N}\right)$ por soqueira de cana-de-açúcar no manejo sem despalhada a fogo. Piracicaba, 1999. 81p. Dissertação (Mestrado) - Escola Superior de Agricultura “Luiz de Queiroz”, Universidade de São Paulo. 
GAVA, G.J.C.; TRIVELIN, PC.O.; VITTI, A.C.; OLIVEIRA, M.W. Balanço do nitrogênio da uréia $\left({ }^{15} \mathrm{~N}\right)$ e da palhada $\left({ }^{15} \mathrm{~N}\right)$ no sistema solo-cana-de-açúcar (canasoca). In: CONGRESSO NACIONAL DA SOCIEDADE DOS TECNICOS AÇÚCAREIROS E ALCOOLEIROS DO BRASIL, 8., Recife, 2002. Anais. Olinda: STAB, 2002. p.245-251.

GRAHAM, M.H.; HAYNES, R.J.; MEYER, J.H. Soil organic matter content and quality: effects of fertilizer applications, burning and trash retention on a long-term sugarcane experiment in South Africa. Soil Biology and Biochemistry, v.34, p.93$102,2002$.

GREENLAND, D.J. Interaction between clays and organic compounds in soils. Part I. Mechanisms of interaction between clays and defined organic compounds. Soils Fertility, v.28, p.415-425, 1965a.

GREENLAND, D.J. Interaction between clays and organic compounds in soils. Part II. Adsorption of soil organic compounds and this effect on soil properties. Soils Fertility, v.28, p.521-532, 1965 b.

HARMSEN, G.W.; VAN SCHREVEN, D.A. Mineralization of organic nitrogen in the soil. Advances in Agronomy, v.7, p.299-398, 1955.

HART, S.C.; MYROLD, D.D. ${ }^{15} \mathrm{~N}$ tracer studies of soil nitrogen transformations. In: BOUTTON, W.T.; YAMASAKI, S. (Ed.). Mass spectrometry of soils. New York: Marcel Dekker, 1996. p.225-245.

HAUCK, R.D. Nitrogen - Isotope ratio analysis. In: PAGE, A.L.; MILLER, R.H.; KEENEY, D.R. (Ed.). Methods of Soil Analysis. 2. ed. Madison: American Society of Agronomy, 1982. cap. 4, p.735- 802.

HAUCK, R.D.; BREMNER, J.M. Use of tracers for soil and fertilizer nitrogen research. Advances in Agronomy, v.28, p.219-266, 1976.

HSIEH, Y.P. Pool size and mean age of stable organic carbon in cropland. Soil Science Society of America Journal, v.56, p.460-464, 1992.

INTERGOVERNMENTAL PANEL ON CLIMATE CHANGE. Climate change in 1994: radioactive forcing of climate change. Cambridge: Cambridge University Press, 1995. 339p. 
INTERNATIONAL ATOMIC ENERGY AGENCY. Tracer manual on crops and soils. Vienna: IAEA, 1976. 277p. (Technical Reports Series, 171).

INTERNATIONAL ATOMIC ENERGY AGENCY. A guide to the use of nitrogen-15 and radioisotopes in studies of plant nutrition: calculations and interpretation of data. A technical document issued by the International Atomic Agency, Vienna: IAEATECDOC-288, 1983.63p.

JENKINSON, D.S. Studies on the decomposition of 14-C labelled organic matter in soil. Soil Science, v.111, p.64-70, 1971.

LARSON, W.E.; CLAPP, C.E.; PIERRE, W.H.; MORACHAN, Y.B. Effects of increasing amounts of organic residue on continuous corn: II Organic carbon, nitrogen, phosphorus, and sulphur. Agronomy Journal, v.64, p.204-208, 1972.

LOVETT, J.V.; HURNEY, A.P. Allelopathy: a possible contributor to yield decline in sugar cane. Plant Protection Quarterly, v.17, p.180-182, 1992.

MARTEL, Y.A.; PAUL, E.A. Effects of cultivation on the organic matter of grassland soils as determined by fractionation and radiocarbon dating. Canadian Journal of Soil Science, v.54, p.419-426, 1974.

McINTYRE, G.; SEERUTTUN, S.; BARBE, C. Trash management in Mauritian sugarcane plantations. In: COCK, J.H.; BREKELBAUM, T. (Ed). INTERNATIONAL SOCIETY OF SUGAR CANE TECHNOLOGISTS CONGRESS, 22., Cartagena, 1995. Proceedings. Cali: Tecnicaña, 1996. p.213-216.

MINISTÉRIO DA CIÊNCIA E TECNOLOGIA. A cana-de-açúcar no Brasil. http://www.mct.gov.be/clima/comunic_old/cana3.htm. (30/01/2004).

MONNIER, G.; TURC, L.; JEANSIN-LUUSINANG, C. Une méthode de fractionnament densimétrique par centrifugation des matières organiques $\mathrm{du}$ sol. Annales Agronomiques, v.13, p.55-63, 1962.

MYERS, R.J.K.; PALM, C.A.; CUEVAS, E.; GUNATILLEKE, I.U.N, BROSSARD, M. The synchronization of nutrient mineralization and plant nutrient demand. In: WOOMER, PL.; SWIFT, M.J. (Ed.). The biological management of tropical soil fertility. Chichester: Wiley, 1994. p.81-116. 
NG KEE KWONG, K.F.; DEVILLE, J.; CAVALOT, P.C.; RIVIERE, V. Value of cane trash in nitrogen nutrition of sugarcane. Plant and Soil, v.102, p.79-83, 1987.

OJIMA D.S.; SCHIMEL, D.S.; PARTON, W.J.; OWENSBY, C.E. Long- and shortterm effects of fire on nitrogen cycling in tall grass prairie. Biogeochemistry, v.24, p.67-84, 1994.

OLIVEIRA, M.W.; TRIVELIN, P.C.O.; BOARETTO, A.E.; MURAOKA, T.; MORTATTI, J. Leaching of nitrogen, potassium, calcium and magnesium in a sandy soil cultivated with sugarcane. Pesquisa Agropecuária Brasileira, v.37, n.6, p.861$868,2002$.

OLIVEIRA, J.C.M.; TIMM, L.C.; TOMINAGA, T.T.; CÁSSARO, F.A.M.; REICHARDT, K.; BACCHI, O.O.S.; DOURADO-NETO, D.; CÂMARA, G.M. DE S. Soil temperature in a sugarcane crop as function of the management system. Plant and Soil, v.230, p.61-66, 2000.

OLIVEIRA, M.W.; TRIVELIN, P.C.O.; PENATTI, C.P.; PICCOLO, M.C. Decomposição e liberação de nutrientes da palhada de cana-de-açúcar em campo. Pesquisa Agropecuária Brasileira, v.34, n.12, p.2359-2362, 1999a.

OLIVEIRA, M.W.; TRIVELIN, P.C.O.; GAVA, G.J.C.; PENATTI, C.P. Degradação da palhada de cana-de-açúcar. Scientia Agrícola, v.56, n.4, p.803-809, 1999b.

PADOVESE, P.P. Movimento e perdas de nitrogênio e potássio num solo com cana-deaçúcar (Saccharum spp.). Piracicaba, 1988. 118p. Dissertação (Mestrado) - Escola Superior de Agricultura “Luiz de Queiroz”, Universidade de São Paulo.

RASMUSSEN, P.E.; ALLMARAS, R.R.; ROHDE, C.R.; ROAGER JUNIOR, N.C. Crop residue influences on soil carbon and nitrogen in a wheat-fallow system. Soil Science Society of America Journal, v.44, p.596-600, 1980.

REICHARDT, K.; LIBARDI, P.L.; URQUIAGA, S.C. Fate of fertilizer nitrogen in soilplant system with emphasis on the tropics. In: INTERNATIONAL SYMPOSIUM ON AGROCHEMICAL: fate in food and the environmental using isotope techniques, Rome, 1982. Proceedings. Vienna: International Atomic Energy Agency, 1982. p.177-190. 
RIPOLI, T.C.; MOLINA, JUNIOR, W.F.; STUPIELLO, J.P.; NOGUEIRA, M.C.; SACCOMANO, J.B. Potencial energético de residuos de cosecha de la caña verde. STAB - Açúcar, Álcool e Subprodutos, v.10, n.1, p.22-28, 1991.

SAMPAIO, E.V.S.B.; SALCEDO, I.H.; BATTANY, J. Dinâmica de nutrientes em canade-açúcar. I. Eficiência na utilização de uréia $\left({ }^{15} \mathrm{~N}\right)$ em aplicação única ou parcelada. Pesquisa Agropecuária Brasileira, v.19, p.943-949, 1984.

SENEVIRATNE, G. Litter quality and nitrogen release in tropical agriculture: a synthesis. Biology and Fertility of Soils, v.31, p.60-64, 2000.

SKJEMSTAD, J.O.; TAYLOR, J.A.; JANIK, L.J.; MARVANEK, S.P. Soil carbon dynamics under long-term sugarcane monoculture. Australian Journal of Soil Research, v.37, p.151-164, 1999.

SIQUEIRA, J.O.; FRANCO, A. A. Biotecnologia do solo: fundamentos e perspectivas. Brasília: MEC/ABEAS/ESAL/FAEPE, 1988. 236p.

TAKAHASHI, D.T. Fate of applied fertilizer nitrogen as determined by use of ${ }^{15} \mathrm{~N}$. II. Summer plant and ratoon crops at Hilo, Hawaii. Hawaiian Planters' Record, v.58, n.2, p.13-20, 1969.

THOMPSON, J.P. soil biotic and biochemical factors in a long-term tillage and stubble management experiment on a vertisol. 2. Nitrogen deficiency with zero tillage and stubble retention. Soil and Tillage Research, v.22, p.339-361, 1992.

TIAN, G.; KANG, B.T.; BRUSSAARD, L. Biological effects of plant residues with contrasting chemical composition under humid tropical conditions - decomposition and nutrient release. Soil Biology and Biochemistry, v.24, p.1051-1060, 1992.

TIESSEN, H.; STEWART, J.W.B. Particle-size fractionation and their use in studies of soil organic matter: II. Cultivation effects on organic matter composition in size fractions. Soil Science Society of America Journal, v.47, p.509-514, 1983.

TIMM, L.C. Efeito do manejo da palhada da cana-de-açúcar nas propriedades físicohídricas de um solo. Piracicaba, 2002. 115p. Tese (Doutorado) - Escola Superior de Agricultura "Luiz de Queiroz”, Universidade de São Paulo. 
TOMINAGA, T.T., CÁSSARO, F.A.M., BACCHI, O.O.S., REICHARDT, K., OLIVEIRA, J.C.M., TIMM, L.C. Variability of soil water content and bulk density in a sugarcane field. Australian Journal of Soil Research, v.40, p.605-614, 2002.

TRIVELIN, P.C.O.; SALATI, E.; MATSUI, E. Preparo de amostras para análise de ${ }^{15} \mathrm{~N}$ por espectrometria de massas. Piracicaba: CENA/USP, 1973. 41p. (CENA. Boletim Técnico, 2).

TRIVELIN，P.C.O.; VICTORIA，R.L.; RODRIGUÊS，J.C.S. Aproveitamento por soqueira de cana-de-açúcar de final de safra do nitrogênio da aquamônia- ${ }^{15} \mathrm{~N}$ e uréia${ }^{15} \mathrm{~N}$ aplicado ao solo em complemento à vinhaça. Pesquisa Agropecuária Brasileira, v.30, n.12, p.1375-1385, 1995.

TRIVELIN, P.C.O.; BENDASSOLLI, J.A.; OLIVEIRA, M.W. Potencialidade da mistura de aquamônia com vinhaça na adubação de canaviais colhidos sem despalha a fogo: I. Estabilidade química da mistura. STAB - Açúcar, Álcool e Subprodutos, v.16, n.2, p.26-29, 1997.

TRIVELIN, P.C.O.; BENDASSOLLI, J.A.; OLIVEIRA, M.W. Potencialidade da mistura de aquamônia com vinhaça na adubação de canaviais colhidos sem despalha a fogo. Parte II: Perdas por volatilização de amônia e recuperação do ${ }^{15} \mathrm{~N}$ aplicado ao solo. STAB Açúcar, Álcool e Subprodutos, v.16, n.3, p.23-29, 1998.

URQUIAGA, S.; BODDEY, R.M.; OLIVEIRA, O.C.; LIMA, E.; GUIMARÃES, D.H.V. Importância de não queimar a palhada da cana-de-açúcar. Seropédica: EMBRAPA, CNPAB, 1991. 12p. (Comunicado Técnico, 5).

VALLIS, I.; KEATING, B.A. Uptake and loss of fertilizer and soil nitrogen in sugarcane crops. In: CONFERENCE OF THE AUSTRALIAN SOCIETY OF SUGAR CANE TECHNOLOGISTS, 16., Journsville, 1994. Proceedings. Journsville: Watson Ferguson, 1994. p.105-113.

VALLIS, I.; PARTON, W.J.; KEATING, B.A.; WOOD, A.W. Simulation of the effects of trash and $\mathrm{N}$ fertilizer management on soil organic matter levels and yields of sugarcane. Soil and Tillage Research, v.38, p.115-132, 1996. 
VANLAUWE, B.; DENDOOVEN, L.; MERCKY, R. Residue and fractionation decomposition: The significance of the active fraction. Plant and Soil, v.158, p.263274, 1994.

VEIGA, F.M.; DOBEREINER, J.; PINTO, R.S.; GONDIM, G.S. Influência do tratamento do palhiço da cana-de-açúcar na matéria orgânica do solo. Divulgação Agronômica, n.6, p.10-13, 1962.

VIGIL, M.F.; KISSEL, D.E. Equations for estimating the amount of nitrogen mineralized from crop residues. Soil Science Society of America Journal, v.55, p.757-761, 1991.

VITTI, A.C. Adubação nitrogenada da cana-de-açúcar (soqueira) colhida mecanicamente sem a queima prévia: manejo e efeito na produtividade. Piracicaba, 2003. 114p. Tese (Doutorado) - Centro de Energia Nuclear na Agricultura, Universidade de São Paulo.

WENG, T.H.; LI, S.W. Nitrogen mineralization potential and rate in soil. Taiwan Sugar, v.39, n.3, p.8-11, 1992.

WOOD, A.W. Green cane trash management in the Herbert valley. Preliminary results and research priorities. In: CONFERENCE OF THE AUSTRALIAN SOCIETY OF SUGAR CANE TECHNOLOGISTS, 8., Brisbane, 1986. Proceedings. Brisbane: Watson Ferguson, 1986. p.85-94.

WOOD, A.W. Management of crop residues following green harvesting of sugarcane in north Queensland. Soil and Tillage Research, v.20, p.69-85, 1991. 
APÊNDICES 


\section{APÊNDICE 1}

Tabela 16. Temperatura $(\mathrm{T})$, precipitação $(\mathrm{P})$ e radiação solar global (Rs) correspondente ao período de 1997 a 1999

\begin{tabular}{|c|c|c|c|c|c|c|}
\hline \multirow[t]{2}{*}{ Mês } & \multicolumn{3}{|c|}{$\mathrm{T}\left({ }^{\circ} \mathrm{C}\right)$} & \multicolumn{2}{|c|}{$\mathrm{P}(\mathrm{mm})$} & \multirow{2}{*}{$\begin{array}{c}\text { Rs } \\
\left(\text { cal.cm }{ }^{-2} \cdot d^{-1}\right)\end{array}$} \\
\hline & máxima & mínima & média & mensal & acumulada & \\
\hline Jan. 97 & 29,7 & 20,1 & 24,9 & 352,2 & 352,2 & 361,1 \\
\hline Fev. 97 & 31,7 & 19,5 & 24,7 & 87,1 & 439,3 & 424,1 \\
\hline Mar. 97 & 29,9 & 17,5 & 23,7 & 73,1 & 512,4 & 380,5 \\
\hline Abr. 97 & 28,7 & 15,0 & 21,9 & 22,0 & 534,4 & 356,2 \\
\hline Mai. 97 & 25,7 & 12,6 & 19,2 & 55,0 & 589,4 & 304,7 \\
\hline Jun. 97 & 23,5 & 11,4 & 17,4 & 124,5 & 713,9 & 250,1 \\
\hline Jul. 97 & 26,1 & 11,3 & 18,7 & 15,4 & 729,3 & 307,2 \\
\hline Ago. 97 & 27,8 & 11,2 & 19,5 & 15,9 & 745,2 & 362,2 \\
\hline Set. 97 & 29,4 & 15,3 & 22,4 & 95,0 & 840,2 & 340,5 \\
\hline Out. 97 & 29,4 & 17,3 & 23,3 & 62,8 & 903,0 & 408,7 \\
\hline Nov. 97 & 30,3 & 19,5 & 24,9 & 269,4 & 1172,4 & 426,9 \\
\hline Dez. 97 & 31,1 & 19,7 & 25,4 & 186,7 & 1359,1 & 479,4 \\
\hline Jan. 98 & 31,7 & 20,6 & 26,2 & 121,2 & 121,2 & 457,5 \\
\hline Fev. 98 & 30,0 & 20,5 & 25,3 & 362,2 & 483,4 & 416,2 \\
\hline Mar. 98 & 31,0 & 19,8 & 25,4 & 127,8 & 611,2 & 379,9 \\
\hline Abr. 98 & 28,4 & 17,0 & 22,7 & 66,7 & 677,9 & 354,9 \\
\hline Mai. 98 & 25,0 & 12,8 & 18,9 & 97,6 & 775,5 & 293,0 \\
\hline Jun. 98 & 24,1 & 9,9 & 17,0 & 26,6 & 802,1 & 278,6 \\
\hline Jul. 98 & 25,9 & 10,8 & 18,4 & 13,9 & 816,0 & 298,7 \\
\hline Ago. 98 & 27,4 & 14,4 & 20,9 & 21,8 & 837,8 & 310,0 \\
\hline Set. 98 & 27,7 & 15,3 & 21,5 & 89,3 & 927,1 & 335,3 \\
\hline Out. 98 & 27,1 & 16,3 & 21,7 & 183,1 & 1110,2 & 369,1 \\
\hline Nov. 98 & 30,0 & 16,5 & 23,2 & 26,6 & 1136,8 & 474,3 \\
\hline Dez. 98 & 30,0 & 19,2 & 24,6 & 292,6 & 1429,4 & 441,0 \\
\hline Jan. 99 & 30,6 & 20,4 & 25,5 & 382,8 & 382,8 & 383,1 \\
\hline Fev. 99 & 30,7 & 20,1 & 25,4 & 198,3 & 581,1 & 410,0 \\
\hline Mar. 99 & 31,4 & 19,0 & 25,2 & 210,8 & 791,9 & 428,9 \\
\hline Abr. 99 & 28,5 & 15,2 & 21,9 & 89,0 & 880,9 & 388,2 \\
\hline Mai. 99 & 25,4 & 11,2 & 18,3 & 51,3 & 932,2 & 327,7 \\
\hline Jun. 99 & 23,9 & 11,0 & 17,5 & 68,6 & 1000,8 & 257,2 \\
\hline Jul. 99 & 26,4 & 12,0 & 19,2 & 2,7 & 1003,5 & 289,0 \\
\hline Ago. 99 & 27,9 & 10,2 & 19,1 & 0,0 & 1003,5 & 374,5 \\
\hline Set. 99 & 28,8 & 14,0 & 21,4 & 85,9 & 1089,4 & 422,9 \\
\hline Out. 99 & 28,5 & 15,4 & 21,9 & 28,5 & 1117,9 & 453,9 \\
\hline Nov. 99 & 29,5 & 15,7 & 22,6 & 52,1 & 1170,0 & 479,7 \\
\hline Dez. 99 & 30,6 & 19,0 & 24,8 & 269,9 & 1439,9 & 507,9 \\
\hline
\end{tabular}




\section{APÊNDICE 2}

Tabela 17. Temperatura $(\mathrm{T})$, precipitação $(\mathrm{P})$ e radiação solar global (Rs) correspondente ao período de 2000 a 2002

\begin{tabular}{|c|c|c|c|c|c|c|}
\hline \multirow[t]{2}{*}{ Mês } & \multicolumn{3}{|c|}{$\mathrm{T}\left({ }^{\circ} \mathrm{C}\right)$} & \multicolumn{2}{|c|}{$\mathrm{P}(\mathrm{mm})$} & \multirow{2}{*}{$\begin{array}{c}\text { Rs } \\
\left(\text { cal.cm }{ }^{-2} \cdot d^{-1}\right)\end{array}$} \\
\hline & máxima & mínima & média & mensal & acumulada & \\
\hline Jan. 00 & 30,2 & 19,1 & 24,7 & 235,9 & 235,9 & 464,0 \\
\hline Fev. 00 & 29,9 & 19,2 & 24,6 & 124,0 & 359,9 & 450,1 \\
\hline Mar. 00 & 29,7 & 18,5 & 24,1 & 185,3 & 545,2 & 410,5 \\
\hline Abr. 00 & 29,4 & 14,5 & 21,9 & 0,8 & 546,0 & 450,5 \\
\hline Mai. 00 & 26,6 & 11,2 & 18,9 & 5,3 & 551,3 & 347,3 \\
\hline Jun. 00 & 27,2 & 11,4 & 19,3 & 5,2 & 556,5 & 304,4 \\
\hline Jul. 00 & 24,7 & 8,8 & 16,6 & 60,4 & 616,9 & 320,4 \\
\hline Ago. 00 & 26,5 & 12,5 & 19,5 & 84,4 & 701,3 & 324,4 \\
\hline Set. 00 & 27,2 & 15,1 & 21,2 & 91,2 & 792,5 & 396,0 \\
\hline Out. 00 & 32,1 & 18,0 & 25,0 & 114,2 & 906,7 & 479,6 \\
\hline Nov. 00 & 29,8 & 17,7 & 23,8 & 239,2 & 1145,9 & 465,2 \\
\hline Dez. 00 & 29,8 & 19,0 & 24,4 & 196,2 & 1342,1 & 447,9 \\
\hline Jan. 01 & 31,9 & 19,6 & 25,8 & 229,6 & 229,6 & 508,9 \\
\hline Fev. 01 & 31,7 & 20,4 & 26,0 & 92,7 & 322,3 & 457,2 \\
\hline Mar. 01 & 31,5 & 19,3 & 25,4 & 164,2 & 486,5 & 449,6 \\
\hline Abr. 01 & 30,6 & 17,1 & 23,9 & 24,1 & 510,6 & 419,5 \\
\hline Mai. 01 & 25,4 & 12,9 & 19,2 & 60,6 & 571,2 & 316,1 \\
\hline Jun. 01 & 25,1 & 11,9 & 18,5 & 19,9 & 591,1 & 281,6 \\
\hline Jul. 01 & 26,3 & 10,9 & 18,6 & 27,2 & 618,3 & 305,1 \\
\hline Ago. 01 & 28,0 & 12,5 & 20,2 & 44,2 & 662,5 & 390,7 \\
\hline Set. 01 & 28,1 & 14,7 & 21,4 & 48,4 & 710,9 & 424,7 \\
\hline Out. 01 & 29,5 & 16,1 & 22,8 & 173,3 & 884,2 & 496,3 \\
\hline Nov. 01 & 30,7 & 18,7 & 24,7 & 152,4 & 1036,6 & 466,2 \\
\hline Dez. 01 & 29,2 & 18,7 & 24,0 & 204,2 & 1240,8 & 427,3 \\
\hline Jan. 02 & 29,8 & 19,3 & 24,6 & 320,2 & 320,2 & 409,9 \\
\hline Fev. 02 & 29,0 & 18,8 & 23,9 & 187,9 & 508,1 & 404,1 \\
\hline Mar. 02 & 32,0 & 19,5 & 25,8 & 274,6 & 782,7 & 462,0 \\
\hline Abr. 02 & 31,8 & 17,6 & 24,7 & 27,2 & 809,9 & 393,0 \\
\hline Mai. 02 & 26,8 & 14,5 & 20,7 & 112,4 & 922,3 & 298,0 \\
\hline Jun. 02 & 27,9 & 12,6 & 20,3 & 0,0 & 922,3 & 307,4 \\
\hline Jul. 02 & 25,2 & 10,2 & 17,7 & 23,4 & 945,7 & 267,0 \\
\hline Ago. 02 & 28,9 & 14,3 & 21,6 & 79,6 & 1025,3 & 316,8 \\
\hline Set. 02 & 27,5 & 13,6 & 20,6 & 44,8 & 1070,1 & 340,0 \\
\hline Out. 02 & 33,8 & 18,8 & 26,3 & 49,4 & 1119,5 & 430,7 \\
\hline Nov. 02 & 30,6 & 18,8 & 24,7 & 176,5 & 1296,0 & 432,2 \\
\hline Dez. 02 & 31,2 & 19,7 & 25,4 & 166,1 & 1462,1 & 460,7 \\
\hline
\end{tabular}

